\author{
UNIVERSIDADE DE SÃO PAULO \\ ESCOLA DE ENGENHARIA DE SÃO CARLOS \\ FACULDADE DE MEDICINA DE RIBEIRÃO PRETO \\ INSTITUTO DE QUÍMICA DE SÃO CARLOS
}

Gabriel Augusto Ginja

Desenvolvimento e validação de um ambiente de Realidade Virtual para reabilitação de membros superiores em pessoas com Lesão Medular

São Carlos 

Gabriel Augusto Ginja

\title{
Desenvolvimento e validação de um ambiente de Realidade Virtual para reabilitação de membros superiores em pessoas com Lesão Medular
}

\begin{abstract}
Dissertação apresentada ao Programa de PósGraduação Interunidades em Bioengenharia da Escola de Engenharia de São Carlos Faculdade de Medicina de Ribeirão Preto e Instituto de Química de São Carlos da Universidade de São Paulo, como requisito para a obtenção do Título de Mestre em Ciências.
\end{abstract}

Orientador: Prof. Dr. Alberto Cliquet Junior

"VERSÃO CORRIGIDA"

São Carlos

2021 
AUTORIZO A REPRODUÇÃO TOTAL OU PARCIAL DESTE TRABALHO POR QUALQUER MEIO CONVENCIONAL OU ELETRÔNICO, PARA FINS DE ESTUDO E PESQUISA, DESDE QUE CITADA A FONTE.

Ficha catalográfica elaborada pela Biblioteca Prof. Dr. Sérgio Rodrigues Fontes da EESC/USP com os dados inseridos pelo(a) autor(a).

GINJA, GABRIEL AUGUSTO

G118d Desenvolvimento e validação de um ambiente de Realidade Virtual para reabilitação de membros superiores em pessoas com Lesão Medular / GABRIEL AUGUSTO GINJA; orientador Alberto Cliquet Junior. São Carlos, 2021.

Dissertação (Mestrado) - Programa de Pós-Graduação Interunidades em Bioengenharia e Área de Concentração em Bioengenharia -- Escola de Engenharia de São Carlos; Faculdade de Medicina de Ribeirão Preto; Instituto de Química de São Carlos, da Universidade de São Paulo, 2021.

1. Lesão Medular. 2. Realidade Virtual. 3. Vicon. I. Título.

Eduardo Graziosi Silva - CRB - 8/8907 


\section{FOLHA DE JULGAMENTO}

\section{Candidato(a): Gabriel Augusto Ginja}

Título: "Desenvolvimento e validação de um ambiente de realidade virtual para reabilitação de membros superiores em pessoas com lesão medular."

Data da defesa: 29/04/2021

\section{Comissão Julgadora}

Prof(a). Dr(a). Alberto Cliquet Junior UNICAMP

1) Prof(a). Dr(a). Fernando Santos Osorio ICMC/USP

1/Prof(a). Dr(a). Carolina de Medeiros Rimkus InRad FM/USP

1) Prof(a). Dr(a). Rodrigo Gonçalves Pagnano UNICAMP
Assinatura

Resultado

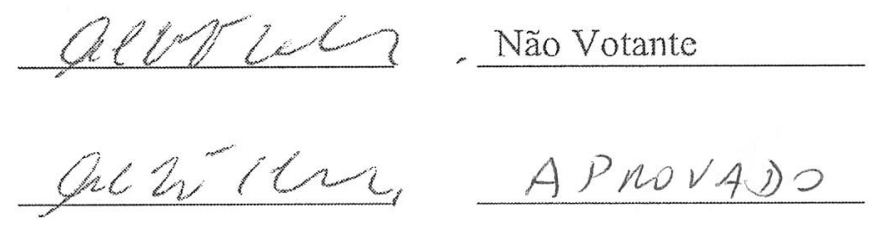

aCUFCLL APNOVAD

QCEECR, APnOUADO 



\section{Agradecimentos}

Agradeço à minha mãe e ao meu avô que sempre me incentivaram a estudar e me apoiaram durante toda a minha trajetória escolar e acadêmica.

Agradeço aos meus colegas do LABCIBER-USP e do LABRAL-UNICAMP pelo apoio e aprendizado durante todos esses anos.

Agradeço ao meu orientador pelas oportunidades de desenvolver esse projeto e de praticar a engenharia biomédica.

Agradeço ao CNPQ e à FAPESP pelo financiamento e pelo suporte para a realização desse projeto. 

"Sempre acredite em você mesmo.

Faça isso e não importa onde você esteja, você não terá nada a temer"

(Hayao Miyazaki) 



\section{Resumo}

GINJA, G.A. Desenvolvimento e validação de um ambiente de Realidade Virtual para reabilitação de membros superiores em pessoas com Lesão Medular. 2021. Dissertação (Mestrado) - Escola de Engenharia de São Carlos, Universidade de São Paulo, São Carlos, 2021.

Este trabalho caracteriza dados cinemáticos de membros superiores de pessoas com lesão medular durante um protocolo de alcance com o objetivo de desenvolver um ambiente de realidade virtual personalizado para treinar atividades de vida diária. Quatro pacientes com nível neurológico de lesão de C5 a C8 alcançaram cinco pontos sobre a mesa para simular uma atividade da vida diária que utiliza ombro e flexão de cotovelo. Eles estavam usando clusters com marcadores ao lado de câmeras VICON para capturar ângulos de flexão de ombros e cotovelo. Os dados cinemáticos coletados são usados juntamente com a antropometria em um ambiente de realidade virtual parametrizado para treinar membros superiores

Palavras-chave: Lesão Medular. Realidade Virtual. Cinemática. 



\section{Abstract}

GINJA, G.A. Development and validation of a Virtual Reality environment for rehabilitation of upper limbs in people with Spinal Cord Injury. 2021. Dissertation (Msc) - São Carlos School of Engineering, University of São Paulo, 2021.

This work characterizes kinematic data from upper limbs of people with spinal cord injury during a reach protocol in order to develop a personalized virtual reality environment to train activities of daily living. Four patients with neurological level of lesion from C5 to C8 reached five points over table to simulate an activity of daily living that uses shoulder and elbow flexion. They were using clusters with markers alongside VICON cameras to capture flexion angles from shoulders and elbow. The kinematic data collected is used alongside anthropometry in a parameterized virtual reality environment to train upperlimbs.

Keywords: Spinal Cord Injury. Virtual Reality. Kinematics. 



\section{Lista de ilustrações}

Figura 1 - Processo de desenvolvimento do ambiente de RV . . . . . . . . . . . . 22

Figura 2 - Estrutura celular de um neurônio . . . . . . . . . . . . . . . 24

Figura 3 - Regiões do cérebro . . . . . . . . . . . . . . . . 25

Figura 4 - Regiões do córtex cerebral Sobotta . . . . . . . . . . . . 27

Figura 5 - Homúnculos de Brodmann . . . . . . . . . . . . . . . 28

Figura 6 - Medula espinhal dividida nas seções cervical, torácica, lombar e sacral . 29

Figura 7 - Medula Espinhal com os músculos correspondentes . . . . . . . . . . 30

Figura 8 - Formulário AIS . . . . . . . . . . . . . . . . . 31

Figura 9 - Modelo muscular de HILL . . . . . . . . . . . . . . . . . . . 32

Figura 10 - Estímulo do sistema nervoso e ativação muscular . . . . . . . . . . . . 33

Figura 11 - Modelo de Dempster para segmentos . . . . . . . . . . . . . . . 34

Figura 12 - Relações de centro de massa e massa de Dempster para segmento . . . 34

Figura 13 - Referência global e exemplos de Referências locais para segmentos anatômicos . . . . . . . . . . . . . . . . . 35

Figura 14 - Referências para articulações de membros superiores . . . . . . . . . 36

Figura 15 - Referências para rotações anatômicas de ombros, cotovelos e punhos . . 36

Figura 16 - Exemplo de Cardboard . . . . . . . . . . . . . . . . 37

Figura 17 - Oculus Quest . . . . . . . . . . . . . . . . 38

Figura 18 - Leap com referências e modelo 3D das mãos . . . . . . . . . . . . . . . 39

Figura 19 - Oculus Touch . . . . . . . . . . . . . . . . . . . . 39

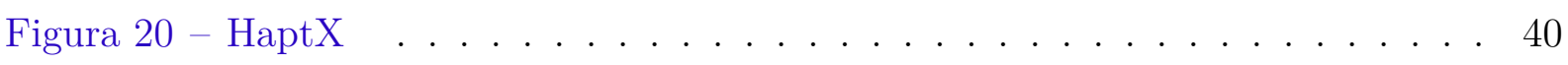

Figura 21 - Rastreamento das Mãos . . . . . . . . . . . . . . . . . 40

Figura 22 - Interface da Unity $3 \mathrm{D} \ldots \ldots \ldots$. . . . . . . . . . . . 41

Figura 23 - Diagrama para representar a metodologia de caracterização . . . . . . 47

Figura 24 - Representação da Mesa utilizada no protocolo . . . . . . . . . . . . . . 48

Figura 25 - Disposição das câmeras do Motion Monitor. A região em roxo é o campo de visão de uma das câmeras (aproximadamente 45 graus) . . . . . . . 50

Figura 26 - Imagem super exposta (esquerda) e com a exposição correta (direita). Na imagem da direita, é possível ver apenas os marcadores . . . . . . . 51

Figura 27 - Varinha e Stylus . . . . . . . . . . . . . . . . . 51

Figura 28 - Modelo gerado pelo Motion Monitor . . . . . . . . . . . . . . . . . 52

Figura 29 - Posicionamento dos clusters (roxo) e pontos utilizados com a stylus (setas vermelhas) . . . . . . . . . . . . . . . . 53

Figura 30 - Espectro de frequência sem filtro passa-baixa . . . . . . . . . . . . 53

Figura 31 - Exemplo de dados de cinemática normalizados. As 3 coletas apresentadas foram feitas para o mesmo paciente. . . . . . . . . . . . 54 
Figura 32 - Exemplo de média e desvio padrão calculados para 31 . . . . . . . . . 54

Figura 33 - Menu principal . . . . . . . . . . . . . . . . . . . 55

Figura 34 - Exemplo do GIC . . . . . . . . . . . . . . . . 56

Figura 35 - Menu para calibrar a altura . . . . . . . . . . . . . . 56

Figura 36 - Aumento e diminuição unitária de altura . . . . . . . . . . . . . . 57

Figura 37 - Aumento e diminuição de altura em incrementos e decrementos de $10 \mathrm{~cm} 57$

Figura 38 - Botão para voltar a tela anterior . . . . . . . . . . . . 57

Figura 39 - Botão para sair da aplicação . . . . . . . . . . . . . . . . 58

Figura 40 - Botão para começar o protocolo piloto . . . . . . . . . . . . . . 58

Figura 41 - Cena principal do ambiente de realidade virtual do protocolo piloto (em terceira pessoa). A figura ampliada dentro do circulo preto são os 5 pontos da mesa (blocos azuis). . . . . . . . . . . . . . . . 59

Figura 42 - Menu do protocolo piloto . . . . . . . . . . . . . . . . 60

Figura 43 - Representações das mãos no ambiente virtual . . . . . . . . . . . . . . 61

Figura 44 - Painel Auxiliar . . . . . . . . . . . . . . . . . . . . 61

Figura 45 - Sinalização dos pontos da mesa . . . . . . . . . . . . . . . . . 62

Figura 46 - Média de tempo e pontos alcançados por repetição . . . . . . . . . . . 62

Figura 47 - Referência dentro do ambiente virtual . . . . . . . . . . . . . 65 


\section{Lista de tabelas}

Tabela 1 - Informações dos participantes . . . . . . . . . . . . . . 63

Tabela 2 - Ângulos de movimento dos participantes (em graus) . . . . . . . . . 64 



\section{Lista de símbolos}

RV Realidade Virtual

LM Lesão Medular

AVDs $\quad$ Atividade de Vida Diária

EENM Estimulação Elétrica Neuromuscular

AVC Acidente Vascular Cerebral

ASIA American Spinal Injury Association

AIS ASIA Impairment Scale

LABRAL Laboratório de Reabilitação do Aparelho Locomotor

LABCIBER Laboratório de Biocibernética e Engenharia de Reabilitação

HMD Head-Mounted Display

GIC Gaze Input Controller 



\section{Sumário}

INTRODUÇÃo $\ldots \ldots \ldots \ldots \ldots \ldots \ldots \ldots$

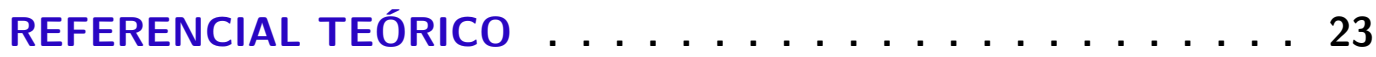

2.1 Neuroanatomia e mecanismos do sistema nervoso . . . . . . . . . 23

2.1.1 Anatomia geral do sistema nervoso . . . . . . . . . . . . . 23

2.1 .2 Sistema nervoso central . . . . . . . . . . . . . . . . . . . . . . . . 24

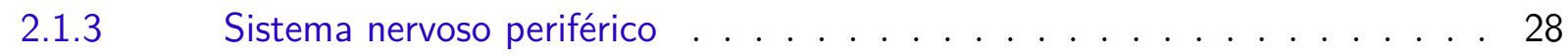

2.2 Lesão Medular . . . . . . . . . . . . . . . . . . . . . 29

2.2 .1 Caracterização da $\mathrm{LM} \ldots \ldots \ldots$

2.2 .2 Reabilitação da LM . . . . . . . . . . . . . . . . . . . 31

$2.3 \quad$ Biomecânica dos Membros Superiores . . . . . . . . . . . . . . . 31

2.3.1 Modelos muscular e esquelético do corpo humano . . . . . . . . . . . . . 31

2.3.2 Antropometria . . . . . . . . . . . . . . . . 33

2.3.3 Referências para análise de movimentos . . . . . . . . . . . . 35

$2.4 \quad$ Realidade Virtual $(\mathrm{RV}) \ldots \ldots \ldots$

2.4.1 Hardwares para visualização e interação com o ambiente de RV . . . . . 36

2.4.2 Dispositivos de Entrada . . . . . . . . . . . . . . . . . . 38

$2.5 \quad$ Rastreamento das Mãos . . . . . . . . . . . . . . . . 39

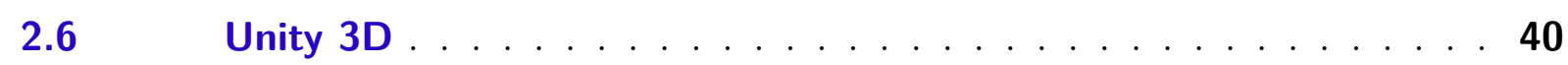

2.7 Aplicações de Realidade Virtual na Reabilitação Motora . . . . . . . 43

2.7.1 Imagética Motora . . . . . . . . . . . . . . . . . . . . 43

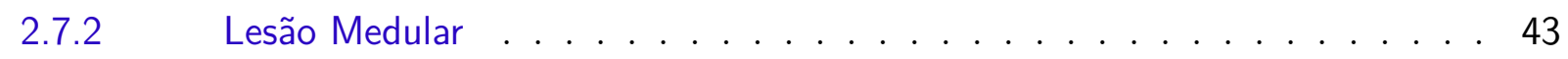

2.8 Considerações finais sobre o Referencial teórico . . . . . . . . . 45

3 METODOLOGIA . . . . . . . . . . . . 47

$3.1 \quad$ Estudo Piloto . . . . . . . . . . . . . . . . . . 47

$3.2 \quad$ Captura de Movimentos com o Motion Monitor . . . . . . . . . . 48

3.3 Critério de Seleção dos pacientes e posicionamento dos marcadores 51

3.4 Processamento de Dados de movimento . . . . . . . . . . . 52

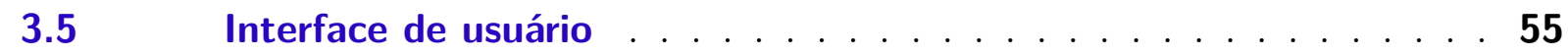

$3.6 \quad$ Ambiente de Realidade Virtual do protocolo piloto . . . . . . . . 59

$4 \quad$ RESULTADOS . . . . . . . . . . . . . 63

$4.1 \quad$ Impacto do covid-19 nos testes do ambiente virtual . . . . . 63

$4.2 \quad$ Ângulos de movimentos . . . . . . . . . . . . . 63

$4.3 \quad$ Teste do ambiente virtual em pessoas com LM . . . . . . . . 65 
CONCLUSÕES . . . . . . . . . . . . . . . . . 67

REFERÊNCIAS .................... 69

ANEXOS

ANEXo A - DOCUMENTOS COMITÊ DE ÉTICA . . . . . . 75 ANEXO B - GRÁFICOS DO PROTOCOLO PILOTO DE ALCANCE 85 


\section{Introdução}

No Brasil, há cerca de 6 a 8 mil novos tetraplégicos e paraplégicos por ano, sendo que a maioria das lesões na medula espinhal tem origem traumática (PASCHE; MENDES, 2013). Além de limitar as capacidades motoras e sensoriais, Lesão Medular (LM) afeta diretamente a qualidade de vida dos pacientes e a realização de atividades de vida diária (AVDs). Os músculos abaixo do nível neurológico da lesão pouco ou nada respondem aos comandos cerebrais. Atividades cotidianas como andar ou comer se tornam desafios na vida dos portadores da LM.

Além disso, há mais AVDs de igual importância para membros superiores, como comer, alcançar um objeto e mover a cadeira de rodas, do que para membros inferiores, em que a atividade funcional mais importante é o ciclo de marcha. Cada atividade de vida diária requer uma análise cinemática diferente, o que dificulta ainda mais o estudo de movimento e o desenvolvimento de tecnologias para tetraplégicos (GATES et al., 2016).

Existem alguns recursos reconhecidos pela comunidade científica que estimulam a neuroplasticidade cerebral. Neuroplasticidade é o processo no qual estruturas do sistema nervoso modificam para lidar com as demandas de atividades neurológicas (HUTSON; Di Giovanni, 2019). Nos lesados medulares, o aumento de neuroplasticidade cerebral pode resultar no aumento da massa cinzenta no nível neurológico da lesão, recuperação das raízes nervosas além do nível de lesão e reorganização de circuitos espinhais existentes (ENG; TEASELL, 2007).

Neste âmbito, o Laboratório de Biocibernética e Engenharia de Reabilitação (LABCIBER), da USP, e o Laboratório de Biomecânica e Aparelho Locomotor (LABRAL), da UNICAMP, pesquisam e aplicam recursos e tecnologias inovadoras para a reabilitação de indivíduos com LM. O destaque entre os recursos é a Estimulação Elétrica Neuromuscular (EENM) que, aliada à fisioterapia, visa recuperar e manter o tônus muscular (VAROTO; CLIQUET, 2015). Porém, as sequelas das lesões raquimedulares ainda desafiam a ciência reabilitativa. Pesquisadores buscam, constantemente, encontrar estímulos que promovam o aumento da capacidade neuroplástica nesses pacientes. Os ambientes de realidade virtual são exemplos disso.

A Realidade Virtual (RV) é definida como uma interface avançada de usuário para visualização tridimensional e em tempo real de aplicações do computador (TREVISAN et al., 2014). A interface exige alta capacidade de processamento, uma vez que as imagens devem ser renderizadas muito rapidamente. Há a RV imersiva, na qual o usuário utiliza um óculos para visualizar o ambiente de aplicação, e há a RV não-imersiva, na qual o ambiente gráfico é projetado em uma tela ou monitor. Apesar da RV imersiva proporcionar 
uma experiência mais realista, a RV não-imersiva é mais utilizada por seu atrativo custobenefício. A RV imersiva utiliza o Head-Mounted Display (HMD) junto com outros dispositivos de entrada para permitir a interação com o ambiente virtual.

A RV já foi utilizada em tratamentos de doenças neurológicas como Acidente Vascular Cerebral (AVC) e resultaram em reabilitação de capacidades cognitivas e motoras (FONSECA; SILVA; PINTO, 2017). O AVC resulta em sequelas similares à lesão raquimedular como a perda das habilidades sensório-motoras. A reabilitação do AVC através da RV consiste no treino de atividades funcionais. Segundo Villiger et al (2013), a repetição destes movimentos associado a um ambiente lúdico imersivo resultou na recuperação motora e cognitiva de alguns pacientes, além de redução de dor crônica (VILLIGER et al., 2013). A base teórica deste tratamento é a imagética motora, que consiste na autorregulação cerebral por meio de um estímulo visual. Durante a prática mental, isto é, o paciente imagina o movimento que seria realizado, as áreas do cérebro ativadas são as mesmas das áreas que seriam ativadas durante a realização do movimento. A repetição do estímulo visual pode resultar na correção de disfunções motoras e cerebrais. Alguns atletas utilizam a imagética motora junto ao treinamento convencional para aperfeiçoar seus movimentos antes de uma competição (MIZUGUCHI et al., 2012).

Diante disso, este projeto teve como objetivo estudar o movimento de alcance das pessoas com LM e criar um ambiente de RV adaptado para simular e exercitar as AVDs que utilizam os membros superiores. A figura 1 mostra as etapas para o desenvolvimento do sistema de realidade virtual.

Figura 1 - Processo de desenvolvimento do ambiente de RV

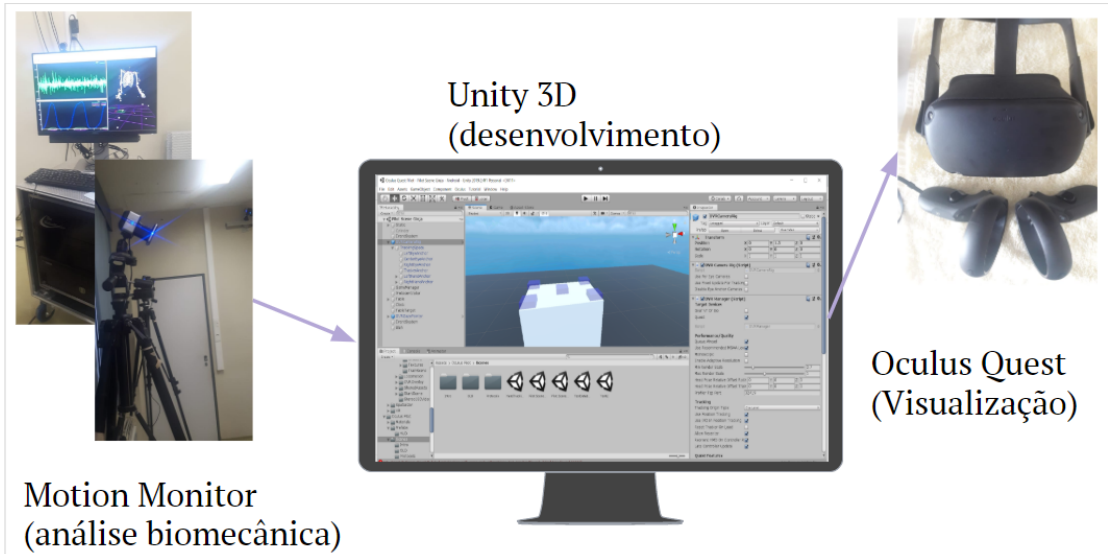

Fonte: Autoria própria 


\section{Referencial Teórico}

\subsection{Neuroanatomia e mecanismos do sistema nervoso}

\subsubsection{Anatomia geral do sistema nervoso}

O sistema nervoso é responsável por coordenar as funções motoras e sensoriais do corpo humano e pelo aprendizado motor e cognitivo. A anatomia deste sistema inclui o encéfalo, onde as decisões mais complexas são tomadas, a medula espinhal e células sensoriais na pele.

Os neurônios são as estruturas celulares que compõem majoritariamente o sistema nervoso. Eles permitem uma rápida capacidade de comunicação entre partes distantes do corpo, o que possibilita acionar um músculo em poucos milésimos de segundo após um comando do cérebro. A figura 2 mostra a estrutura celular de um neurônio.

O núcleo do neurônio é envolto por uma membrana plasmática semipermeável. O restante das estruturas é imersa no citoplasma o qual possui proteínas e enzimas que permitem a transmissão de informações pelo neurônio. As ramificações ao redor do núcleo são os dentritos e o prolongamento maior é o axônio. O axônio é envolto na bainha de mielina e ele termina nos terminais pré-sinápticos. Estas estruturas são responsáveis por otimizar a velocidade dos impulsos nervosos e por ligar o neurônio em outros neurônios ou em células musculares, respectivamente (Kandel, E. R., Shwartz, 2013).

A transmissão de informação entre neurônios do sistema nervoso é feita através de sinapse. As sinapses são representadas na figura 2 por pequenos círculos no terminal sináptico. Elas definem o sentido para o qual o impulso nervoso se destina. Existem as sinapses químicas e as sinapses elétricas e elas utilizam neurotransmissores e eletricidade para ativar os neurônios, respectivamente. Alguns neurotransmissores mais conhecidos são a serotonina, que regula o humor, e o ácido gama-aminobutírico, que é responsáveis pela regulação do tônus muscular.

A sinapse química possibilita a comunicação unidirecional. A liberação do neurotransmissor ocorre no neurônio precedente, ela percorre o axônio e é transferida para o neurônio seguinte pelos terminais pré-sinápticos. Os terminais pré-sinápticos estão em contato com os dentritos do próximo neurônio, onde o ciclo de propagação se repete. Esta propriedade permite com que o sistema nervoso consiga acionar áreas específicas do corpo ao direcionar um estímulo nervoso para ativar um conjunto de células. Por exemplo, o sistema nervoso pode gerar um estímulo no cérebro para acionar células musculares e, consequentemente, contrair um grupo muscular. 
Figura 2 - Estrutura celular de um neurônio

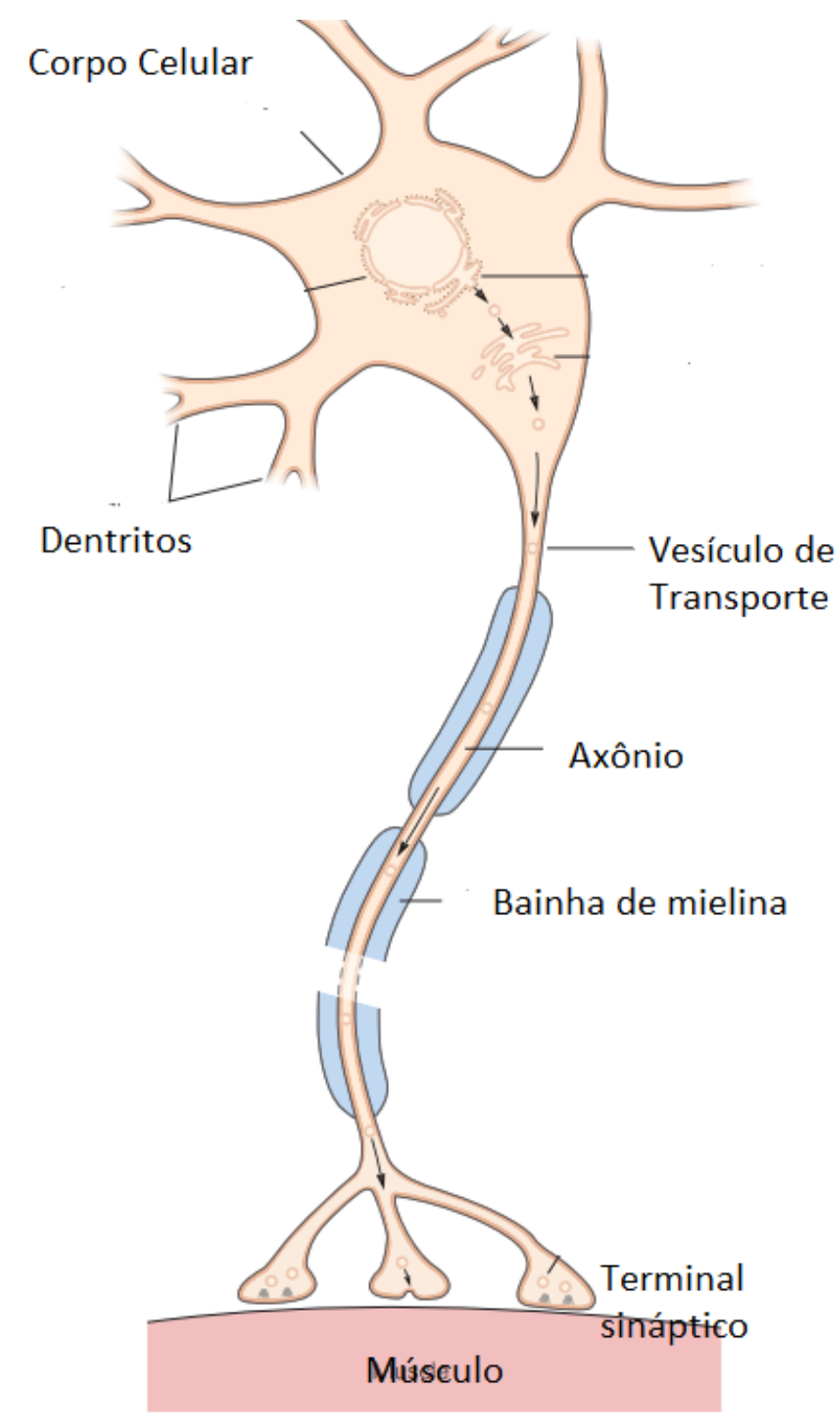

Fonte: Adaptado de (Kandel, E. R., Shwartz, 2013)

A sinapse elétrica ocorre pela condução de eletricidade por sinapses em forma de tubo denominadas gap. Os gaps permitem a transmissão de íons livres e, por meio da despolarização destes íons, um potencial elétrico é gerado entre os neurônios. Um exemplo de sinapse elétrica ocorre com os neurônios presentes entre as fibras de músculos lisas e viscerais (Arthur C. Guyton, 2011).

\subsubsection{Sistema nervoso central}

O sistema nervoso central é composto pelo encéfalo e a medula espinhal. O encéfalo é formado por seis partes: cerebelo, telencéfalo, diencéfalo, bulbo, ponte e mesencéfalo. A figura 3 mostra detalhadamente as partes do cérebro:

Ponte, bulbo e mesencefálo formam o tronco encefálico. A ponte transmite infor- 
Figura 3 - Regiões do cérebro

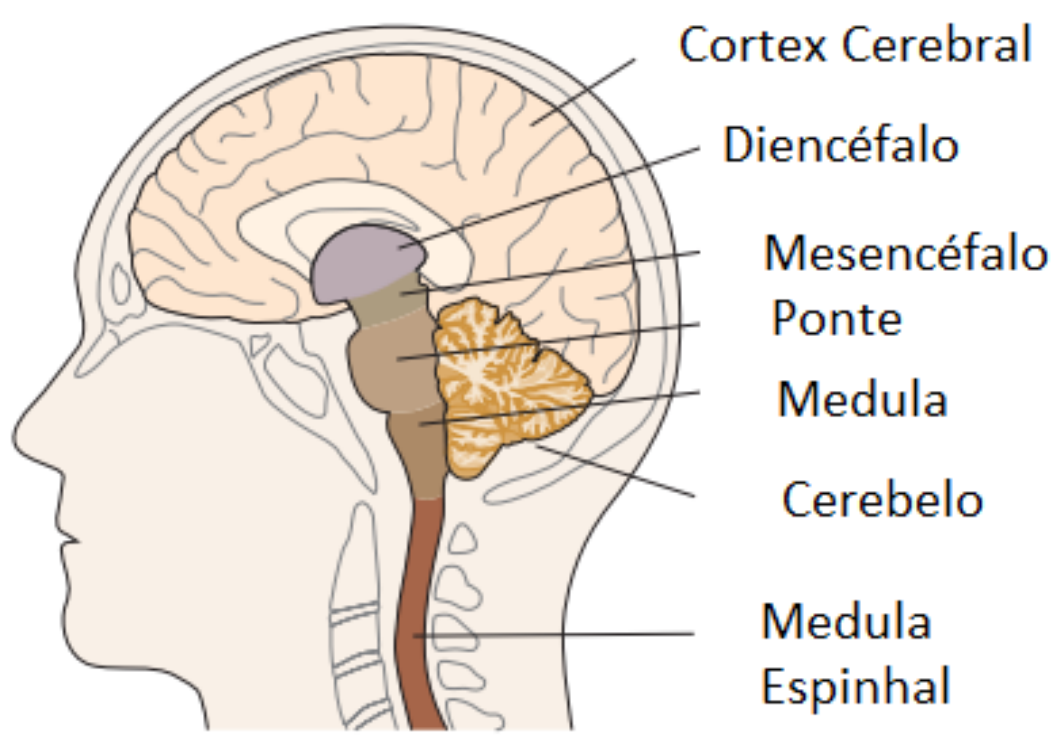

adaptado de (Kandel, E. R., Shwartz, 2013)

Fonte:

mações motoras e sensoriais do telencéfalo para o cerebelo. O bulbo é responsável por controlar a pressão sanguínea e a respiração, por receber estímulos sensoriais auditivos e de paladar, e controlar os músculos da face e do pescoço. Ele fica na parte mais caudal do tronco encefálico e ela se liga diretamente na medula espinhal. O bulbo também pode ser denominado medula oblonga, pois ele possui funções motoras semelhantes as da medula espinhal. O mesencéfalo permite a conexão entre partes do sistema motor tais como ganglia basal, cerebelo e os hemisférios cerebrais. Ele também regula parte dos sistemas auditivo e visual.

O tronco encefálico possui 5 funções básicas relacionadas ao sistema nervoso central (Kandel, E. R., Shwartz, 2013). A primeira função é controlar as informações sensoriais e motoras das regiões da cabeça, pescoço e face através de 11 nervos craniais. A segunda função é receber dados sensoriais como paladar e audição. A terceira função é possuir caminhos ascendentes e descentes para carregar informações sensoriais e motoras para diferentes partes do sistema nervoso central. A quarta função é mediar reflexos parasimpáticos, tais como compressão das pupilas e pressão sanguínea. Por fim, o tronco encefálico possui um núcleo chamado de formação reticular, que é responsável por controlar o sono e a atividade elétrica cortical.

O cerebelo está localizado atrás da ponte e ele possui funções majoritariamente motoras. Algumas das funções são o controle de postura e coordenação de movimentos 
dos olhos, braços e cabeça e ele possui mais neurônios do que qualquer outra estrutura do cérebro. O cerebelo recebe informações da medula espinhal, de equilíbrio de órgãos vestibulares do ouvido e sensoriais e motoras do córtex cerebral. Além das funções motoras, o cerebelo participa do aprendizado cognitivo.

O diencéfalo é divido em tálamo e hipotálamo. O tálamo serve de caminho para informações sensoriais das regiões periféricas para regiões sensoriais do córtex cerebral. Já o hipotálamo é responsável por regular o comportamento emocional, que pode ser exemplificado com funções como regulação do sono e da vigília e de comportamentos como comer e beber. Algumas dessas funções estão relacionadas ao ciclo de dia e noite.

O telencéfalo é a maior parte do cérebro e ele é formado pelo córtex cerebral, ganglia basal, amígdalas cerebrais e o hipocampo. Ele é dividido em 2 hemisférios unidos pelo corpo caloso, que é majoritariamente composto de substância branca. As células da ganglia basal possuem importância no aprendizado motor e cognitivo, as amígdalas cerebrais estão relacionadas com a expressão de emoção e o hipocampo forma as memórias.

O córtex cerebral é responsável pelo planejamento e execução da maioria das tarefas diárias. Ele é dividido em quatro lobos: lobo frontal, lobo occipital, lobo pariental e lobo temporal. Analogamente, as extremidades de cada lobo é denominada polo, de modo que existem os polos frontal, occipital, pariental e temporal. Cada lobo possui subdivisões funcionais como, por exemplo, o lobo temporal possui regiões com funções auditivas e visuais. A figura 4 mostra as regiões do córtex cerebral.

Dentre estas subdivisões, duas delas possuem grande importância no controle dos movimentos: córtex motor e córtex pré-motor. O córtex motor localiza-se no lobo frontal e ele realiza as atividades motoras mais habilidosas. Ele controla quais músculos vão contrair ou relaxar, com qual intensidade e frequência ela vai ocorrer (CHENEY, 1985). Uma propriedade singular do córtex motor é que a o córtex esquerdo controla o lado direito do corpo e vice-versa. Além desta função, o córtex motor comunica outras áreas do cérebro a intenção do movimento e participa de reflexos musculares.

A ativação muscular ocorre quando o córtex motor recebe informação de neurônios sensoriais do sistema periférico e as traduz na ativação ou inibição de neurônios motores da medula espinhal. Os neurônios motores podem ativar um único músculo ou um grupo de músculos sinérgicos para realizar uma atividade. Um estudo feito com mamíferos com estrutura neurológica similar à humana mostrou que uma única entrada sináptica produzia sinais de eletromiografia (EMG) em músculos diferentes (FETZ; CHENEY, 1980). Os movimentos voluntários normalmente envolvem a inibição e a ativação de músculos opostos. Por exemplo, a extensão do braço é resultado da contração do tríceps e relaxamento dos bíceps ou, para iniciar o movimento de caminhada, um membro inferior precisa flexionar o quadril, tornozelo e joelho enquanto o outro estende as articulações para acomodar a troca de carga entre os membros. 
Figura 4 - Regiões do córtex cerebral Sobotta

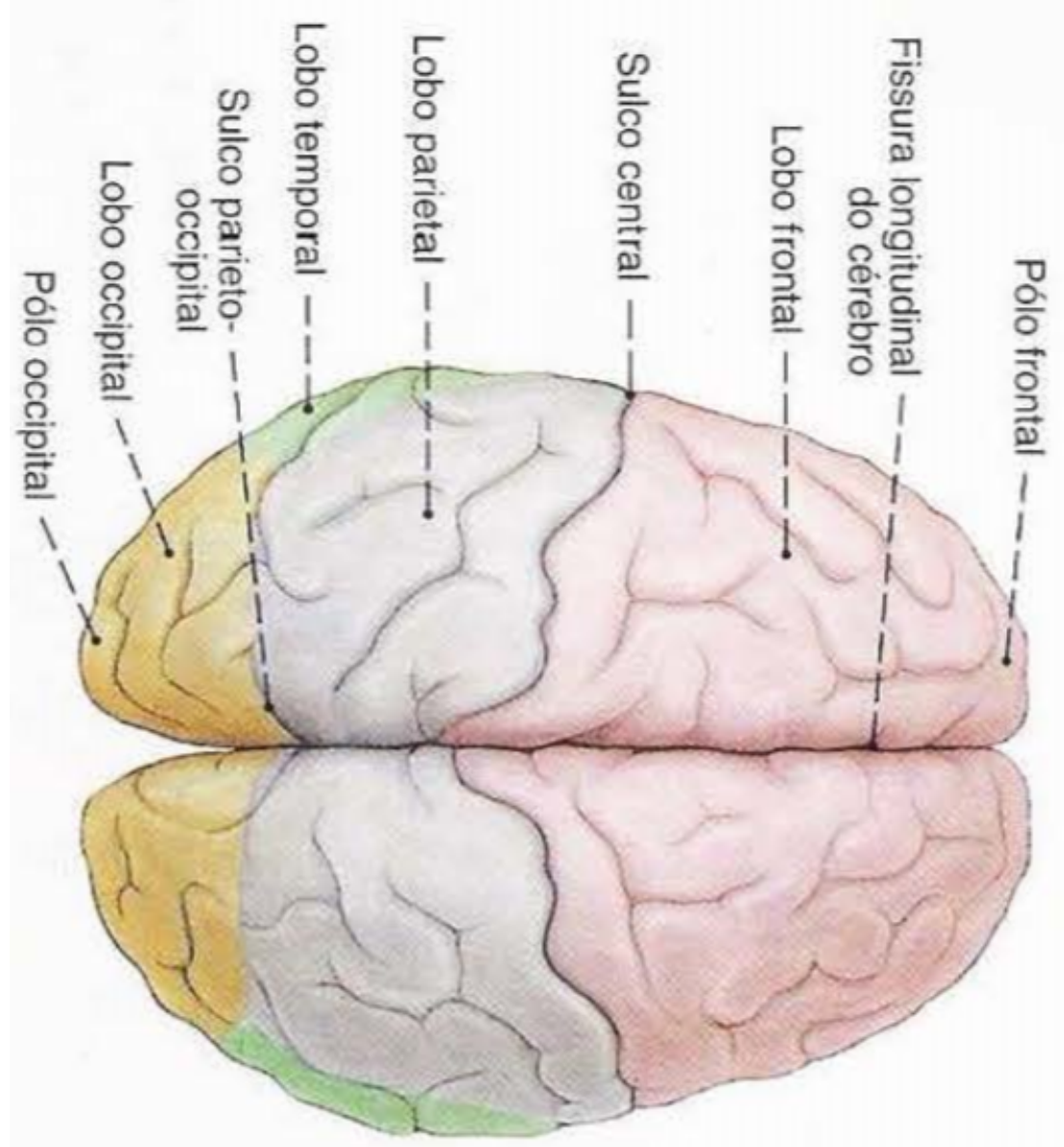

Fonte: adaptado de (SOBOTTA, 2000)

Enquanto o córtex motor é responsável por planejar e realizar os movimentos voluntários, o córtex pré-motor produz o comando para iniciar o movimento. Os neurônios do córtex pré-motor são acionados entre o estímulo sensorial e o movimento voluntário (MONTGOMERY; CONNOLLY, 2003). Os neurônios do córtex pré-motor também avaliam a cinemática envolvida nos movimentos de alcance dos membros superiores.

De forma geral, os córtices motor e pré-motor avaliam estímulos sensoriais, planejam os movimentos e acionam os agrupamentos correspondentes. O homúnculo de Brodmann é uma representação visual que relaciona as regiões sensoriais e motoras do corpo com a região correspondente do córtex. Algumas regiões afetam uma área maior do córtex como, por exemplo, os lábios e as mãos para sensações e as pernas e o tórax para a atividade motora. A figura 5 mostra os dois homúnculos de Brodmann.

Todos os estímulos motores do encéfalo são transmitidos às células musculares pela medula espinhal. A medula espinhal possui 30 segmentos, sendo que são 8 segmentos cervicais, 12 segmentos torácicos, 5 segmentos lombares e 5 segmentos sacrais. Ela é composta por um chifre em formato de $\mathrm{H}$ feito de substância cinzenta revestida por 
Figura 5 - Homúnculos de Brodmann
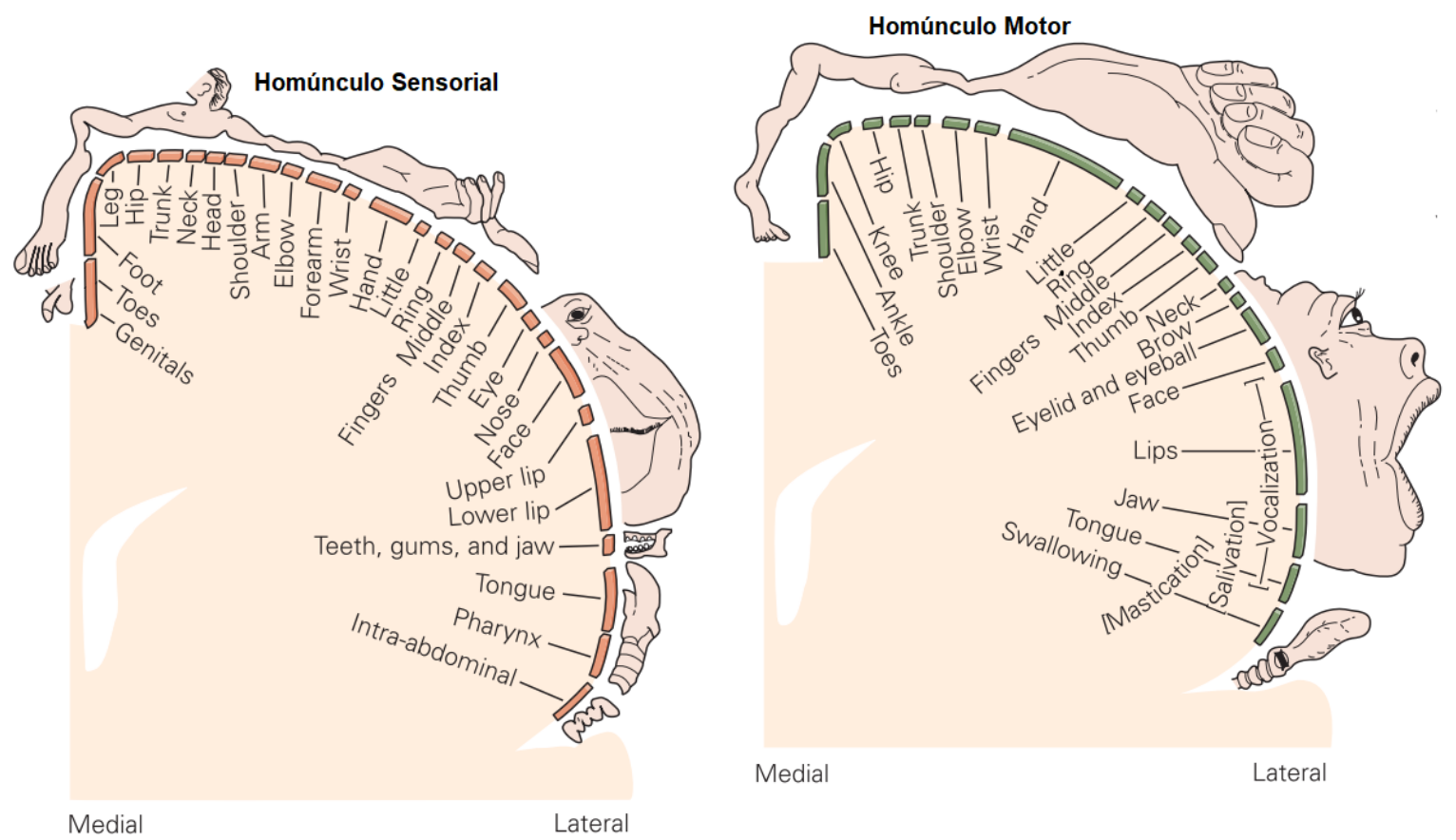

Fonte: adaptado de (Kandel, E. R., Shwartz, 2013)

massa branca. A principal diferença entre os dois tipos de substância é que a substância branca possui apenas os prolongamentos axonais dos neurônios, enquanto que a substância cinzenta possui os prolongamentos axonais e os núcleos celulares dos neurônios. A medula espinhal possui canais de comunicação de informações sensoriais e motoras nas direções ascendente e descendente, respectivamente. A região dorsal do chifre possui neurônios sensoriais que captam estímulos das regiões periféricas do corpo e a região ventral possui neurônios motores que levam os comandos do encéfalo para os músculos. Já na região de substância branca, há ambos os tipos de neurônios. Os segmentos mais próximos à cervical possuem maior quantidade de matéria branca, enquanto os segmentos sacrais possuem mais substância cinzenta. A figura 6 mostra a medula espinhal em seções:

\subsubsection{Sistema nervoso periférico}

O sistema nervoso periférico é formado por nervos e gânglios nervosos e ele se espalha por todo o corpo. Os gânglios são conjunto de corpos de neurônios, enquanto que os nervos são formados pelos axônios destes neurônio. Os nervos podem se originar do encéfalo ou da medula espinhal e eles são denominados nervos cranianos e espinhais, respectivamente. São 12 pares de nervos cranianos e 31 pares de nervos espinhais. Existem os nervos aferentes e eferentes, responsáveis por transmitir informação para o sistema nervoso do meio externo e do sistema nervoso central para o sistema nervoso periférico, respectivamente.

Do ponto de vista funcional, o sistema nervoso periférico pode ser dividido em 
Figura 6 - Medula espinhal dividida nas seções cervical, torácica, lombar e sacral

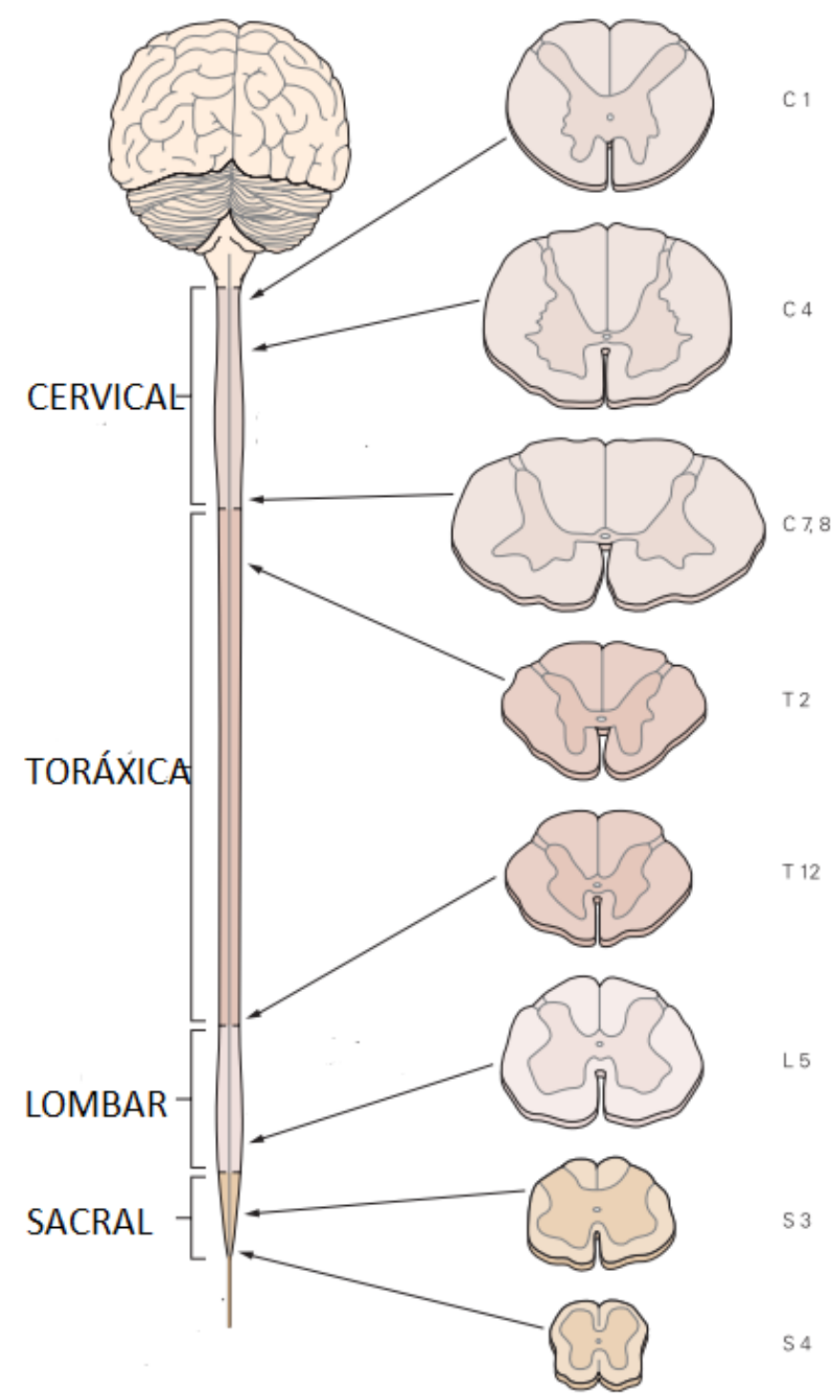

Fonte: adaptado de (Kandel, E. R., Shwartz, 2013)

sistema autônomo e sistema somático. O sistema somático é responsável pelas ações voluntárias, como a contração de músculos da porção esquelética do corpo. Já o sistema autônomo controla ações involuntárias, como por exemplo, a respiração (Arthur C. Guyton, 2011).

\subsection{Lesão Medular}

\subsubsection{Caracterização da LM}

A LM é uma disfunção neurológica caracterizada pela interrupção da comunicação entre regiões mais elevadas do sistema nervoso central com a porção motora do sistema 
nervoso periférico e, consequentemente, com as unidades motoras musculares. Todos os músculos abaixo do nível neurológico de lesão são comprometidos. A origem da LM normalmente é traumática e as principais causas são acidentes de carro e de moto (ENG; TEASELL, 2007). A figura 7 mostra as principais relações entre o segmento da medula espinhal e grupo muscular correspondente.

Figura 7 - Medula Espinhal com os músculos correspondentes

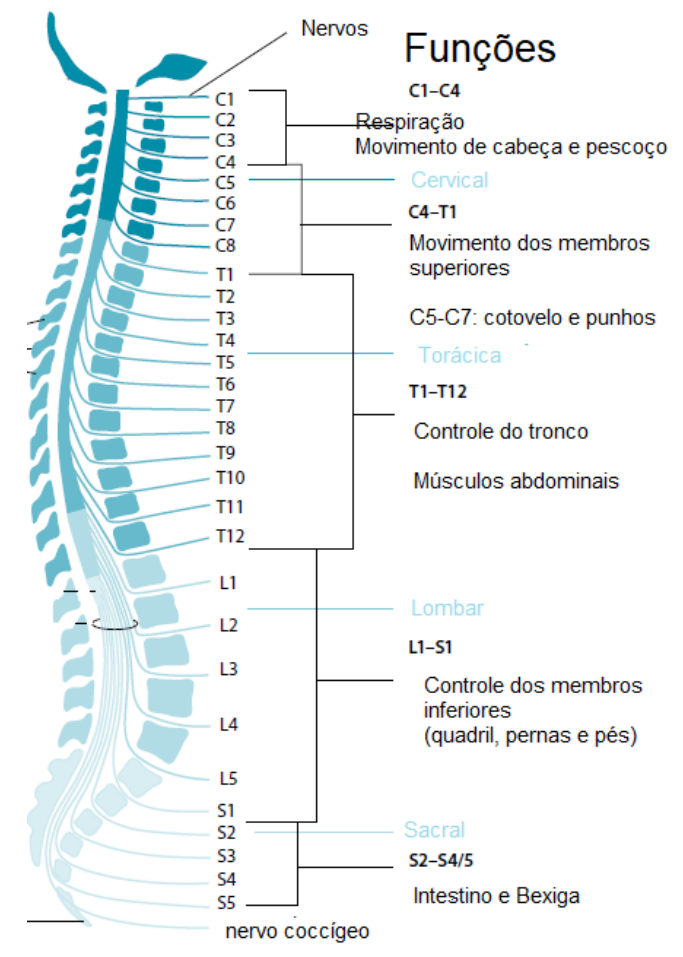

Fonte: Adaptado de Spinal Cord Injury Rehabilitation Evidence (ENG; TEASELL, 2007)

Além da limitação motora, os caminhos sensoriais que levam informações do meio externo para o cérebro são danificados pela LM. Isto tem uma implicação direta no aprendizado motor, uma vez que o aprendizado motor funciona como um sistema de malha fechada (MONTGOMERY; CONNOLLY, 2003). Desta forma, a ausência de um sinal sensorial externo implica que o cérebro não possui um parâmetro para corrigir o movimento. Outra implicação da falta de sensibilidade é a ausência de propriocepção. A propriocepção é definida como a noção espacial do corpo. A ausência dessa capacidade implica que os tratamentos direcionados aos lesados medulares precisam ter uma cautela maior para a segurança do paciente.

A classificação da LM é feita com o exame da American Spinal Injury Association (ASIA) denominado de ASIA Impairment Scale (AIS). Este exame é feito por meio de uma avaliação sensorial e motora do paciente para cada grupo muscular. O nível neurológico da lesão é o ponto mais caudal no qual o paciente não possui ou possui parcialmente capacidades motoras (MAYNARD et al., 1997). A imagem 8 mostra o protocolo do exame AIS. As capacidades motoras são ranqueadas em um valor qualitativo de 0 até 5 . 
Figura 8 - Formulário AIS

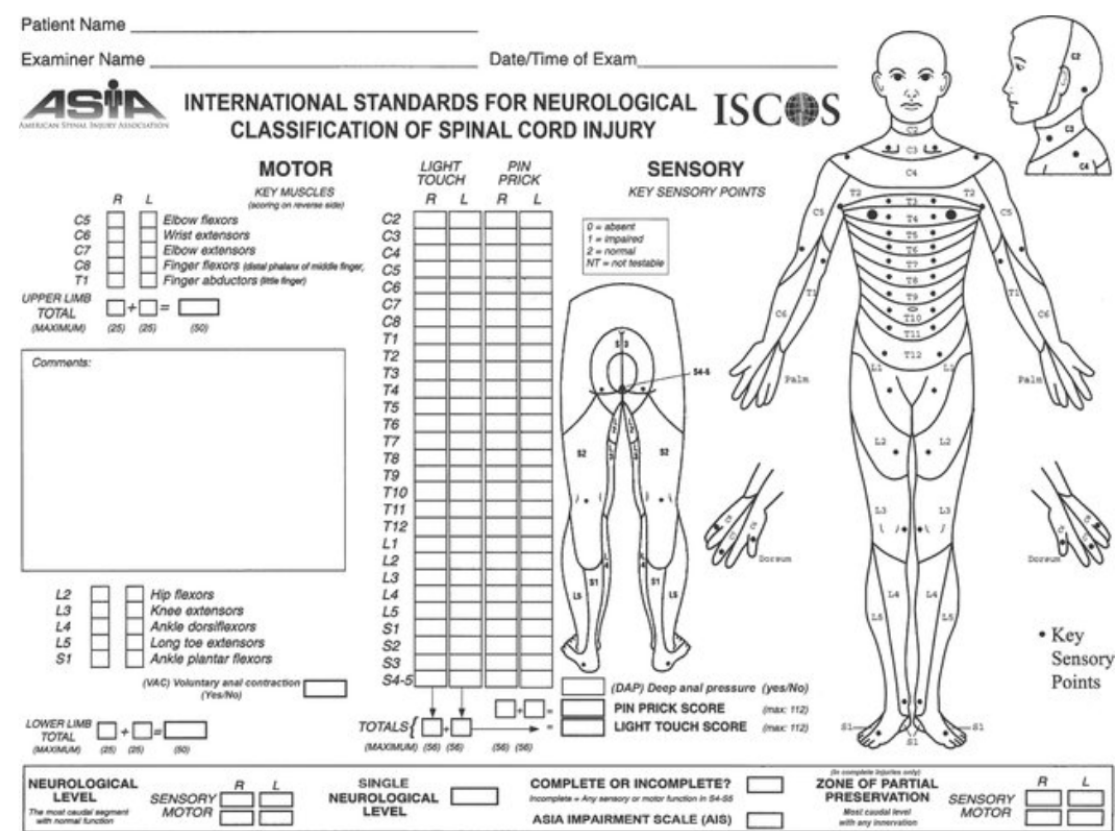

Fonte: Adaptado de American Spinal Injury Association (American Spinal Injury Association, 2016)

Além do nível neurológico, o AIS classifica a lesão em uma de cinco categorias. ASIA A é definido como LM completa onde não há nenhuma atividade motora ou sensorial preservada abaixo do nível neurológico de lesão. ASIA B é uma lesão incompleta onde não há atividade motora abaixo do nível neurológico, porém há alguma sensibilidade. ASIA C e D indicam que há atividade motora reduzida abaixo do nível neurológico. Finalmente, ASIA E indica uma pessoa normal com todas as funções sensoriais e motoras preservadas.

\subsubsection{Reabilitação da LM}

A reabilitação dos lesados medulares é um processo longo e que envolve uma série de tratamentos diferentes para maximizar a recuperação funcional e sensorial. Ela começa na fase aguda com procedimentos variados e se estende até a fase sub-aguda com processos mais específicos de reabilitação. Algumas áreas envolvidas no processo de reabilitação são enfermagem, fisioterapia, terapia ocupacional, atendimento com psicólogo e com nutricionista (HARNETT et al., 2020).

\subsection{Biomecânica dos Membros Superiores}

\subsubsection{Modelos muscular e esquelético do corpo humano}

Outra forma de analisar os movimentos é a construção de modelos matemáticos e físicos para simular o funcionamento dos músculos. Diferentemente da neuroanatomia, a 
biomecânica tem como foco entender o funcionamento da estrutura muscular e esquelético por meio da análise cinética dos movimentos ao invés de explicar a estrutura celular. A explicação a seguir do modelo de funcionamento do músculo foi adaptada do livro (ROBERTSON, 2013).

O modelo físico mais simples para entender o funcionamento do músculo foi proposto por A.V. Hill na segunda metade do século XX. O modelo muscular de Hill é composto por uma componente de contração (CC), uma componente elástica em série (CES) e uma componente elástica em paralelo (CEP). A figura 9 mostra o modelo de músculo de Hill:

Figura 9 - Modelo muscular de HILL

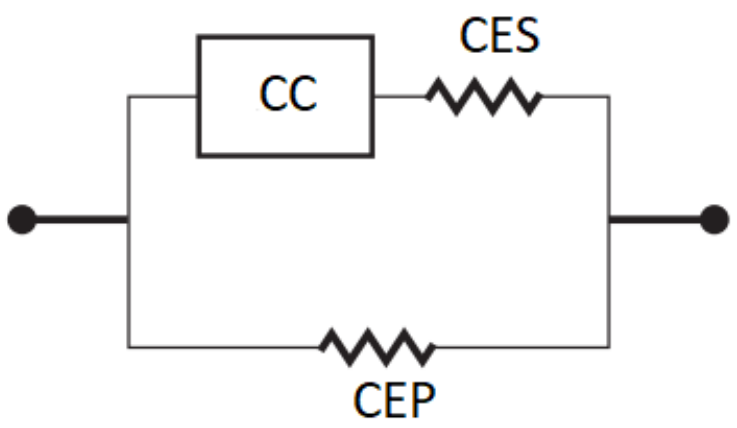

Fonte: adaptado de (ROBERTSON, 2013)

A componente de contração é o elemento ativo do músculo que transforma o impulso nervoso em contração muscular. Existem 4 relações que regulam a força de contração: Ativação-Estimulação, Ativação-Força, Força-Comprimento e Força-Velocidade. A Ativação-Estimulação consiste na conversão dos impulsos nervosos em potencial de ativação das unidades motoras. A ativação muscular ocorre por meio da liberação de íons de cálcio, que é respondido pelas proteínas de actina e miosina presentes em filamentos finos e grossos, respectivamente. A Ativação-Estimulação também é responsável por regular a frequência com que os musculos contraem e relaxam. A relação de Ativação-Força cresce proporcionalmente com a Ativação-Estímulo. A figura 10 mostra os processos de contração e relaxamento muscular após um estímulo elétrico. Observa-se que o tempo de relaxamento costuma ser maior do que o tempo de contração.

A relação entre força e velocidade é a mais importante do componente de contração. A força de contração (PHill) aumenta conforme a velocidade (VHill). A força máxima (P0) é obtida na isometria quando a velocidade de contração do músculo é nula. Em termos de Força-Comprimento, a força máxima é obtida quando o componente de contração atinge metade do seu tamanho máximo. A equação 2.1 relaciona velocidade e força muscular com dois parâmetros mecânicos do músculo, a e b.

$$
(P H i l l+b)(\text { VHill }+a)=P 0 * b
$$


Figura 10 - Estímulo do sistema nervoso e ativação muscular

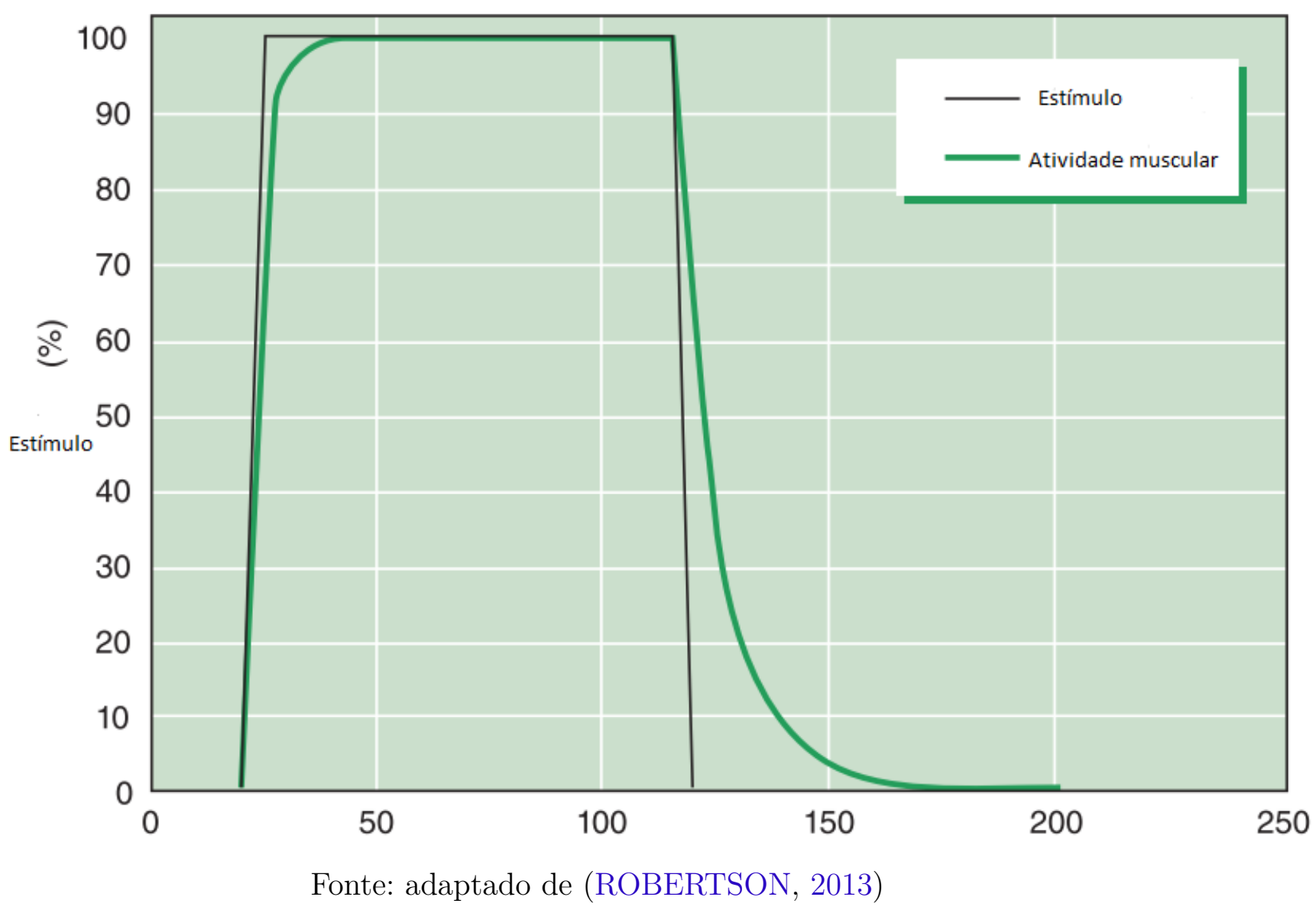

As componentes elástica em série e em paralelo são elementos passivos do modelo de Hill que representam a resistência da estrutura muscular à contração. A componente elástica em série responde diretamente à contração muscular, enquanto que a componente elástica em paralelo mantém o músculo parcialmente esticado mesmo quando não há contração muscular.

\subsubsection{Antropometria}

Antropometria é o estudo das proporções dos segmentos anatômicos. Ela é importante na análise biomecânica para a construção do modelo 3D do qual os dados serão extraídos. A antropometria consegue estimar parâmetros específicos do corpo humano a partir de medidas gerais de altura, idade, sexo e massa.

Um dos modelos mais simples de antropometria é utilizado para estimar os segmentos do corpo a partir da altura total. O modelo de Dempster foi criado a partir da medição de cadáveres (ROBERTSON, 2013) e ele define porcentagens da altura total para estimar os segmentos do corpo humano. A figura 11 mostra esse modelo.

Outro cálculo feito por Dempster foi com relação a massa e centro de massa de cada segmento do corpo e ela é importante para o cálculo de forças, trabalho e energia 
Figura 11 - Modelo de Dempster para segmentos

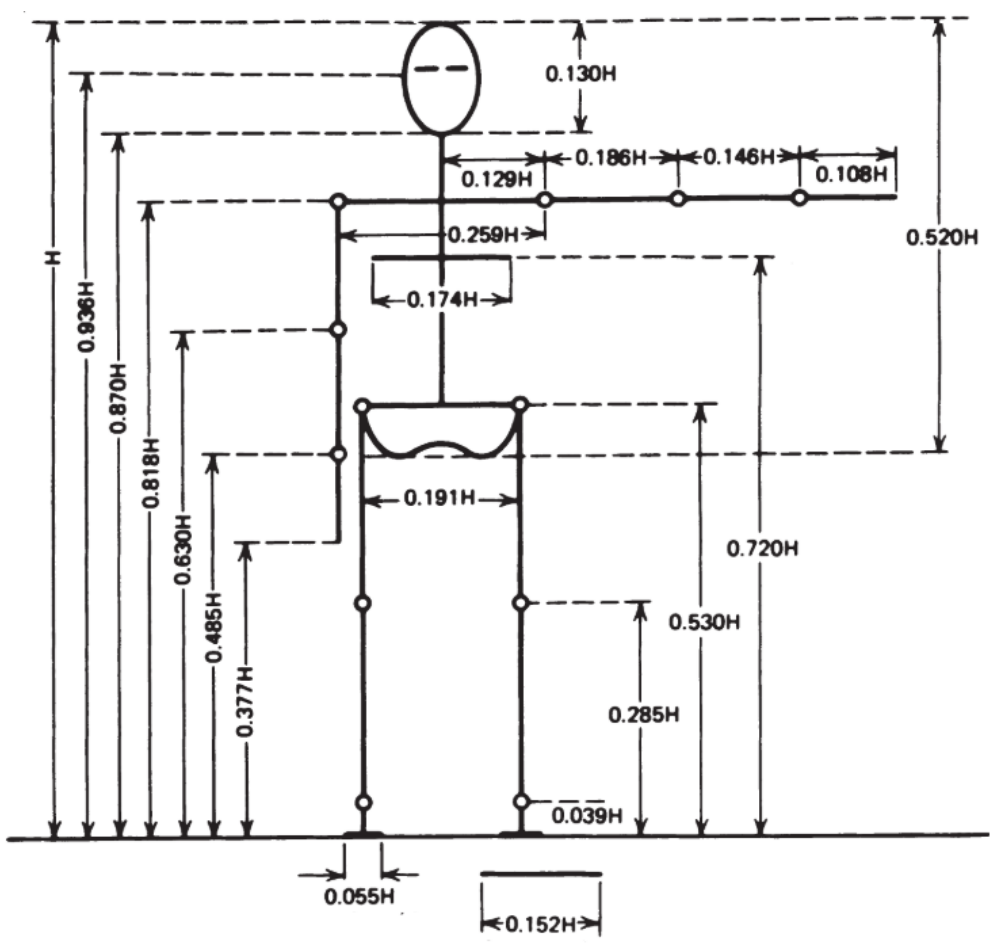

Fonte: adaptado de (WINTER, 2009)

para uma determinada atividade física (WINTER, 2009). A figura 12 mostra os valores de centro de massa e massa dos segmentos em função da porcentagem de massa.

Figura 12 - Relações de centro de massa e massa de Dempster para segmento

\begin{tabular}{|c|c|c|c|c|}
\hline \multirow[b]{2}{*}{ Segment } & \multirow[b]{2}{*}{ Definition } & \multirow{2}{*}{$\begin{array}{l}\text { Massa do } \\
\text { segmento/m } \\
\text { assa total }\end{array}$} & \multicolumn{2}{|c|}{$\begin{array}{l}\text { Centro de Massa/ } \\
\text { tamanho do } \\
\text { segmento }\end{array}$} \\
\hline & & & Proximal & Distal \\
\hline Hand & Wrist axis/knuckle II middle finger & $0.006 \mathrm{M}$ & 0.506 & $0.494 \mathrm{P}$ \\
\hline Forearm & Elbow axis/ulnar styloid & $0.016 \mathrm{M}$ & 0.430 & $0.570 \mathrm{P}$ \\
\hline Upper arm & Glenohumeral axis/elbow axis & $0.028 \mathrm{M}$ & 0.436 & $0.564 \mathrm{P}$ \\
\hline Forearm and hand & Elbow axis/ulnar styloid & $0.022 \mathrm{M}$ & 0.682 & $0.318 \mathrm{P}$ \\
\hline Total arm & Glenohumeral joint/ulnar styloid & $0.050 \mathrm{M}$ & 0.530 & $0.470 \mathrm{P}$ \\
\hline Foot & Lateral malleolus/head metatarsal II & $0.0145 \mathrm{M}$ & 0.50 & $0.50 \mathrm{P}$ \\
\hline Leg & Femoral condyles/medial malleolus & $0.0465 \mathrm{M}$ & 0.433 & $0.567 \mathrm{P}$ \\
\hline Thigh & Greater trochanter/femoral condyles & $0.100 \mathrm{M}$ & 0.433 & $0.567 \mathrm{P}$ \\
\hline Foot and leg & Femoral condyles/medial malleolus & $0.061 \mathrm{M}$ & 0.606 & $0.394 \mathrm{P}$ \\
\hline Total leg & Greater trochanter/medial malleolus & $0.161 \mathrm{M}$ & 0.447 & $0.553 \mathrm{P}$ \\
\hline Head and neck & $\mathrm{C} 7-\mathrm{T} 1$ and Ist rib/ear canal & $0.081 \mathrm{M}$ & 1.000 & $-\mathrm{PC}$ \\
\hline Shoulder mass & Sternoclavicular joint/glenohumeral axis & is $\quad-$ & 0.712 & 0.288 \\
\hline Thorax & $\mathrm{C} 7-\mathrm{T} 1 / \mathrm{T} 12-\mathrm{L} 1$ and diaphragm* & $0.216 \mathrm{PC}$ & 0.82 & 0.18 \\
\hline Abdomen & T12-L1/LA-L.5* & 0.139 LC & 0.44 & 0.56 \\
\hline Pelvis & L4-L.5/greater trochanter ${ }^{6}$ & $0.142 \mathrm{LC}$ & 0.105 & 0.895 \\
\hline Thorax and abdomen & $\mathrm{C} 7-\mathrm{T} 1 / \mathrm{L}_{4}-\mathrm{L}^{*}$ & $0.355 \mathrm{LC}$ & 0.63 & 0.37 \\
\hline Abdomen and pelvis & T12-L1/greater trochanter* & $0.281 \mathrm{PC}$ & 0.27 & 0.73 \\
\hline Trunk & Greater trochanterfglenohumeral joint* & $0.497 \mathrm{M}$ & 0.50 & 0.50 \\
\hline Trunk head neck & Greater trochanterfglenohumeral joint* & $0.578 \mathrm{MC}$ & 0.66 & $0.34 \mathrm{P}$ \\
\hline $\begin{array}{l}\text { Head, arms, and } \\
\text { trunk (HAT) }\end{array}$ & Greater trochanter/glenohumeral joint* & $0.678 \mathrm{MC}$ & 0.626 & $0.374 \mathrm{PC}$ \\
\hline HAT & Greater trochanter/mid rib & 0.678 & 1.142 & - \\
\hline
\end{tabular}

Fonte: Adaptado de (WINTER, 2009) 


\subsubsection{Referências para análise de movimentos}

A International Society of Biomechanics (ISB) define normas para as referências adotadas para a análise de movimento, de forma a unificar os estudos feitos nessa área (WU; CAVANAGH, 1995). A figura 13 mostra uma visão geral dos pontos anatômicos utilizados para os eixos coordenados (X, Y e Z) dos sistemas de referências global e de cada segmento. O sistema de referências global está posicionado no chão e ele possui o Figura 13 - Referência global e exemplos de Referências locais para segmentos anatômicos

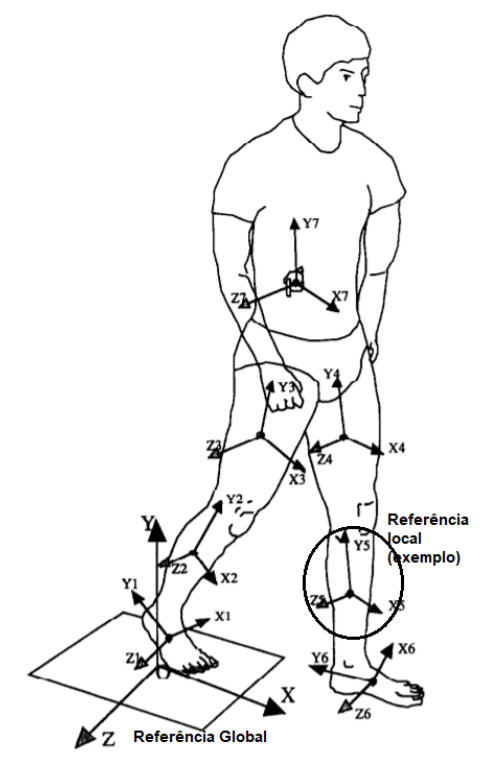

Fonte: adaptado de (WU; CAVANAGH, 1995)

eixo X orientado para a direção na qual o movimento será realizado e o eixo Y contra a direção da gravidade. O eixo $\mathrm{Z}$ é sempre definida pelo produto vetorial $\times \vec{Y}$.

O sistema de referência local de cada segmento possui a origem no centro de massa do segmento respectivo e as direções dos eixos coordenados dele são iguais as direções do sistema de coordenadas global para a posição de repouso, na qual o corpo fica reto na direção onde será realizado o movimento (eixo X).

A referência das articulações requer uma análise mais detalhada dos segmentos anatômicos, pois cada uma dessas referências depende das orientações adotadas para os segmentos proximal e distal (WU et al., 2005). As AVDs dos membros superiores requerem o uso dos músculos deltoide anterior, bíceps braquial, tríceps braquial, flexores e extensores de punho para realizar os movimentos de extensão e flexão de ombros, cotovelos e punhos (VARGAS, 2012). A figura 14 possui as referências para as articulações com base em segmentos distal e proximal.

Ao se aplicar a regra da mão direita para definir as rotações pela referência, os sentidos positivos de rotação para os lados direito e esquerdo de cada segmento do corpo seriam os mesmos, porém esses segmentos rotacionariam em sentidos anatômicos diferentes 
Figura 14 - Referências para articulações de membros superiores

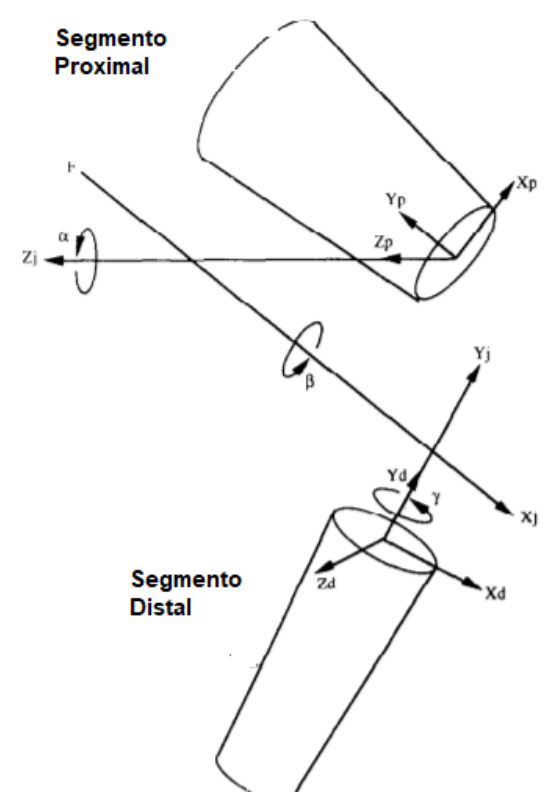

Fonte: adaptado de (WU; CAVANAGH, 1995)

(WU et al., 2005). Dessa forma, para se orientar a rotação dos dois lados do corpo, adota-se os sentidos de rotação anatômicos como positivos (MOORE; DALLEY; AGUR, 2004). A figura 15 mostra os sentidos de rotação positivos para os movimentos de flexão de ombro, adução de ombro, extensão de cotovelo e flexão de punho.

Figura 15 - Referências para rotações anatômicas de ombros, cotovelos e punhos

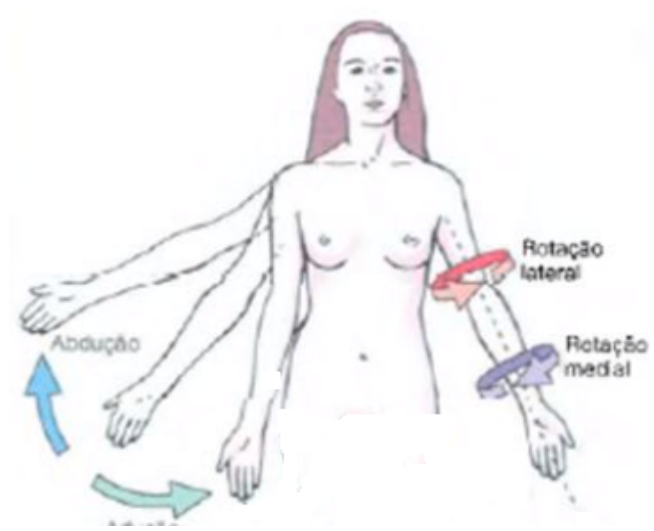

Fonte: adaptado de (MOORE; DALLEY; AGUR, 2004)

\subsection{Realidade Virtual (RV)}

\subsubsection{Hardwares para visualização e interação com o ambiente de RV}

O Head-Mounted Display (HMD) é o dispositivo utilizado para visualizar ambientes imersivos de realidade virtual. Todo HMD possui duas lentes que representam duas imagens similares com perspectivas diferente. Estas duas imagens 2D sobrepostas são processadas 
pelo cérebro como uma única imagem tridimensional. Este fenômeno é denominado visão estereoscópica (UREY et al., 2011) e ele é uma das bases da RV pois ela transforma uma experiência não imersiva 2D em um ambiente 3D imersivo.

Outro aspecto do HMD que torna as experiências com RV mais imersivas é o rastreamento da posição da cabeça. Os sensores de giroscópio e acelerômetro presentes no HMD são responsáveis por ratrear rotação e posição da cabeça do usuário. Os dois sensores combinados com a visão estereoscópica resultam em um ambiente tridimensional onde o usuário pode ver objetos com a mesma perspectiva de um objeto real. Alguns exemplos de HMDs são descritos a seguir:

\section{Google Cardboard}

O Google Cardboard (figura 16) é um suporte plástico que utiliza os sensores de movimento do celular para rastrear a posição da cabeça. O Google Carboard funciona em conjunto com um aplicativo homônimo que é compatível com celulares com sistema operacional Android. A principal vantagem do Cardboard é que o custo desse HMD é inferior a outros HMDs que possuem um hardware específico para RV e ele é portátil.

Figura 16 - Exemplo de Cardboard

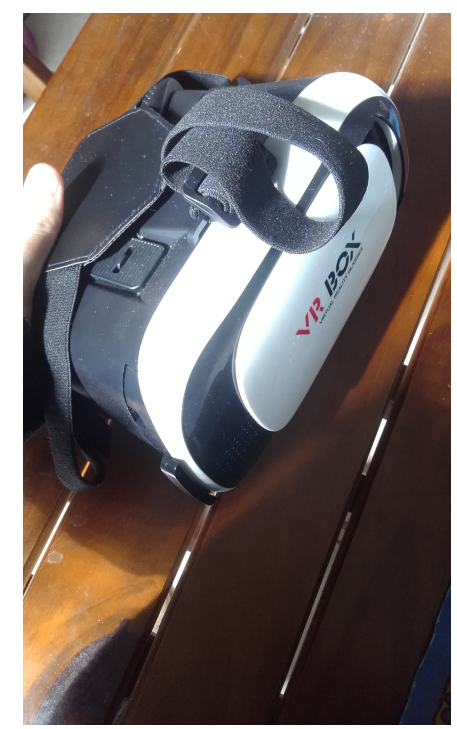

Fonte: Autoria própria

\section{Oculus Rift e HTC Vive}

O Oculus Rift e o HTC Vive são HMDs que possuem hardwares dedicados para RV. Ambos possuem sensores próprios, capacidade de processamento elevada e controles ajustados para as mãos. Além disso, o HTC possui câmeras externas que servem para mapear a posição do usuário dentro de uma sala. As principais limitações destes sistemas são o custo e ambos dependem de um computador sofisticado. 
3. Oculus Quest O Oculus Quest (figura 17) é uma versão portátil do Oculus Rift. Ele possui os mesmos dois controles do Rift e ele possui uma biblioteca de reconhecimento de gestos. Por ser portátil, ele é apropriado para aplicações médicas, pois pode ser utilizado em ambientes hospitalares com pouco espaço ou ambientes domésticos. Os 4 círculos em vermelho na figura 17 indicam as quatro câmeras do Oculus Quest utilizadas para o rastreamento das mãos sem o controle.

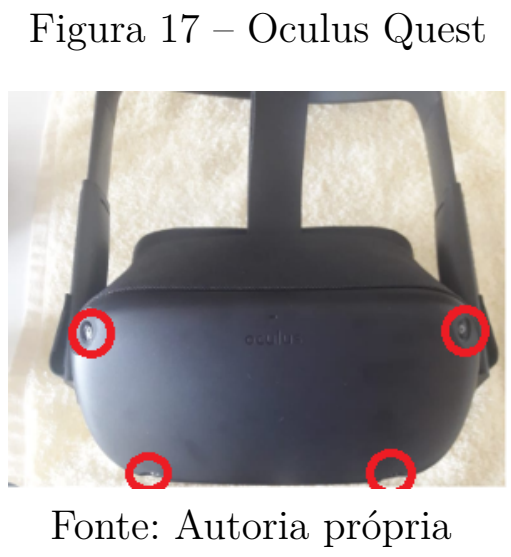

\subsubsection{Dispositivos de Entrada}

Uma das primeiras reações comum aos usuários de RV é procurar por um retorno proprioceptivo das mãos dentro do ambiente virtual. Os dispositivos de entrada são utilizados para interagir com o ambiente virtual e eles normalmente interagem com as mãos. Os dispositivos de entrada podem ser mais simples, como é o caso de controles e botões, ou podem ser mais elaborados, como câmeras com luzes infravermelhas e pulseiras de eletromiografia.

Seguem alguns dos dispositivos de entrada comumente utilizados com RV:

\section{Myo}

Myo é uma pulseira com sensores de eletromiografia. Ela interpreta as intenções de ação do usuário e as traduz em ações dentro do ambiente virtual.

\section{Leap Motion}

O Leap Motion consiste em uma câmera que emite luz infravermelha voltada para a detecção da posição das mão e antebraços. Ela detecta a posição de alguns dos principais ossos e articulações das mãos e dos antebraços. A câmera junto com sistema de referência e as articulações das mãos detectadas pela câmera são mostradas na figura 18 
Figura 18 - Leap com referências e modelo 3D das mãos
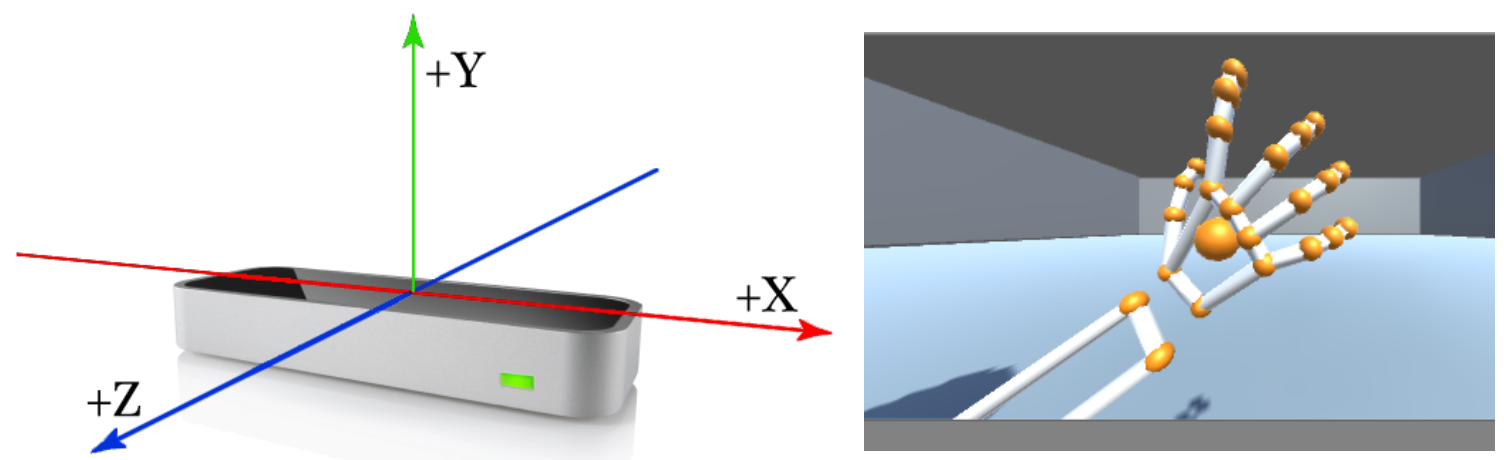

Fonte: Adaptado de (LEAP Motion, 2018)

\section{Oculus Touch}

O Oculus Touch são os controles do Oculus Quest. Diferentemente de controles normais, eles são feitos para a anatomia das mãos. Os botões analógicos se movimentam com facilidade para conceder a sensação de que o usuário interage com o ambiente virtual como se não houvesse controle, além de dois gatilhos que possibilitam o reconhecimento do gesto de preensão de indicador e polegar. O Oculus Touch possui sensores de movimentos para reconhecer a posição das mãos relativa ao Oculus Quest. A figura 19 mostra o Oculus Touch.

Figura 19 - Oculus Touch

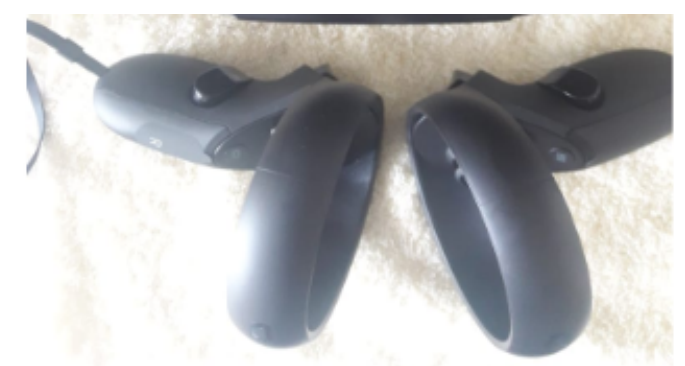

Fonte: Autoria própria

\section{HaptX}

HaptX é uma luva com sensores de movimentos e feedback háptico para interagir com ambientes virtuais. Ela simula o toque por meio de motores que geram uma força nos dedos das mãos. A sensação de toque melhora a percepção de tamanho, peso e forma de objetos virtuais. A figura 20 mostra o HaptX.

\subsection{Rastreamento das Mãos}

O rastreamento de mãos do Oculus Quest permite utilizar as mãos como dispositivo de entrada. As câmeras frontais reconhecem as mãos e conseguem recriar um modelo 


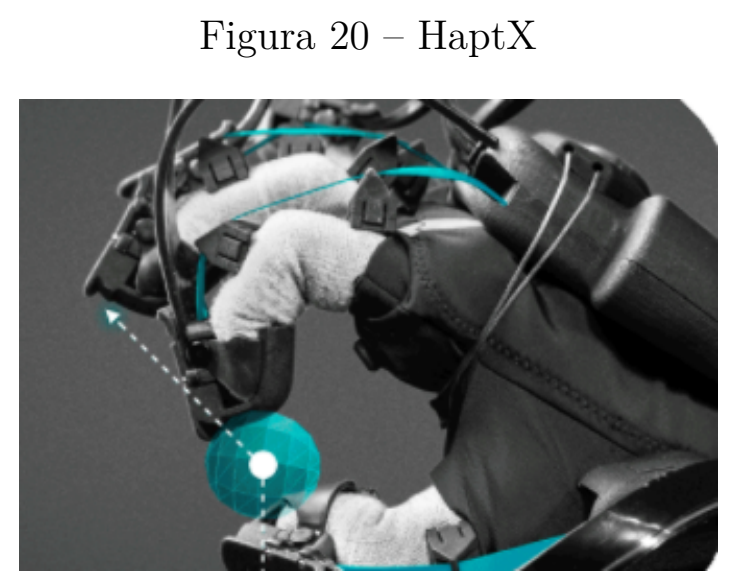

Fonte: Adaptado de (HAPTX, 2019)

tridimensional das mãos no ambiente virtual. Dessa forma, o usuário consegue interagir com o ambiente virtual por meio de gestos e por movimentos das mãos no ambiente real. A biblioteca da Oculus fornece os dados brutos de posições dos dedos e da palma de cada mão relativos a posição do HMD. Desse modo, é possível utilizar objetos para representar a mão do usuário no ambiente virtual. O uso do rastreamento de mãos como dispositivo de entrada é conveniente para pessoas com mobilidade reduzida pois não requer nenhum equipamento extra além do Oculus Quest e os gestos reconhecidos pelo ambiente virtual podem ser adaptados para as limitações do usuário. A figura 21 mostra o modelo das mãos no ambiente virtual. O objeto vermelho foi utilizado para detectar a posição do punho.

Figura 21 - Rastreamento das Mãos

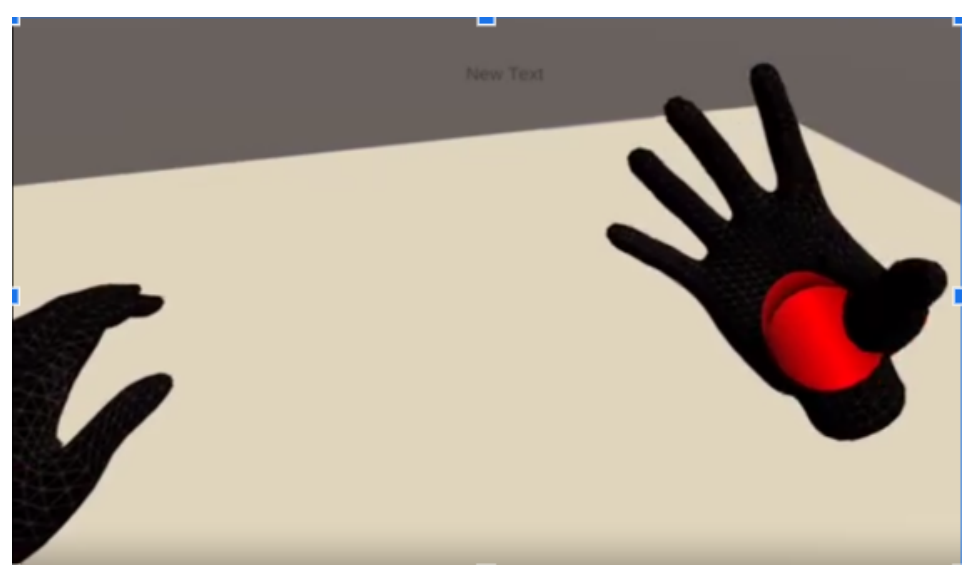

Fonte: Autoria própria

\subsection{Unity 3D}

A Unity 3D é um ambiente de desenvolvimento de jogos no qual é possível modelar objetos, incluir sons, programar comportamentos dos seres do jogo, criar cenas e outras várias funcionalidades. As linguagens de programação compatíveis com a Unity são C\# e Javascript e o site da Unity 3D possui toda documentação e tutoriais necessários para a 
criação dos códigos (LINOWES, 2015).

Figura 22 - Interface da Unity 3D

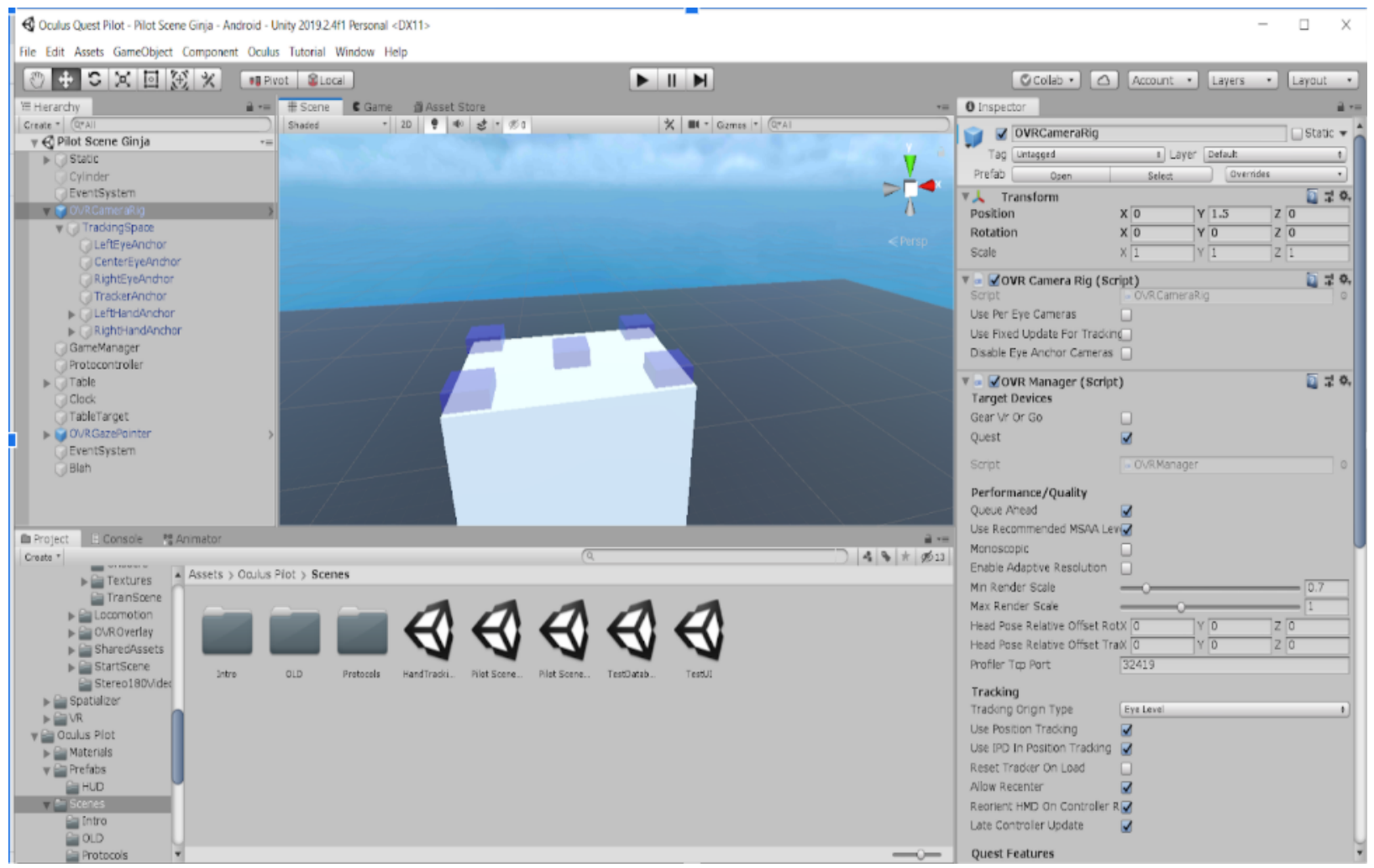

Fonte: Autoria própria

A Unity 3D é composta pelas seguintes interfaces:

- Scene: Essa é a tela em que as cenas do jogo são montadas. Nessa interface é possível arrastar objetos de jogos, redimensioná-los e criar todo o ambiente de jogo. Uma unidade de medida na Unity 3D corresponde a um metro no ambiente virtual. Outros componentes que podem ser editados nessa interface incluem a iluminação e interfaces de usuário. Para a criação de uma interface, é preciso criar painéis chamados de canvas na cena. Sobre esse canvas podem ser inseridos diversos tipos de interface de usuário, tais como barras, botões, textos, barras de rolamento entre outros elementos.

A Unity 3D possui uma inteligência artificial nativa que pode ser muito útil na criação de personagens autônomos, a navmesh. Essa inteligência cria uma malha de navegação na cena onde os objetos estáticos são divididos em navegáveis e nãonavegáveis. Feita essa divisão, configura-se os agentes da navmesh. Esses agentes possuem uma inteligência pré-construída em que configura-se apenas como ele vai andar nas áreas navegáveis e qual é o objetivo final dele. A posição do objetivo final pode ser alterada de acordo com o estado do jogo. 
Outro componente muito importante é a câmera principal. Ela é a visão do jogador durante o jogo. Para esse projeto, ela foi configurada para o modo em primeira pessoa. Dessa forma, conforme o usuário olha ao redor da cena, a câmera acompanha essa visão. Isso melhora a imersão do jogador.

- Project: Nessa janela, ficam todos os assets. Assets são componentes utilizados no desenvolvimento do jogo. Junto a essa interface, tem o console, que mostra erros e avisos de programação. Outras janelas importantes associadas ao project são:

1. Animator: Mostra a máquina de estados da animação (caso tenha algum modelo com animação).

2. Timelines: Permite gravar cenas dentro do jogo. A timeline salva a posição de alguns objetos em instantes escolhidos e faz a interpolação dessas posições. Essa mesma ferramenta permite adicionar sons e câmeras

3. Asset Store: Loja da Unity que possui vários assets gratuitos que podem ser utilizados no jogo.

- Game: Essa é a janela em que o jogo é executado. É possível pausar a execução, alterar coisas da cena durante o jogo. Alterações feitas enquanto o jogo é executado não ficam salvas permanentemente. Isso possibilita a realização de testes sem danificar a cena.

- Inspector / Hierarchy: A Unity é fundamentada em progamação orientada a objetos. Esse conceito é explorado na Hierarchy, onde os objetos filhos herdam todas as propriedades dos objetos pai. Para estabelecer essa hierarquia, basta arrastar um objeto para dentro de outro. Alguns exemplos de propriedades são posição, som, física, velocidade, códigos, colisores. Um objeto pai com seus objetos filhos podem ser salvos como um prefab e esse prefab pode ser instanciado a qualquer momento durante o jogo.

O Inspector mostra essas propriedades e permite alterar os parâmetros correspondentes. Dentre as propriedades mais utilizadas, destaca-se o transform, que é a posição do objeto na cena,e o rigidbody, que é a física do objeto. Nele, também é possível atribuir valores de outras características físicas dos objetos dentro do jogo, tais como gravidade, graus de liberdade, colisão. Outro elemento importante para desenvolver a física do jogo são os colliders. Eles definem a região do objeto que colide com outros objetos que também possuam colisores.

Ambos componentes possuem métodos dentro de suas respectivas classes que possibilitam adicionar forças, mudar velocidades, ou desencadear eventos dentro do jogo. Esses colisores podem ser físico ou triggers, que são responsáveis por desencadear eventos quando algum outro objeto interage com eles. 
A Unity 3D é multiplataforma e os jogos podem ser compilados para consoles e portáteis, incluindo celulares. Quando utilizada em conjunto com o Google VR ou com o Oculus Quest, a Unity compila um arquivo no formato .apk que será executado no hardware correspondente.

\subsection{Aplicações de Realidade Virtual na Reabilitação Motora}

\subsubsection{Imagética Motora}

A RV possui aplicações na reabilitação devido a capacidade de simular ambientes terapêuticos com elevada reprodutibilidade na realização dos treinamentos. Ainda que muitos estudos mostrem a eficácia da RV em recuperar funções sensitivas e motoras causadas por disfunções neurológicas, faltam análises quantitativas mais rigorosas em maior parte dos estudos para se obter evidências mais sólidas (De Araújo et al., 2019).

A principal aplicação da RV na reabilitação é em tratamentos de imagética motora. A imagética motora consiste na mentalização de uma atividade física sem propriamente realizá-la. O planejamento dessa atividade ativa as regiões dos córtex pré-motor e motor como se a atividade fosse ser realizada, mesmo que o sinal gerado pelo cérebro não chegue nas unidades musculares (BRAUN, 2010). Com o estímulo visual da RV, o paciente pode praticar a imagética motora de modo a estimular a plasticidade cerebral e corrigir disfunções.

No tratamento do acidente vascular cerebral (AVC), a RV pode ser recriar exercícios que envolvem AVDs que foram debilitadas pelo AVC. Essa prática se mostrou efetiva para recuperar parcialmente movimentos dos membros inferiores e superiores. Cho et al (2015) (CHO et al., 2015) fez uma simulação de caminhada em RV para treinar um grupo de homens pacientes crônicos de AVC durante 4 semanas e o resultado obtido foi que o grupo que fez intervenção com RV obteve melhora significativa na marcha. Com relação a tratamentos de AVDs de membros superiores, pacientes de AVC na fase aguda (KWON et al., 2012) e crônica (SCHUSTER-AMFT et al., 2018) foram treinados e obtiveram recuperação parcial para movimentos de ombro, cotovelo e punhos.

\subsubsection{Lesão Medular}

A imagética motora não tem causa o mesmo estímulo na medula espinhal que ela causa no encéfalo (MONTGOMERY; CONNOLLY, 2003). Opsommer et al (OPSOMMER; CHEVALLEY; KOROGOD, 2019) realizou uma revisão sistemática sobre os efeitos da imagética motora em pessoas com LM. 18 estudos foram escolhidos envolvendo 282 pacientes, sendo que os tratamentos que visavam a melhora de dor duravam entre 8 e 20 minutos e os tratamentos que visavam melhora melhora de função motora duravam cerca 
de 20 minutos. A diversidade entre as metodologias utilizadas e a falta de caracterização da população de pessoas com LM nestes estudos dificultou uma análise quantitativa dos estudos.

Há alguns estudos de aplicação de RV em pessoas com LM. Trincado-Alonso e Dimbwadyo-Terrer utilizaram um sistema de RV não-imersiva (DIMBWADYO-TERRER et al., 2016; TRINCADO-ALONSO et al., 2014) para treinar tetraplégicos e avaliar a capacidade funcional deles e ele obteve como resultado maior motivação dos pacientes além dos benefícios do tratamento com fisioterapia convencional. O sistema Toyra desenvolvido por eles utiliza sensores de movimento acoplados ao usuário para interagir com um ambiente virtual projetado em um painel.

Lim et al (LIM et al., 2020) utilizou um sistema de realidade virtual imersivo para comparar a eficácia do treinamento virtual associado a terapia ocupacional com a terapia ocupacional convencional. Os participantes possuíam LM a menos de um ano e eles eram capazes de segurar o controle do HTC Vive utilizado com o grupo intervenção. O grupo controle recebeu sessões de 30 minutos de alongamento e 30 minutos de atividades funcionais, enquanto que o grupo intervenção recebeu os mesmos 30 minutos de alongamentos e 30 minutos de RV. Dentro do ambiente de RV, os participantes do grupo intervenção realizaram AVDs como tocar instrumento e alcançar objetos. Ao final do estudo, foram avaliadas as funções motoras dos ombros, cotovelos, punhos e mãos com a American Spinal Injury Association upper extremity motor score (ASIA-UEMS), que avalia de 0 a 100 as funções motoras citadas. O movimento de preensão do grupo intervenção obteve melhora estatisticamente relevante à preensão do grupo controle segundo o artigo. As AVDs realizadas pelo grupo controle não foram especificadas pelos autores.

Outros estudos avaliaram a resposta fisiológica de pessoas com LM sobre o estímulo de jogos virtuais. Jaramillo, Johanson e Kiratli (JARAMILLO; JOHANSON; KIRATLI, 2019) avaliou em 14 pessoas com LM (9 tetraplégicos e 5 paraplégicos) a atividade muscular e a taxa de batimento cardíaco durante a prática de jogos de esporte com o console Nintendo Wii (Nintendo, Japão, 2006). Os participantes não receberam instruções de como realizar os movimentos. Os batimentos cardíacos aumentaram cerca de 10-29 batimentos por minuto em relação a situação de repouso, o que, segundo o estudo, poderia sugerir o uso de jogos virtuais para a prática de exercício em pessoas com LM.

Há aplicações de RV para melhorar a condição de dor de pessoas com paraplegia. Austin et al (AUSTIN et al., 2020) comparou o efeito na redução de dor devido à visualização de uma aplicação em uma tela 2D e de objetos 3D com um HMD. A aplicação utilizada em ambos os casos foi uma caminhada por uma floresta. Os participantes possuíam dor crônica e aqueles que foram expostos ao ambiente 3D experienciaram em uma redução de dor maior do que aqueles que visualizaram a aplicação 2D. Outro tipo de estudo com o objetivo de entender a dor crônica é a incorporação da percepção da cadeira de rodas por 
meio de uma representação da cadeira em um ambiente virtual. Pozeg et al (POZEG et al., 2017) realizou um estudo com 11 pessoas com LM e dor crônica abaixo do nível da lesão e 20 indivíduos saudáveis para controle. Neste estudo, os participantes utilizam um HMD para visualizar duas pernas virtuais em uma posição aproximada das pernas reais deles. Um dos resultados foi que o uso das pernas virtuais poderia melhorar a sensação de propriedade das pernas, que é reduzida em pessoas com LM. Outro resultado secundário foi a redução moderada de dor crônica durante os experimentos.

\subsection{Considerações finais sobre o Referencial teórico}

Neste capítulo, foram apresentados nos itens 2.1 e 2.3 conceitos relacionados ao funcionamento do sistema nervoso e as implicações da LM no corpo e nas atividades diárias dos portadores desta lesão. Neste estudo, o parâmetro escolhido para avaliar os pacientes foi a análise cinemática dos membros superiores e, por isso, o item 2.3 explicou alguns conceitos sobre biomecânica e, principalmente, os referenciais anatômicos que são utilizados para a análise de movimentos. Por fim, o objetivo principal deste trabalho é desenvolver um ambiente de RV para reabilitação, portanto, foram apresentados os principais dispositivos para visualizar ambientes de RV (item 2.4), o rastreamento de mãos que foi escolhido para ser o dispositivo de entrada (item 2.5), o programa utilizado para desenvolver o ambiente virtual (item 2.6) e, finalmente, as aplicações já existentes de RV para a reabilitação (item 2.7 ). 



\section{Metodologia}

\subsection{Estudo Piloto}

O estudo piloto tem como objetivo caracterizar movimentos dos tetraplégicos para servir de referência para o desenvolvimento do ambiente virtual e testar a viabilidade do projeto. A análise biomecânica foi feita paralelamente ao desenvolvimento do ambiente de RV. Para cada treinamento novo desenvolvido no ambiente virtual, um protocolo de análise de biomecânica correspondente ao movimento que será realizado no ambiente virtual é avaliado com os pacientes. A figura 23 mostra este processo.

Figura 23 - Diagrama para representar a metodologia de caracterização

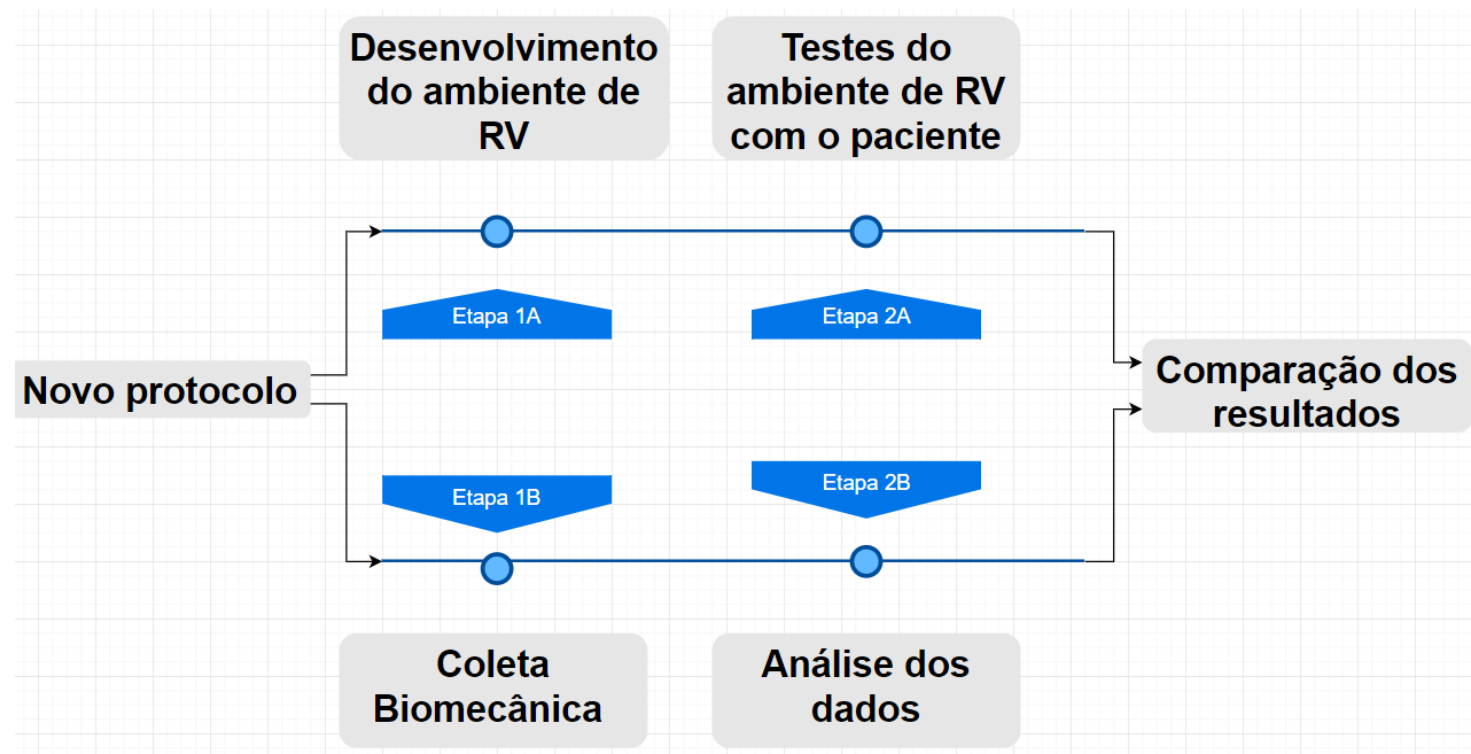

Fonte: Autoria própria

O protocolo piloto de alcance para desenvolvimento do ambiente virtual utilizado é uma composição de duas AVDs que já foram utilizadas em estudos anteriores (VARGAS, 2012), descritos a seguir:

1. Extensão de cotovelo: Os músculos exercitados nesse protocolo são deltoide anterior e bíceps braquial, tríceps braquial. Esse movimento consiste na extensão e na flexão do cotovelo, iniciando o movimento com o cotovelo flexionado.

2. Deslocamento de objeto: Neste protocolo, o paciente precisa segurar esse objeto por um breve período de tempo e deslocá-lo de uma posição até outra.

O protocolo utilizado neste estudo foi o deslocamento das mãos em 5 posições pré-definidas. A figura 24 mostra uma representação (fora de escala) da mesa que foi 
posicionada no colo do paciente enquanto ele fazia o protocolo.

Figura 24 - Representação da Mesa utilizada no protocolo

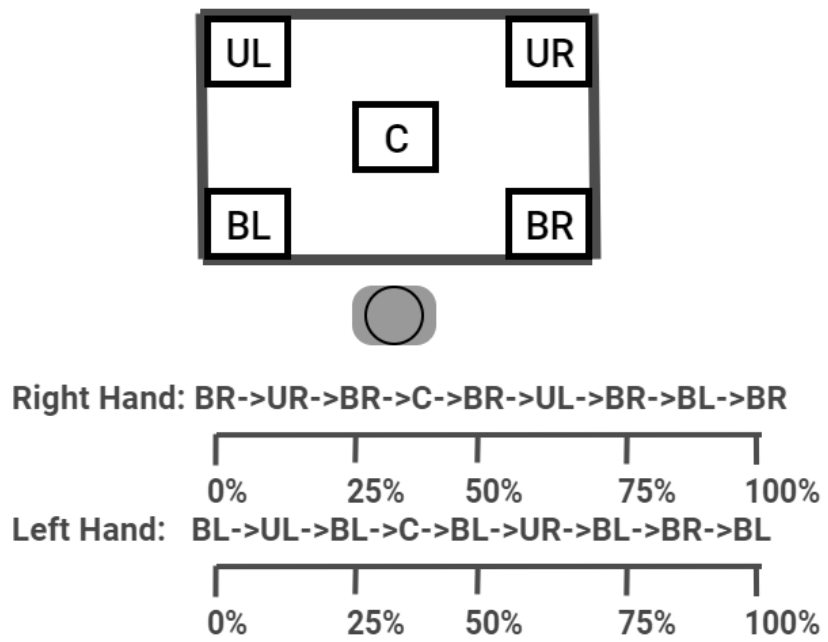

Fonte: Autoria própria

Primeiramente, com a mão esquerda, o paciente deve estender o cotovelo para alcançar os pontos BL-UL-BL-C-BL-UR-BL-BR-BL, nesta ordem. Depois, com mão direita, ele deve tocar nos pontos BR-UR-BR-C-BR-UL-BR-BL-BR. Cada protocolo é repetido 3 vezes para evitar perda de dados. As porcentagens na figura 24 correspondem a porcentagem do movimento para cada mão.

Em paralelo com a análise biomecânica, foi desenvolvido um ambiente virtual com o mesmo protocolo que foi coletado. O vídeo < https://drive.google.com/drive/folders/ 1LVpeSfSfbWdVOuhF5Oy0y1MBrbn0B6pB?usp=sharing $>$ mostra um indivíduo saudável realizando a demonstração do protocolo piloto no ambiente virtual.

\subsection{Captura de Movimentos com o Motion Monitor}

O Motion Monitor é um equipamento que integra hardwares e softwares necessários para a análise biomecânica. O Laboratório de Biomecânica e Reabilitação do Aparelho Locomotor (LABRAL-UNICAMP) possui um modelo do Motion Monitor que coleta e sincroniza os dados de cinemática, plataformas de força e eletromiografia (EMG). Durante os exercícios de reabilitação para membros superiores estes parâmetros são monitorados e gravados para a análise biomecânica pelo Motion Monitor. Uma visão geral dos parâmetros que podem ser coletados por este equipamento é descrita a seguir:

- Análise cinemática: A análise cinemática é feita com um sistema que mescla o uso de marcadores no paciente junto com câmeras que emitem luz infravermelha. Com base na posição desses marcadores, o software cria um modelo tridimensional e plota 
os gráficos correspondentes as posições desses marcadores. Além das articulações dos pacientes, é possível definir alguns objetos e monitorar a posição deles durante os exercícios.

- Eletromiografia: O sinal eletromiográfico é tratado e o software computa os gráficos desse sinal sem pós-processamento, sinal filtrado, RMS e análise em frequência. $\mathrm{O}$ equipamento utilizado para a coleta do sinal EMG é da Noraxon.

- Análise de forças: as plataformas de força possuem 6 células de carga, resultando em 6 graus de liberdade. Isso possibilita a coleta de dados de força e de torque. A análise de forças de membros superiores incluem dinamometria da mão, força de preensão da mão e dinamometria isocinética.

Dentre estas análises, a mais importante para caracterizar o movimento dos pacientes é a análise cinemática que é feita com câmeras da VICON. As câmeras detectam a posição de objetos reflexivos que, no caso da análise cinemática, são clusters com 4 marcadores cada. Estes marcadores são posicionados nas articulações dos pacientes e cada marcador precisa ser observado por pelo menos duas câmeras. O Motion Monitor possui 12 câmeras espalhadas em uma sala retangular para garantir que cada marcador seja visto por pelo menos duas câmeras. A figura 25 mostra um desenho da disposição das câmeras na sala de coleta. O retângulo no centro é uma plataforma de madeira na qual os pacientes realizam os protocolos.

Antes cada coleta, as câmeras precisam ser calibradas para detectar os clusters com clareza. A calibração é dividida em duas etapas: configuração manual da câmera e calibração do software Nexus, que é o programa utilizado para captura de movimentos com a VICON. A configuração manual das câmeras é similar a configuração de uma câmera fotográfica convencional. O foco e a exposição regulam a quantidade de luz e a área que será capturada respectivamente. Cada uma das câmeras precisa ser ajustada de modo a focalizar apenas nos marcadores e não em outros objetos reflexivos na sala e todas as câmeras juntas precisam focar no volume no qual a coleta será feita. Uma estratégia utilizada para garantir que as câmeras conseguem visualizar toda a região de coleta é posicionar quatro marcadores nos cantos extremos de uma rampa onde as coletas são feitas. A figura 26 mostra os ajustes da câmera em dois extremos.

Para que o software Nexus reconheça as câmeras e estabeleça a origem do sistema de coordenadas é utilizada uma varinha com marcadores. O eixo maior da varinha corresponde ao eixo $\mathrm{Y}$ e o eixo menor corresponde ao eixo X. A varinha deve ser posicionada paralelamente ao chão e sempre no mesmo local para todas as coletas do mesmo protocolo.

Após a configuração das câmeras no Nexus, o próximo programa utilizado na coleta é o software do Motion Monitor. Nele, configura-se quais hardwares serão utilizados e 
Figura 25 - Disposição das câmeras do Motion Monitor. A região em roxo é o campo de visão de uma das câmeras (aproximadamente 45 graus)
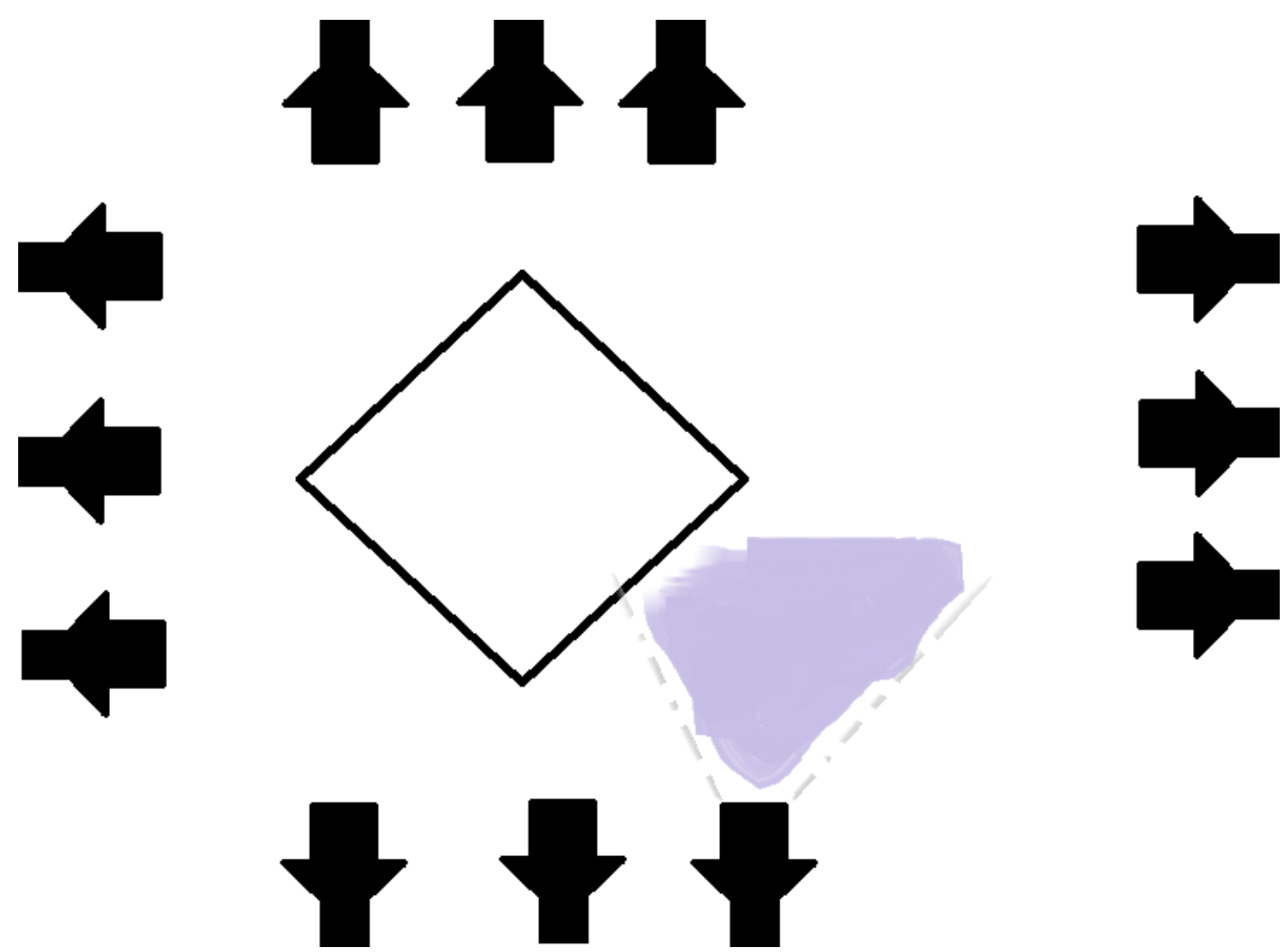

Fonte: Autoria própria

quais marcadores serão analisados. O primeiro passo é ativar os hardwares e calibrar a Stylus (caneta com 4 marcadores que correspondem aos 3 eixos e a origem dos eixos). A figura 27 mostra a varinha e a Stylus.

Para calibrar a Stylus, deve-se revolve-la em um ponto durante alguns segundos. Posteriormente, os clusters são posicionados no paciente e a Stylus é utilizada para detectar as articulações correspondentes aos segmentos compreendidos pelos clusters. O modelo tridimensional resultante mostra uma animação de um esqueleto que se movimenta em tempo real com a movimentação do paciente. A figura 28 mostra um exemplo de modelo 3D gerado pelo Motion Monitor para membros superiores.

O Motion Monitor coleta dados em tempo real. Eles incluem posições, ângulos entre articulação, centro de pressão (no caso das plataformas de força), velocidade, entre outros. Estas informações podem ser salvas em arquivos chamados em um formato (activity) que só pode ser lido pelo software do motion monitor. Entretanto, pode-se exportar os dados brutos de velocidade e ângulos de movimento para analisar em outro programa. 
Figura 26 - Imagem super exposta (esquerda) e com a exposição correta (direita). Na imagem da direita, é possível ver apenas os marcadores
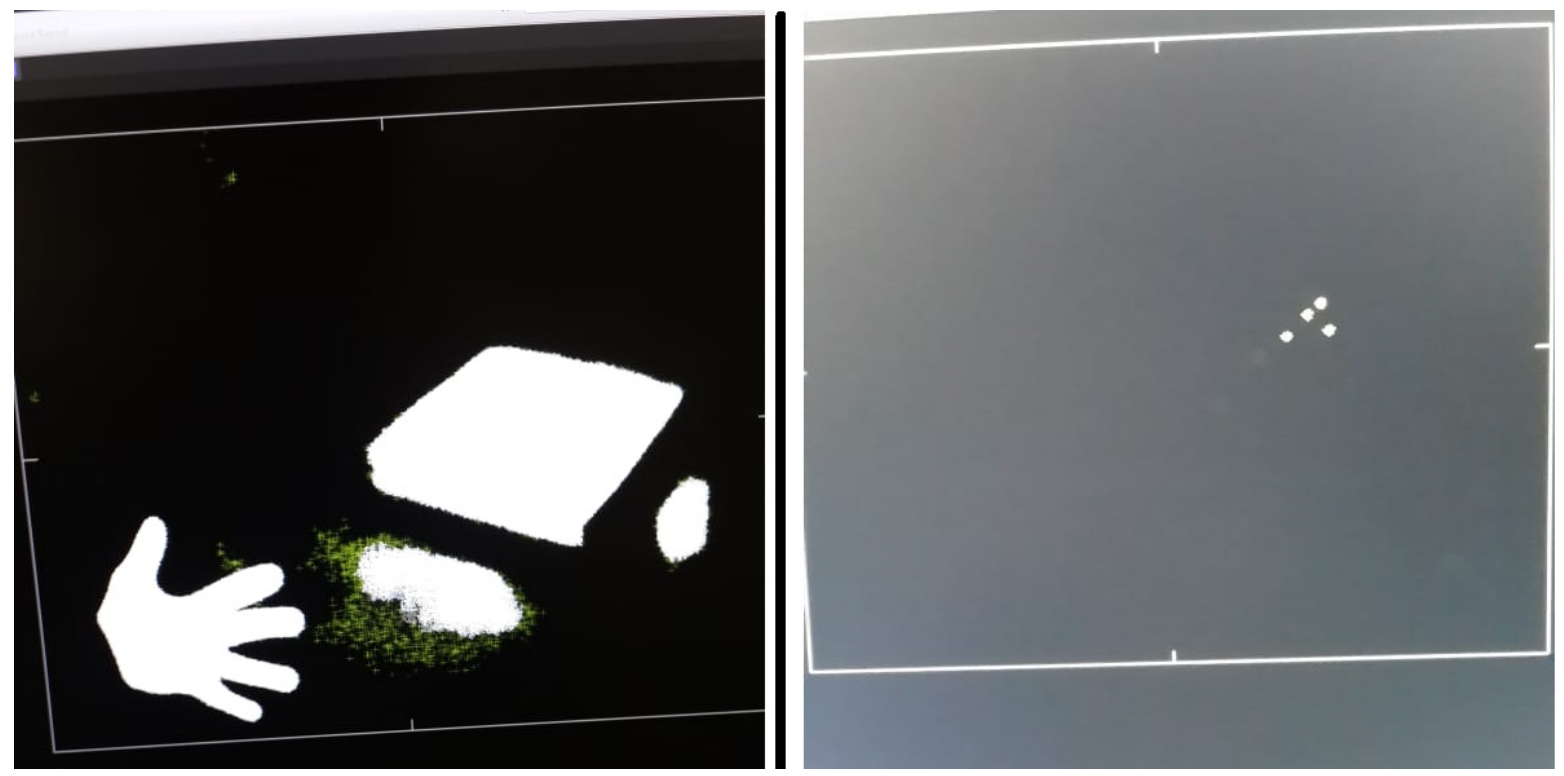

Fonte: Autoria própria

Figura 27 - Varinha e Stylus

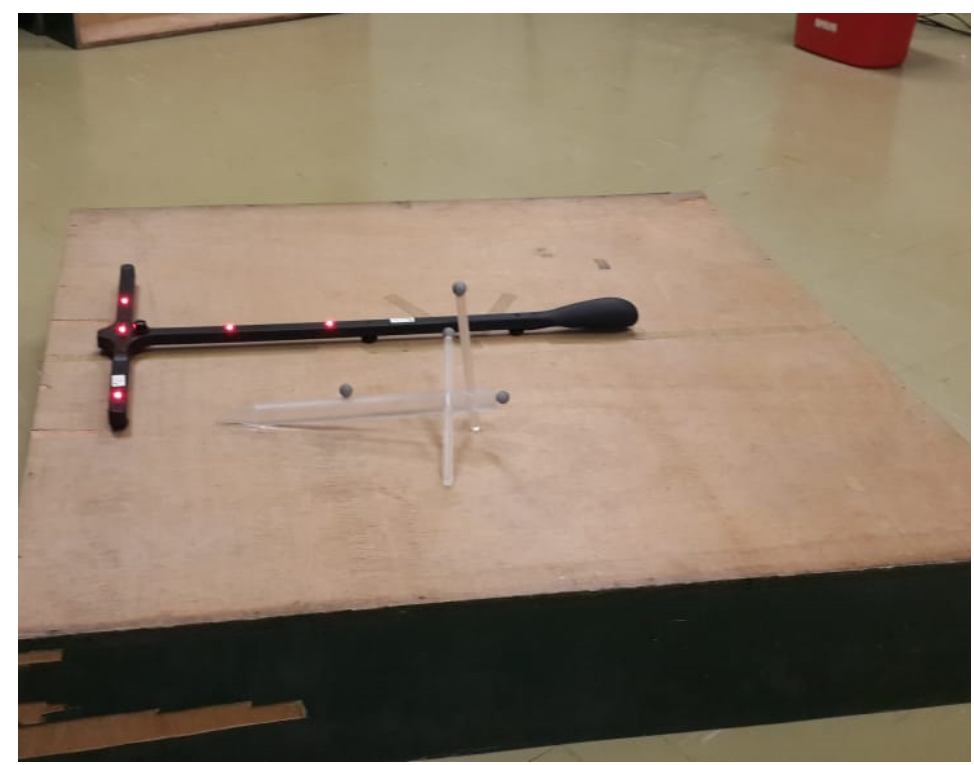

Fonte: Autoria própria

\subsection{Critério de Seleção dos pacientes e posicionamento dos marca- dores}

O critério para selecionar a população de lesados medulares foi tetraplégicos, nível neurológico AIS da ASIA C4 até C8, sem disreflexia autonômica e com mais de um ano de lesão. O objetivo principal deste trabalho é aperfeiçoar AVDs em tetraplégicos por meio de um treinamento com RV. Pacientes C8 podem realizar movimentos dos punhos, enquanto que pacientes $\mathrm{C} 4$ podem movimentar apenas as articulações dos ombros. Desta 
Figura 28 - Modelo gerado pelo Motion Monitor

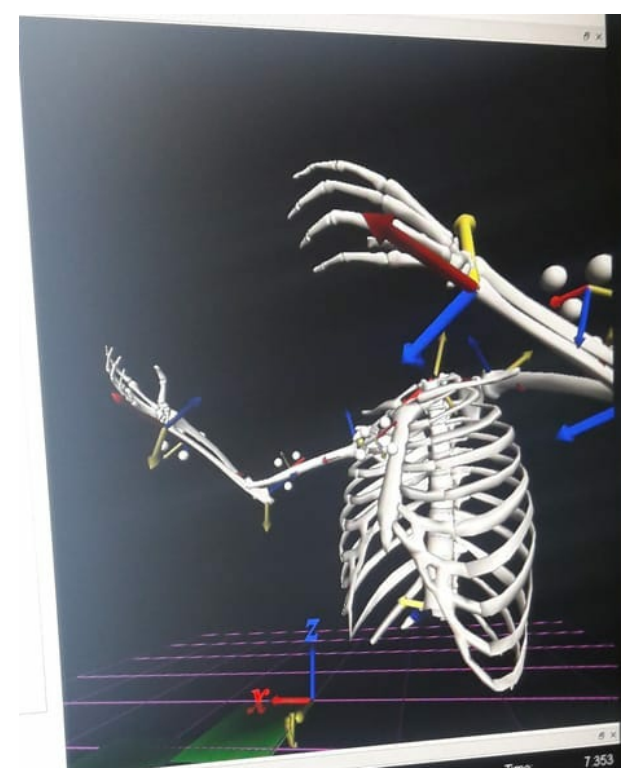

Fonte: Autoria própria

forma, os protocolos escolhidos envolvem majoritariamente movimentos das articulações de ombros e cotovelos. Desta forma, mesmo os pacientes com o nível mais alto de lesão desta população conseguem realizar o treinamento.

Com base na caracterização da população, os marcadores são posicionados de modo a construir um modelo tridimensional com dados de movimentos das articulações de ombros e cotovelos. Para isso, são utilizados 5 clusters nos membros superiores: Braços direito e esquerdo, antebraços direito e esquerdo e tórax. Para a calibração, a ponta da Stylus é posicionada nos pontos da figura 29 sequencialmente conforme a recomendação do programa. Após a calibração, o software reconstrói um modelo 3D dos segmentos esqueléticos do paciente para membros superiores (braços e tronco).

\subsection{Processamento de Dados de movimento}

Os dados brutos relativos à cinemática foram exportados do Motion Monitor e foram processados conforme a literatura (WINTER, 2009) e (DUARTE; WATANABE, 2018). Os procedimentos para o processamento de dados de cinemática são: 1- Filtragem dos dados, 2- segmentação dos ciclos, 3- normalização dos dados, 4- cálculo de média, máximos e mínimos e desvios padrão. Esses passos são descritos a seguir:

1-Filtragem dos dados: A frequência de amostragem utilizada pela câmeras Vicon são de $100 \mathrm{~Hz}$, porém os movimentos do paciente são de baixa frequência. Segundo Winter (WINTER, 2009), para movimentos dos membros inferiores, o maior harmônico de frequência no qual ainda há informações do movimento está em $6 \mathrm{~Hz}$. Por isso, utilizou-se um filtro passa-baixa de $10 \mathrm{~Hz}$ Butterworth 4 ordem. A figura 30 mostra o espectro de 
Figura 29 - Posicionamento dos clusters (roxo) e pontos utilizados com a stylus (setas vermelhas)
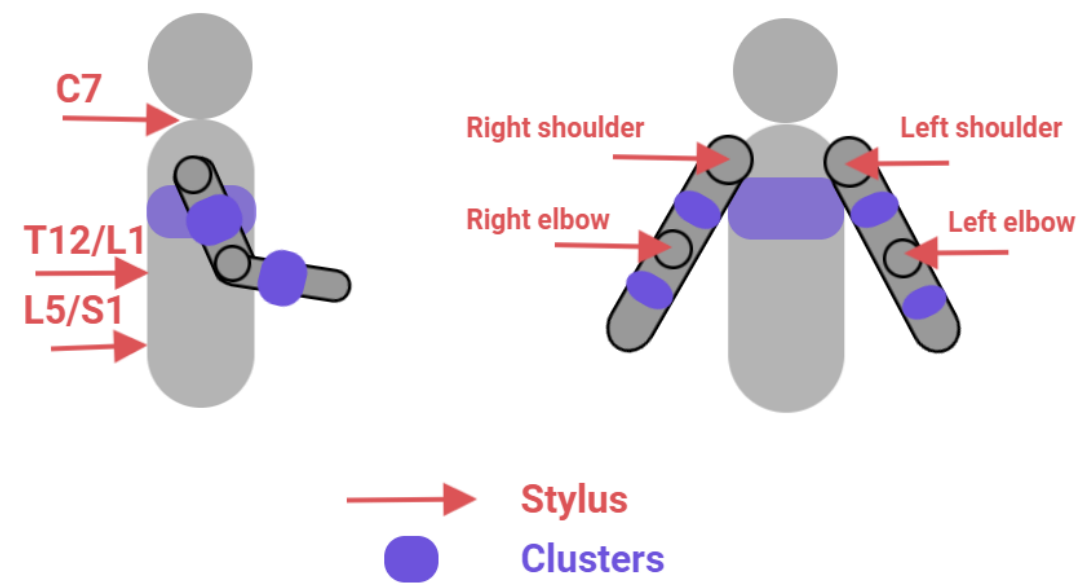

Fonte: Autoria própria

frequências para um dos movimentos coletados. Observa-se que há apenas componentes de movimento em baixas frequências.

Figura 30 - Espectro de frequência sem filtro passa-baixa

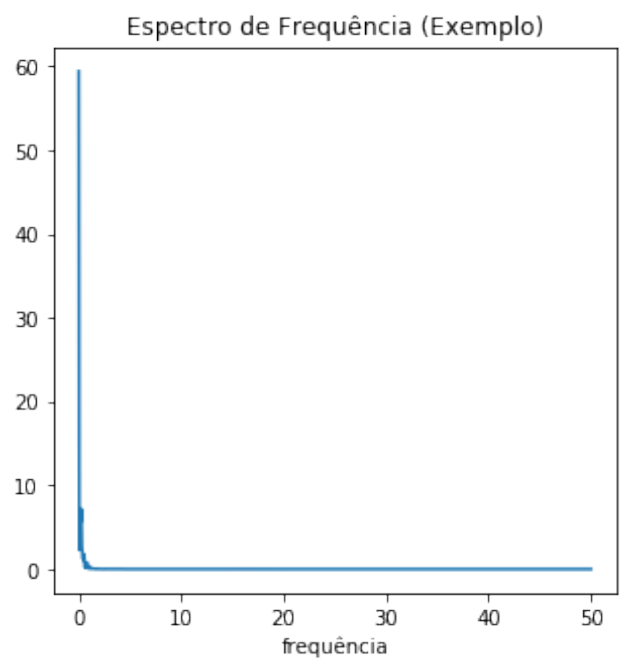

Fonte: Autoria própria

2- Segmentação dos ciclos: A segmentação dos ciclos foi feita com os ângulos de flexão de cotovelo. Uma vez que o paciente precisa flexionar ao máximo o cotovelo para levar o objeto à boca e estendê-lo para retornar o objeto à mesa, os gráficos de ângulo de cotovelo demarcam claramente os ciclos.

3- Normalização dos dados: Cada ciclo e cada coleta possui um tempo de duração distinto e os movimentos precisam ser comparados durante a mesma etapa do ciclo de movimento. A normalização dos dados consiste em interpolar linearmente todas as 
n amostras obtidas em 100 pontos. A figura 31 mostra um exemplo de conjunto de coletas cujo os dados foram normalizados de 0 a 100 porcento.

Figura 31 - Exemplo de dados de cinemática normalizados. As 3 coletas apresentadas foram feitas para o mesmo paciente.

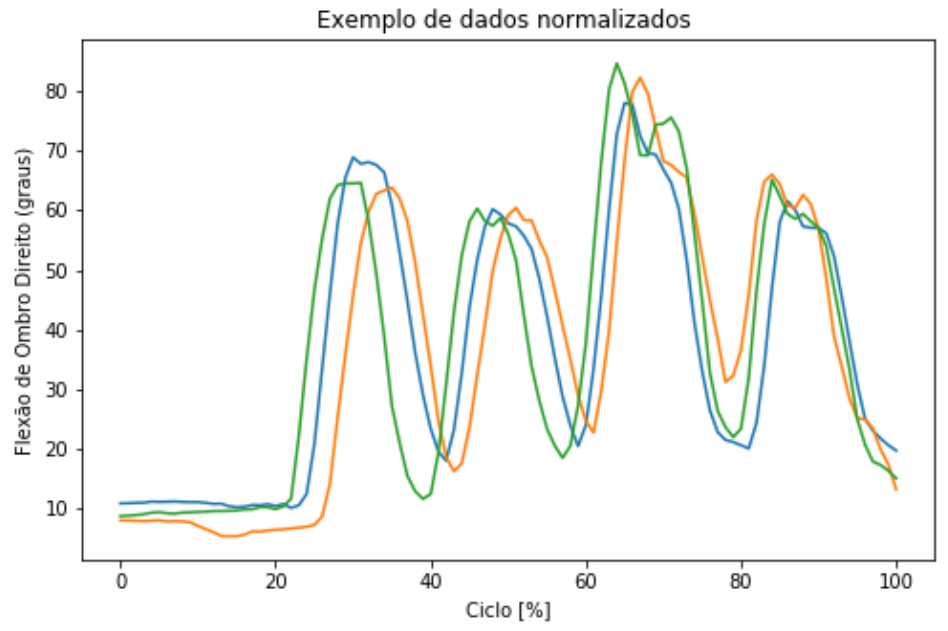

Fonte: Autoria própria

4- Cálculo de médias, máximos e mínimos e desvios padrões: Para cada conjunto de coletas de um mesmo paciente, foram calculados os valores médios e desvios padrão. A figura 32 mostra as médias e desvios padrões calculados para as coletas da figura 31.

Figura 32 - Exemplo de média e desvio padrão calculados para 31

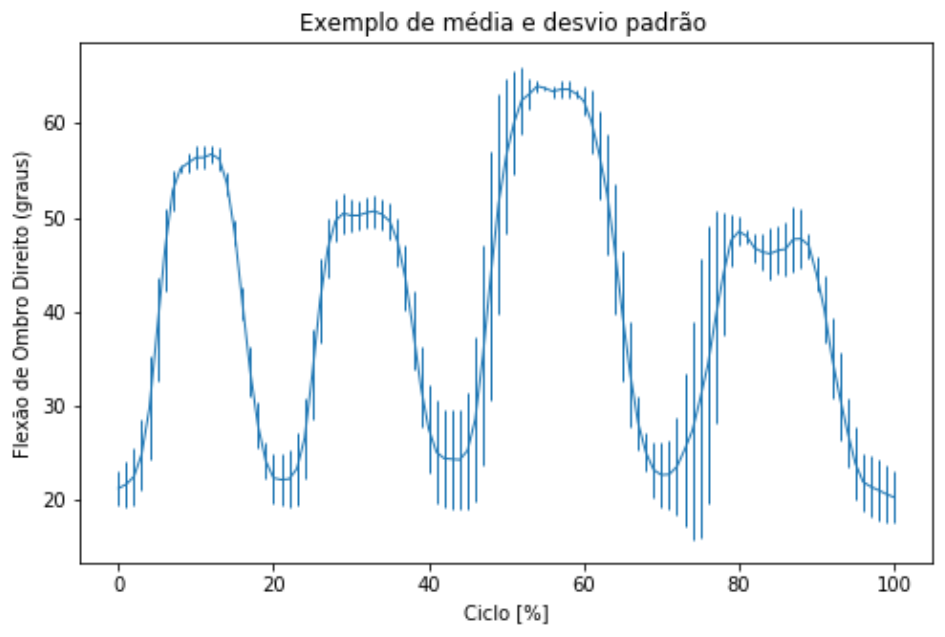

Fonte: Autoria própria 


\subsection{Interface de usuário}

Interações básicas como selecionar uma opção ou uma cena devem ser adaptadas aos portadores de LM. A seção a seguir discutirá como uma interface do usuário adaptada foi criada de maneira que apenas os movimentos da cabeça são usados para acionar eventos no ambiente virtual. O menu principal (figura 33) possui os botões para a configuração do ambiente virtual e o botão para iniciar o protocolo.

Figura 33 - Menu principal

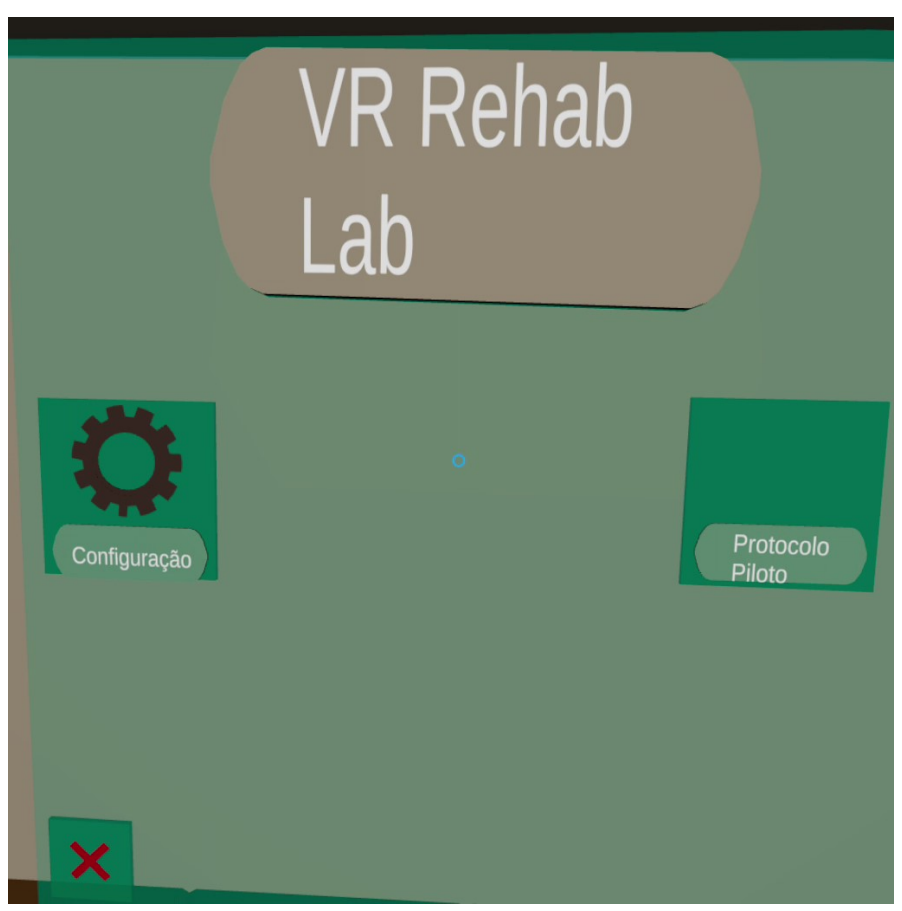

Fonte: Autoria própria

A RV possui um recurso chamado Gaze Input Controller (GIC), que é um ponteiro simbolizado por um pequeno círculo azul. O GIC aponta para a mesma direção que o usuário está olhando e ele pode ser utilizado para interagir com botões e objetos dentro do ambiente virtual. A figura 34 mostra o GIC em duas situações: a) quando o GIC não interage com nenhum botão e b) quando o GIC interage com o botão. Em b), o botão muda de cor indicando que ele foi selecionado e, se o usuário continuar olhando para este botão por alguns segundos, o botão correspondente interpreta esta ação como se fosse um clique.

No caso apresentado na figura 34, ao interagir com o botão de configuração o usuário é direcionado para o menu de calibração. A figura 35 mostra o menu para que o usuário informe a altura dele em centímetros. A altura é utilizada será utilizada como base para criar objetos personalizados em outras telas.

Há dois botões (figura 36) que permitem aumentar ou diminuir em $1 \mathrm{~cm}$ a altura. Eles são acionados após o usuário olhar por alguns segundos e podem ser clicados uma ou 
Figura 34 - Exemplo do GIC

(a) GIC não interage com o botão

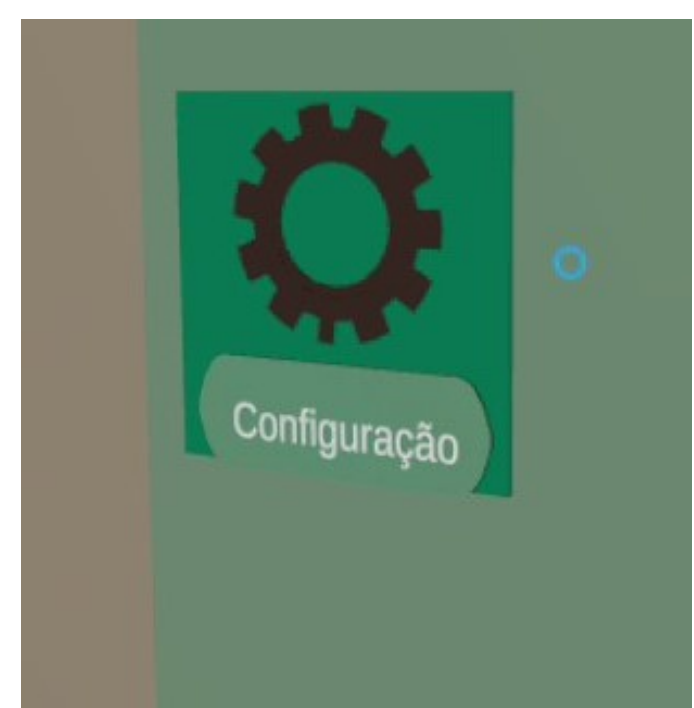

(b) GIC interage com o botão

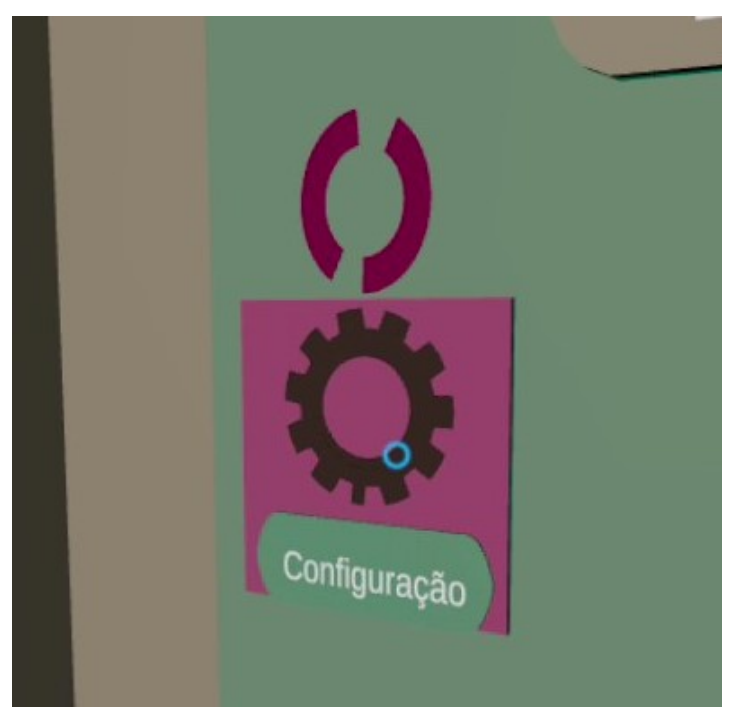

Fonte: Autoria Própria

Figura 35 - Menu para calibrar a altura

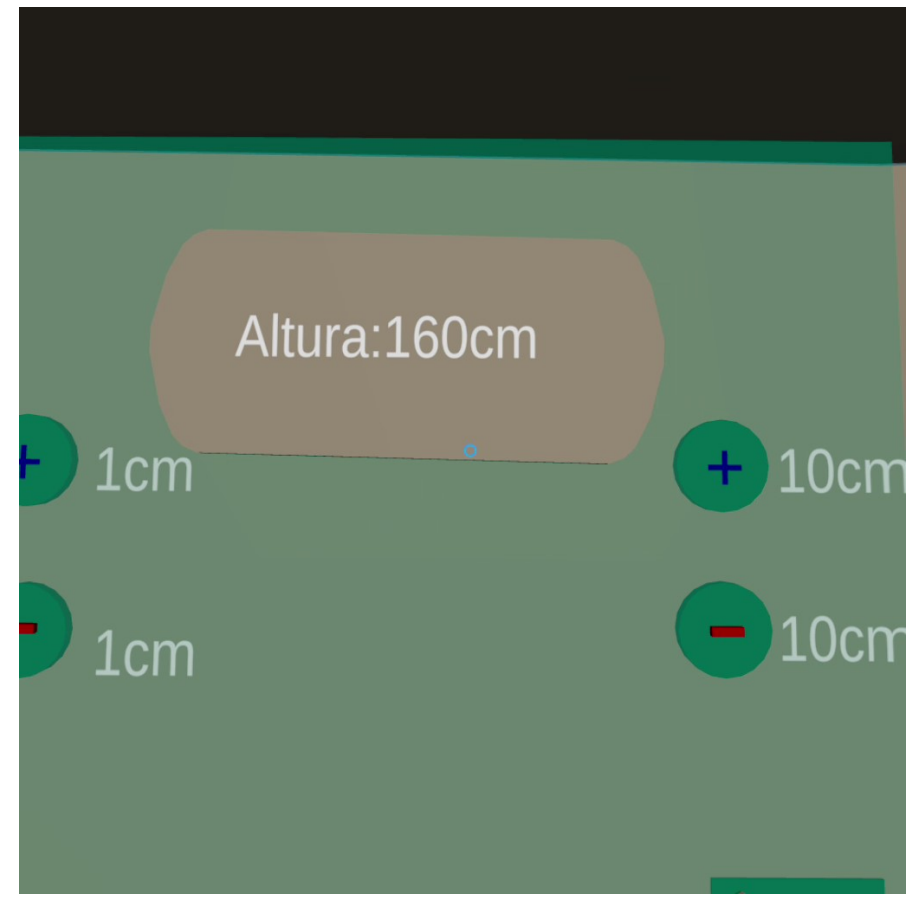

Fonte: Autoria própria

múltiplas vezes.

Para agilizar o processo de calibração, há também 2 botões (figura 37 que permitem alterar a altura em incrementos ou decrementos de $10 \mathrm{~cm}$.

Após a altura do usuário ser configurada, ele pode clicar no botão de retorno (figura 38) para voltar para a tela anterior. Este botão é recorrente em outros menus do ambiente virtual. 
Figura 36 - Aumento e diminuição unitária de altura
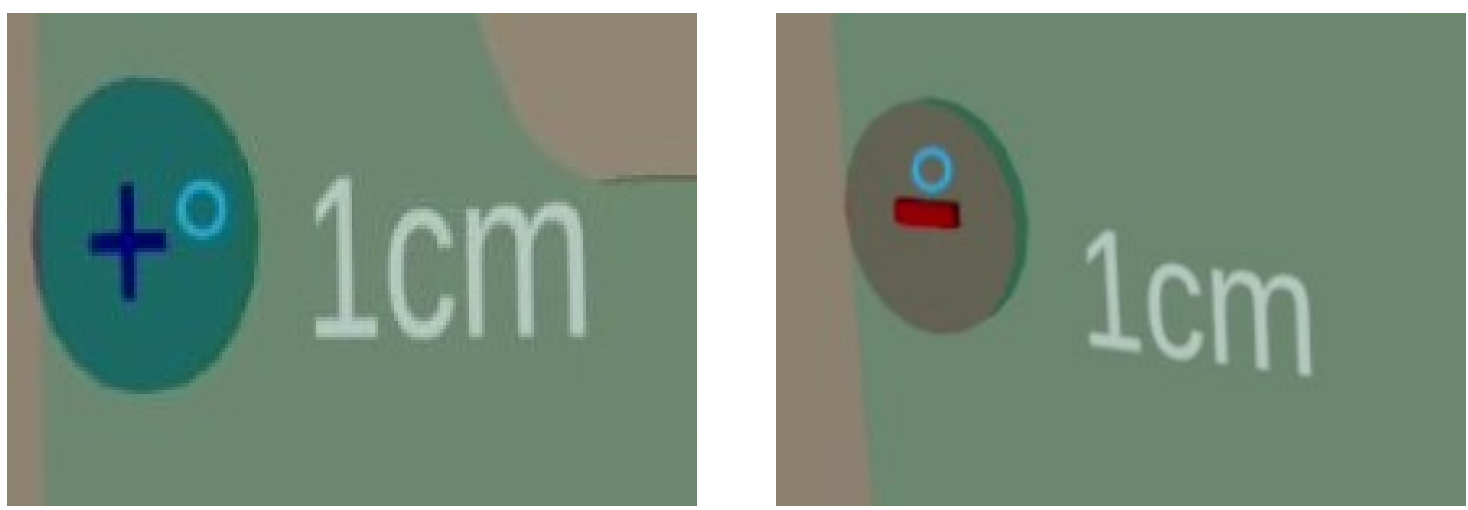

Fonte: Autoria Própria

Figura 37 - Aumento e diminuição de altura em incrementos e decrementos de $10 \mathrm{~cm}$
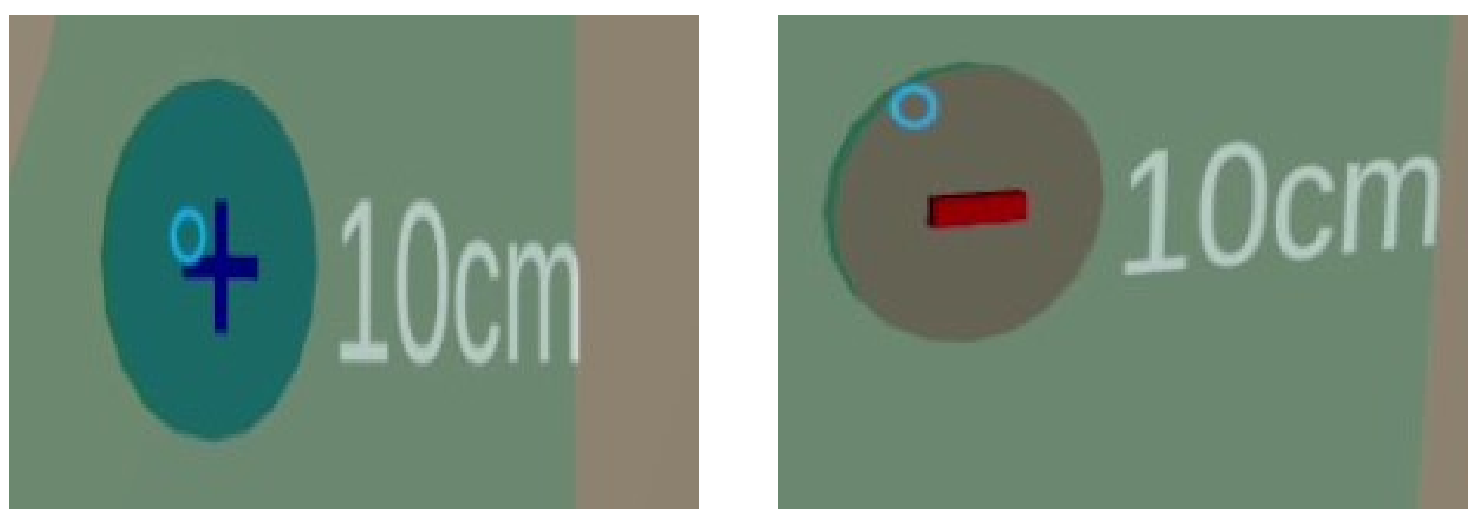

Fonte: Autoria Própria

Figura 38 - Botão para voltar a tela anterior

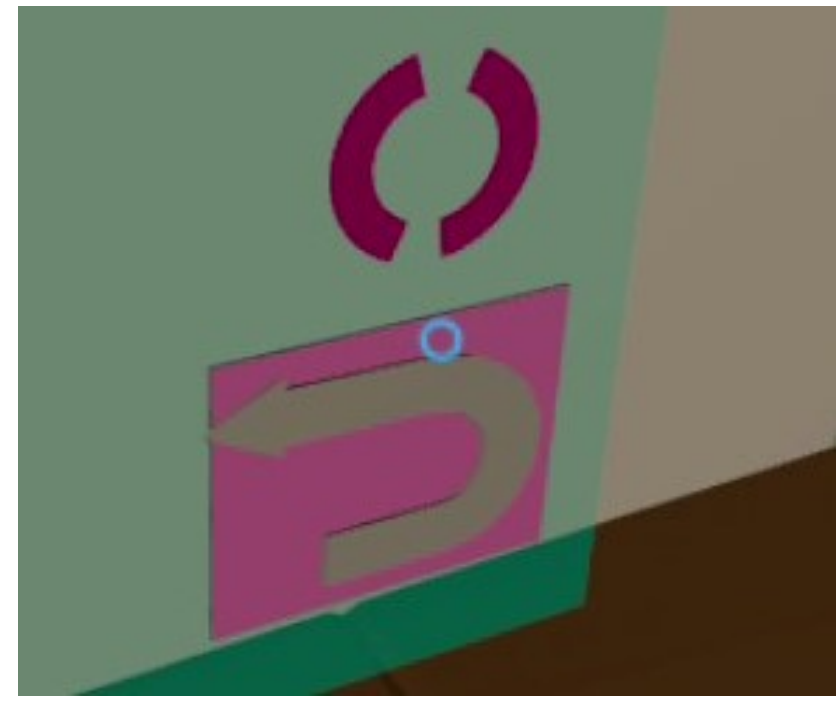

Fonte: Autoria própria

No menu principal, há um botão para sair da aplicação (figura 39). Este botão também aparece em outros menus do ambiente virtual.

Após a calibração de altura, o usuário pode clicar no botão para começar o protocolo 
Figura 39 - Botão para sair da aplicação

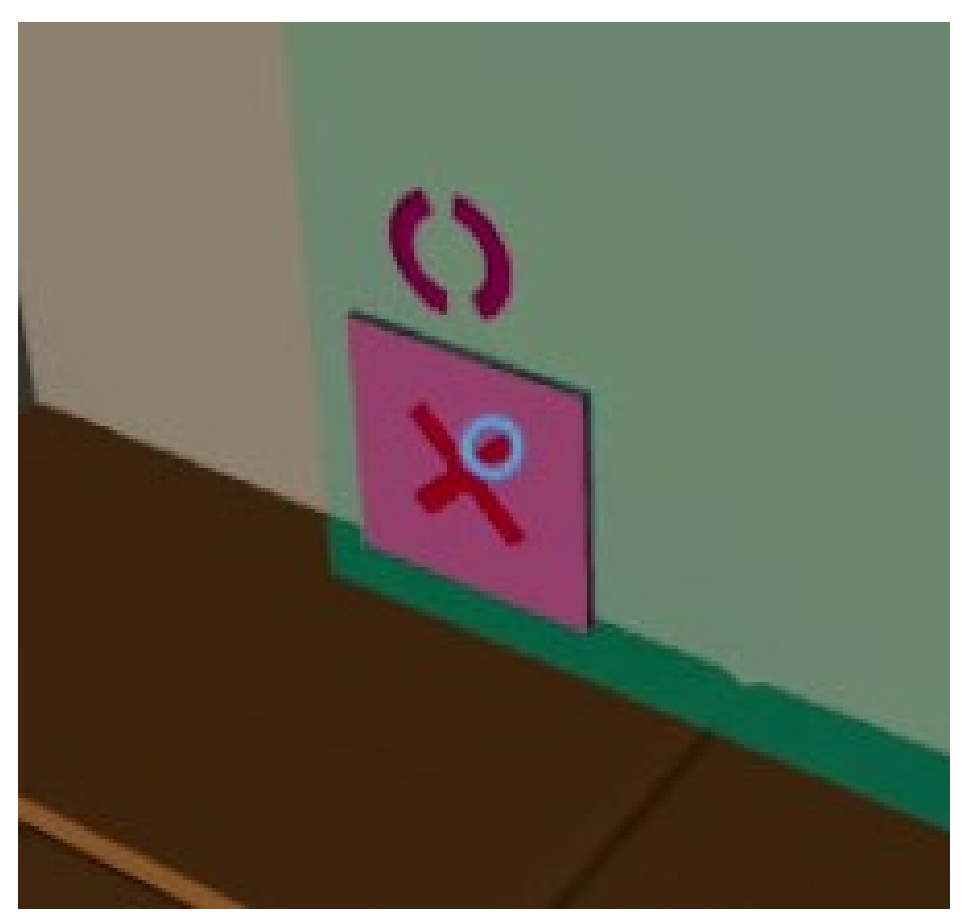

Fonte: Autoria própria

(figura 40) no menu principal.

Figura 40 - Botão para começar o protocolo piloto

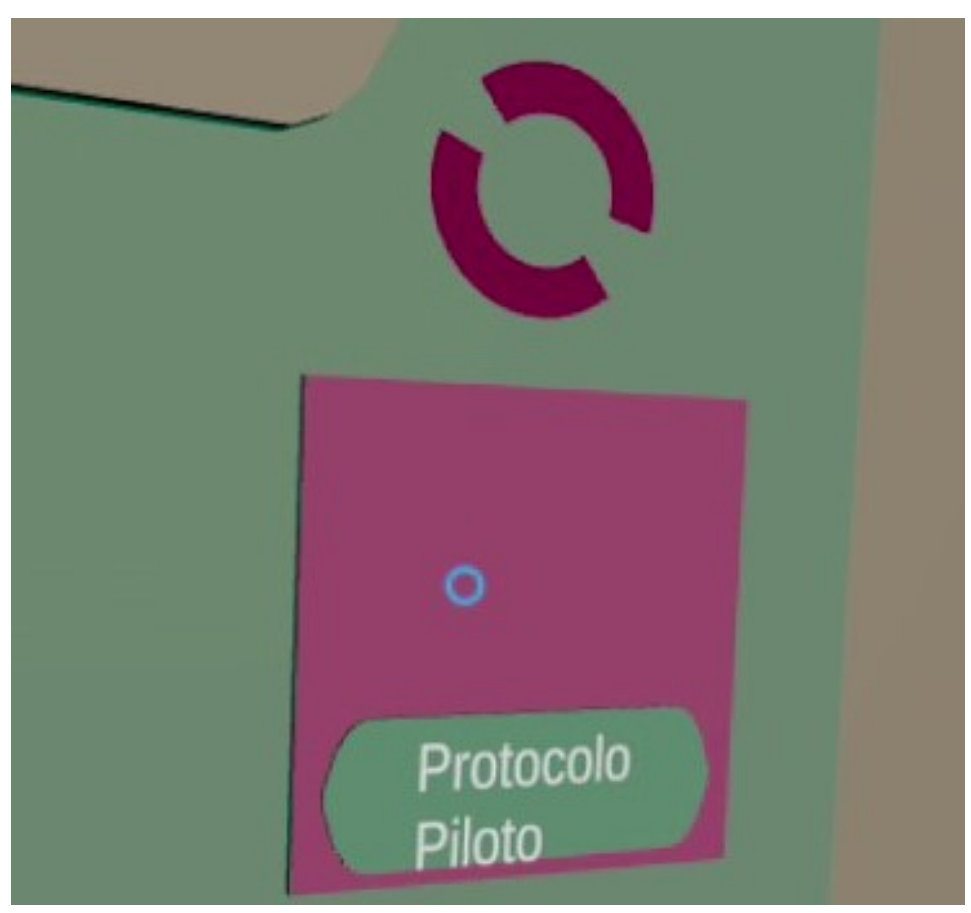

Fonte: Autoria própria 


\subsection{Ambiente de Realidade Virtual do protocolo piloto}

A cena principal do ambiente RV mostra uma mesa com 5 pontos posicionados no centro e em cada canto da mesa. Em cada ciclo, o usuário deve mover sua mão para 5 pontos diferentes em menos de 3 minutos. A sequência é gerada aleatoriamente para cada ciclo para impedir que o paciente memorize a mesma sequência e simule movimentos mais semelhantes às AVDs de alcance. A figura 41 mostra uma visão geral do ambiente de RV do protocolo piloto.

Figura 41 - Cena principal do ambiente de realidade virtual do protocolo piloto (em terceira pessoa). A figura ampliada dentro do circulo preto são os 5 pontos da mesa (blocos azuis).

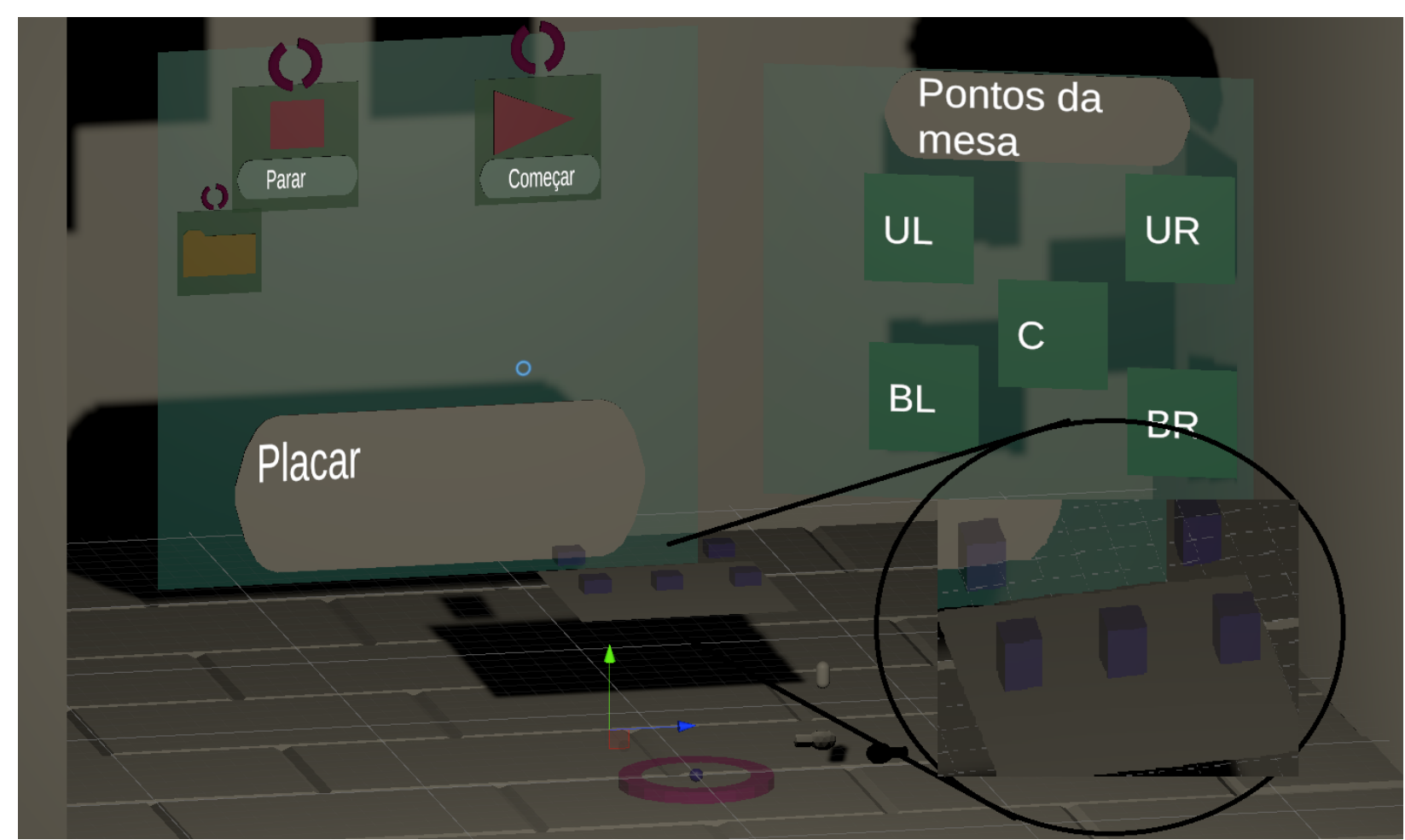

Fonte: Autoria própria

Os blocos azuis indicam todos os pontos possíveis de alcance. O painel verde a frente da mesa (figura 42) possui botões para começar (seta vermelha) e parar (quadrado vermelho) os ciclos. O botão com a pasta amarela serve para parar o protocolo e ir para uma tela com a média de pontos alcançados por ciclo de 5 pontos.

A altura (Ht) e a largura (W) da mesa virtual são calculadas com base na altura do paciente conforme as equações 3.1 e 3.2 .

$$
H t=H O-0.406 H
$$

$$
W=0.259 H
$$


H é a altura do usuário, HO é a altura do Oculus, $0.406 \mathrm{H}$ e $0.259 \mathrm{H}$ são as medidas de perna e peitoral do usuário segundo o modelo de antropometria de Dempster.

Durante o protocolo, o placar mostra o tempo em segundos restante para acabar o ciclo e o número de pontos alcançados.

Figura 42 - Menu do protocolo piloto

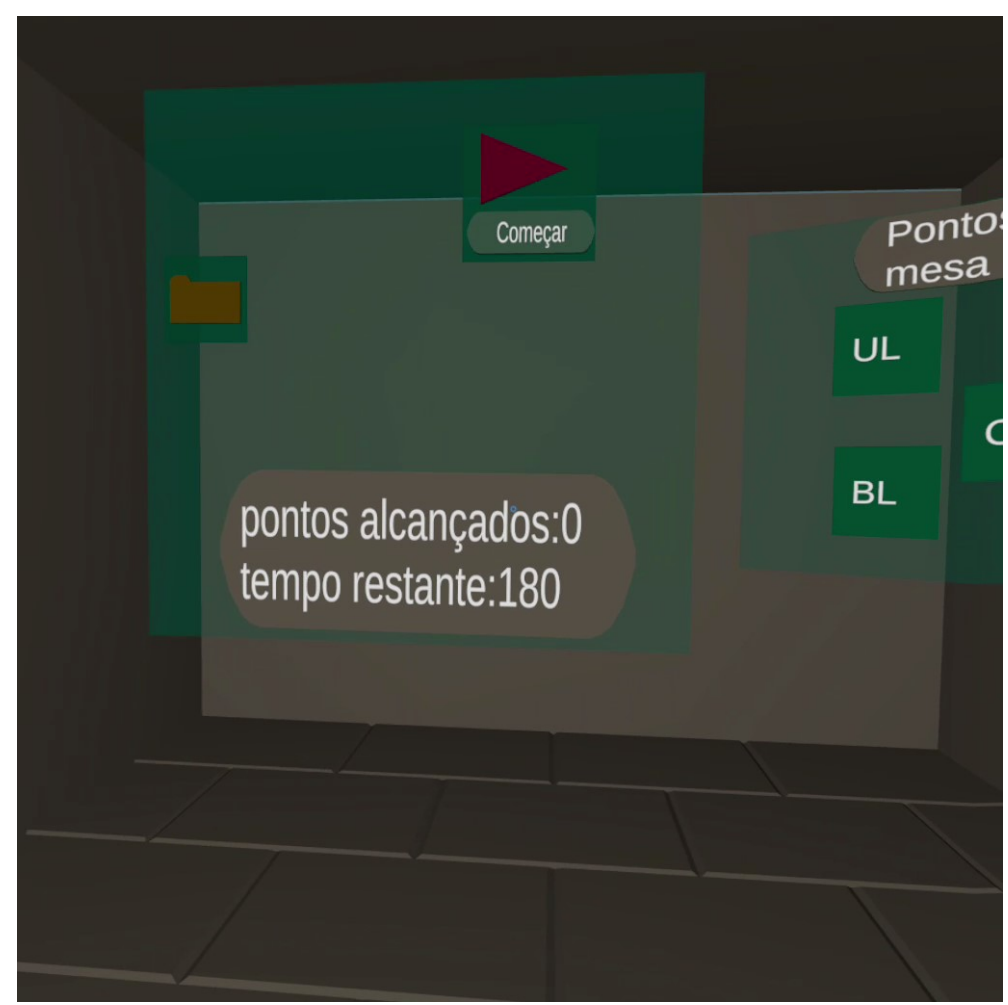

Fonte: Autoria própria

Além do GIC, o ambiente virtual possui modelos que representam as mãos do usuário. O rastreamento de mãos do Oculus Quest foi utilizado para atribuir aos objetos da figura 43 a posição e a rotação das mãos do usuário. O modelo é o mesmo para as duas mãos e a extensão da esfera indica a direção do punho do usuário.

O painel da direita (figura 44 possui uma representação da mesa e ele indica qual é o próximo ponto que o usuário deve alcançar. Após o protocolo começar, o próximo ponto o qual o usuário deve alcançar é indicado pela cor rosa. Quando não há mais pontos a alcançar, todos os pontos ficam verdes.

Quando o usuário alcança um objeto, ele muda de cor. Se o objeto era o próximo da sequência, ele fica verde. Caso contrário, o bloco muda para vermelho. Independentemente do resultado, o próximo bloco da sequência aparece no painel até que os 5 sejam alcançados ou que o tempo acabe.

O protocolo pode ser repetido quantas vezes o usuário quiser. Para sair, o usuário 
Figura 43 - Representações das mãos no ambiente virtual

(a) Mão esquerda

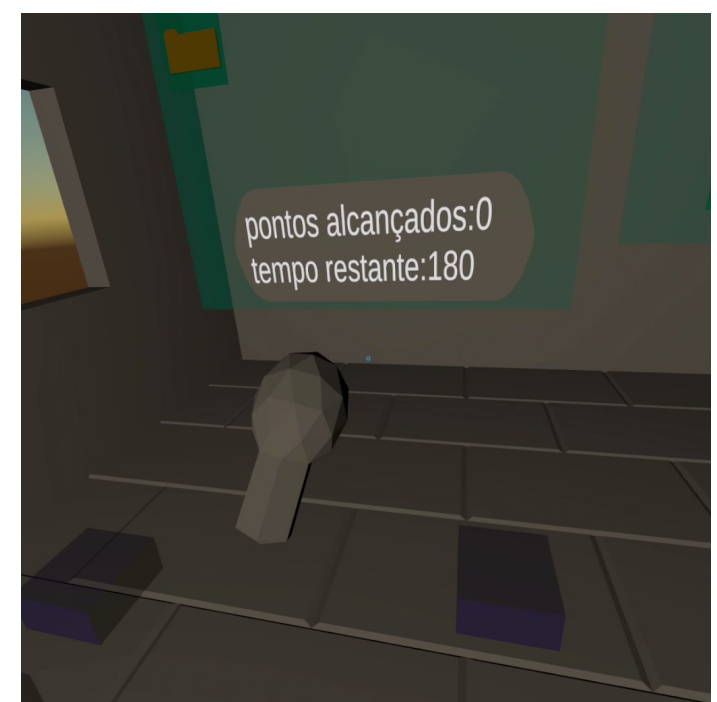

(b) Mão direita

Fonte: Autoria Própria

Figura 44 - Painel Auxiliar

(a) Painel Auxiliar não selecionado

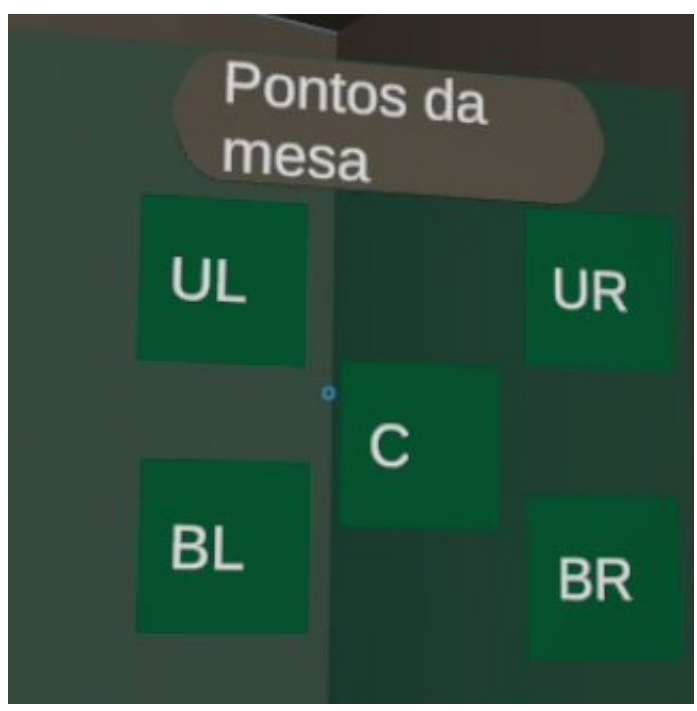

(b) Painel Auxiliar não selecionado

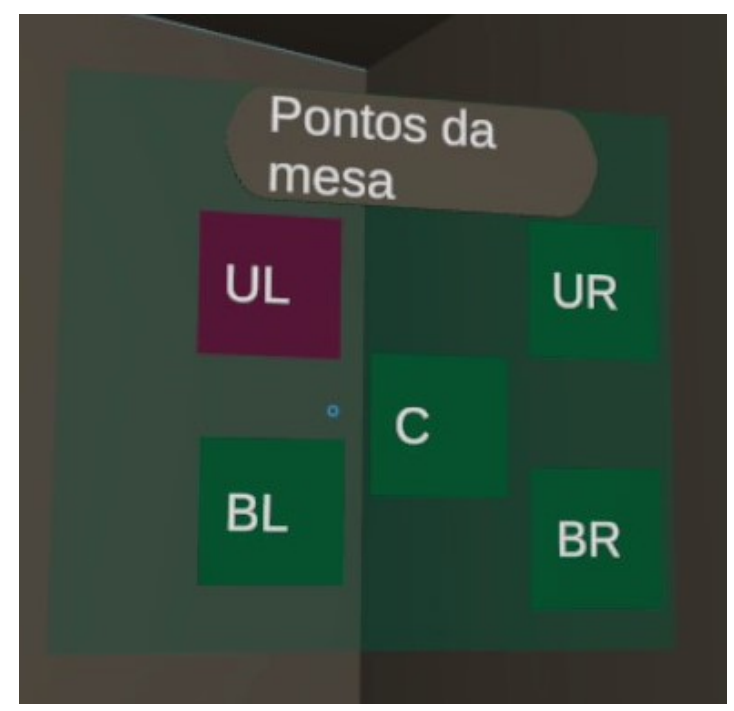

Fonte: Autoria Própria

clica no botão com a imagem de uma pasta amarela e a tela com a média de pontos por ciclo e tempo médio para cada repetição aparece. A figura 46 mostra um exemplo desta tela. 
Figura 45 - Sinalização dos pontos da mesa

(a) Ponto alcançado correto

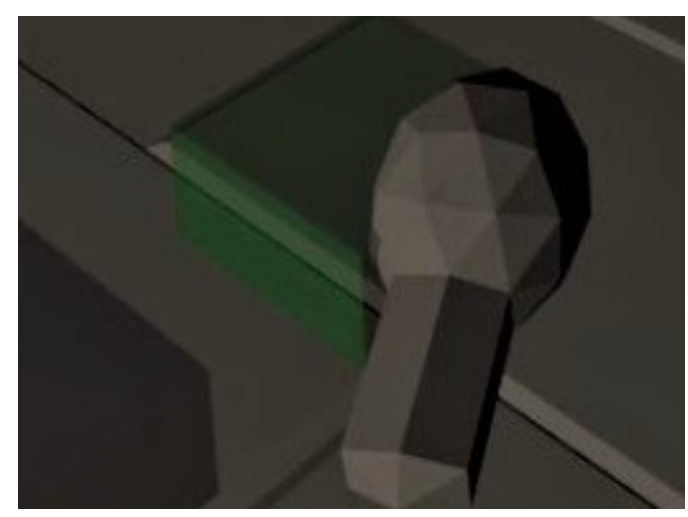

(b) Ponto alcançado errado

Fonte: Autoria Própria

Figura 46 - Média de tempo e pontos alcançados por repetição

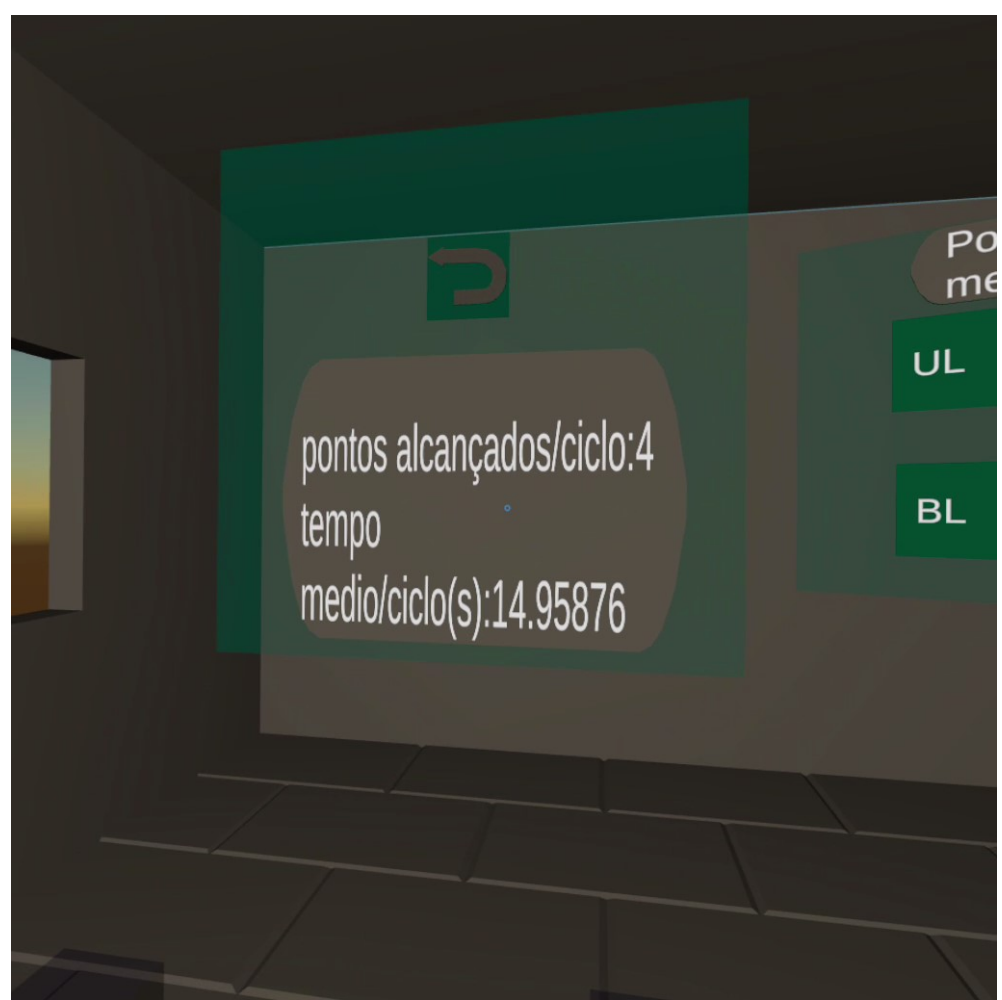

Fonte: Autoria própria 


\section{Resultados}

\subsection{Impacto do covid-19 nos testes do ambiente virtual}

Devido à pandemia do Covid-19, o acesso aos pacientes ficou restrito e algumas etapas deste projeto foram adaptadas. A coleta de dados de movimento foi feita antes da pandemia, com 4 participantes. Os testes com o ambiente de realidade virtual foram realizados já no período de pandemia e, por isso, apenas 2 pacientes participaram dos testes. Durante esta ultima etapa, todas as pessoas envolvidas utilizaram máscaras e o equipamento de realidade virtual foi higienizado antes de cada teste.

\section{2 Ângulos de movimentos}

As características dos 4 participantes estão na tabela 1. Os resultados do estudo de movimento dos 4 participantes são apresentados na tabela 2. Os valores apresentados para cada participante são os valores médios de 3 capturas de movimento do protocolo piloto e a última linha de cada articulação possui o valor médio e o desvio padrão da população. Cada coluna possui as iniciais correspondentes a cada ponto da mesa (conforme a figura 24). Os valores máximos e mínimos de flexão e abdução ocorrem nesses pontos. O anexo B possui os gráficos individuais de cada participante.

Tabela 1 - Informações dos participantes

$\begin{array}{llll}\text { Idade } & \text { Nível de Lesão } & \text { Altura }(\mathrm{m}) & \text { Massa }(\mathrm{Kg}) \\ 51 & \text { C5 } & 1.71 & 83 \\ 50 & \text { C6 } & 1.81 & 72 \\ 34 & \text { C6 } & 1.80 & 72 \\ 54 & \text { C7 } & 1.78 & 86\end{array}$


Tabela 2 - Ângulos de movimento dos participantes (em graus)

\begin{tabular}{|c|c|c|c|c|c|}
\hline Flexão do Ombro Direito & $\mathrm{BR}$ & UR & $\mathrm{C}$ & UL & $\mathrm{BL}$ \\
\hline A & $42.8(2.4)$ & $63.8(2.0)$ & $60.8(0.6)$ & $74.1(1.5)$ & $56.8(4.7)$ \\
\hline B & $21.7(2.5)$ & $56.7(0.9)$ & $50.7(1.7)$ & $64.0(0.5)$ & $48.5(1.5)$ \\
\hline $\mathrm{C}$ & $11.2(5.9)$ & $26.1(16.7)$ & $28.8(4.6)$ & $49.5(3.1)$ & $36.2(1.2)$ \\
\hline $\mathrm{D}$ & $6.0(2.6)$ & $35.4(2.8)$ & $32.1(0.4)$ & $38.0(1.5)$ & $30.3(0.3)$ \\
\hline Média & $20.4(14.1)$ & $45.5(15.3)$ & $48.1(19.9)$ & $56.4(13.7)$ & $43.0(10.3)$ \\
\hline Abdução do Ombro Direito & $\mathrm{BR}$ & UR & $\mathrm{C}$ & UL & $\mathrm{BL}$ \\
\hline A & $30.6(2.5)$ & $28.1(7.4)$ & $-1.5(9.5)$ & $-58.5(2.5)$ & $-33.5(1.1)$ \\
\hline B & $10.3(3.7)$ & $9.8(3.5)$ & $-0.5(1.3)$ & $-35.1(0.7)$ & $-18.1(0.4)$ \\
\hline $\mathrm{C}$ & $22.8(4.4)$ & $18.4(1.7)$ & $14.3(2.9)$ & $-13.8(11.9)$ & $6.3(13.4)$ \\
\hline $\mathrm{D}$ & $23.6(4.2)$ & $14.3(0.7)$ & $7.7(4.0)$ & $-10.5(1.6)$ & $-1.7(2.0)$ \\
\hline Média & $21.8(7.3)$ & $17.7(7.8)$ & $5.0(6.4)$ & $-29.5(19.2)$ & $-11.7(15.3)$ \\
\hline Flexão do Cotovelo Direito & $\mathrm{BR}$ & $\mathrm{UR}$ & $\mathrm{C}$ & $\mathrm{UL}$ & $\mathrm{BL}$ \\
\hline 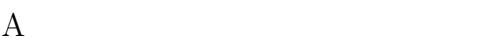 & $88.0(4.5)$ & $60.5(5.8)$ & $60.5(0.7)$ & $31.1(2.8)$ & $52.7(2.3)$ \\
\hline B & $68.2(3.8)$ & $20.7(4.1)$ & $30.3(1.5)$ & $6.3(1.0)$ & $31.2(1.4)$ \\
\hline $\mathrm{C}$ & $101.4(14.6)$ & $83.0(21.5)$ & $83.5(8.3)$ & $50.8(4.1)$ & $82.4(5.0)$ \\
\hline $\mathrm{D}$ & $58.9(3.2)$ & $17.2(3.3)$ & $22.8(2.6)$ & $14.6(1.5)$ & $18.9(0.5)$ \\
\hline Média & $79.2(16.6)$ & $45.3(27.6)$ & $49.3(24.3)$ & $25.7(17.0)$ & $46.3(24.1)$ \\
\hline Flexão do Ombro Esquerdo & $\mathrm{BL}$ & $\mathrm{UL}$ & $\mathrm{C}$ & UR & $\mathrm{BR}$ \\
\hline A & $26.7(2.6)$ & $51.1(5.7)$ & $50.1(0.3)$ & $71.2(5.1)$ & $50.3(3.1)$ \\
\hline B & $5.5(1.3)$ & $47.7(1.9)$ & $40.3(1.1)$ & $71.1(2.2)$ & $48.9(1.6)$ \\
\hline $\mathrm{C}$ & $10.2(3.2)$ & $46.9(3.6)$ & $39.4(1.6)$ & $58.1(2.7)$ & $45.7(0.2)$ \\
\hline $\mathrm{D}$ & $4.3(0.2)$ & $34.9(1.0)$ & $28.2(1.3)$ & $37.8(1.4)$ & $30.1(0.7)$ \\
\hline Média & $11.7(8.9)$ & $45.1(6.1)$ & $39.5(7.7)$ & $59.6(13.6)$ & $43.8(8.0)$ \\
\hline Abdução do Ombro Esquerdo & $\mathrm{BL}$ & $\mathrm{UL}$ & $\mathrm{C}$ & $\mathrm{UR}$ & $\mathrm{BR}$ \\
\hline 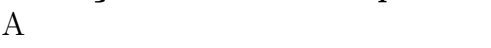 & $38.2(5.1)$ & $36.7(5.1)$ & $10.8(5.0)$ & $-24.1(7.2)$ & $-12.3(1.5)$ \\
\hline B & $18.9(1.5)$ & $12.5(3.4)$ & $6.9(2.2)$ & $-45.3(7.5)$ & $-11.4(1.8)$ \\
\hline $\mathrm{C}$ & $19.0(0.3)$ & $16.0(0.7)$ & $9.4(7.2)$ & $-9.6(4.3)$ & $-2.1(3.0)$ \\
\hline $\mathrm{D}$ & $16.0(1.5)$ & $-4.0(1.1)$ & $-4.8(1.0)$ & $-24.3(0.4)$ & $-13.6(0.4)$ \\
\hline Média & $23.0(8.85)$ & $15.3(14.5)$ & $5.6(6.1)$ & $-25.8(12.7)$ & $-9.9(4.5)$ \\
\hline Flexão do Cotovelo Esquerdo & $\mathrm{BL}$ & $\mathrm{UL}$ & $\mathrm{C}$ & $\mathrm{UR}$ & $\mathrm{BR}$ \\
\hline A & $94.0(4.7)$ & $69.9(13.6)$ & $62.7(5.4)$ & $41.3(3.5)$ & $59.6(1.2)$ \\
\hline B & $84.9(2.9)$ & $33.0(3.1)$ & $52.2(3.8)$ & $16.8(2.3)$ & $49.3(3.1)$ \\
\hline $\mathrm{C}$ & $97.9(0.4)$ & $65.2(6.8)$ & $80.4(16.4)$ & $57.9(9.2)$ & $71.3(6.8)$ \\
\hline $\mathrm{D}$ & $51.7(1.7)$ & $18.6(4.2)$ & $29.5(3.5)$ & $16.2(0.5)$ & $26.6(0.5)$ \\
\hline Média & $82.1(18.2)$ & $46.7(21.5)$ & $56.17(18.4)$ & $33.05(17.5)$ & $51.7(16.4)$ \\
\hline
\end{tabular}

As variações angulares podem ser calculadas a partir dos ângulos da tabela 2 por meio das diferenças entre os ângulos articulares. No sentido sagital (direção da flexão de ombro), a flexão mínima e máxima do ombro direito foram $20.4^{\circ}$ e $45.5^{\circ}$ para o braço direito e $11.7^{\circ}$ e $45.1^{\circ}$ para o braço esquerdo, mínimo e a flexão máxima do cotovelo direito foi de $45.3^{\circ}$ e $79.2^{\circ}$ para o braço direito e $46.7^{\circ}$ e $82.1^{\circ}$ para o esquerdo. No sentido transversal (sentido de abdução de ombro), abdução mínima e máxima do ombro direito foram $-29.5^{\circ}$ e $21.8^{\circ}$ e para o ombro esquerdo foram $-25.8^{\circ}$ e $23.0^{\circ}$.

O objetivo da análise cinemática é comparar os valores de ângulos antes e depois da intervenção para observar se houve aumento da amplitude de movimento após a intervenção. O aumento da amplitude de movimento pode indicar que o paciente consegue alcançar objetos mais distantes em diferentes direções. Desse modo, mais atividades de vida diária poderiam ser realizadas. 


\subsection{Teste do ambiente virtual em pessoas com LM}

O teste do ambiente de RV foi feito com duas pessoas com LM. Os objetivos dos testes eram familiarizar os participantes com o sistema e com o ambiente virtual e observar as possíveis alterações e correções do sistema.

Antes de começar, cada participante recebeu informações de como utilizar o GIC de selecionar os botões e sobre o protocolo. Inicializou-se a aplicação e foi observada a reação de cada participante. Nenhum dos participantes relatou desconforto ou enjoo ao usar o Oculus. Com relação ao GIC, os dois conseguiram utilizá-lo para acionar os botões e, principalmente, para selecionar o valor para a altura na tela de calibração.

O primeiro problema ocorreu no ambiente do protocolo piloto. A posição inicial do paciente no ambiente real não a mesma que o ambiente virtual utiliza como referência. Em vista disso, os paciente precisavam se mover para uma posição confortável e próxima a mesa virtual para realizar o protocolo. A solução proposta para este problema foi a sinalização dentro do ambiente virtual do local onde o usuário deveria ficar para iniciar o protocolo. A sinalização foi feita por meio de um circulo rosa, conforme a figura 47

Figura 47 - Referência dentro do ambiente virtual

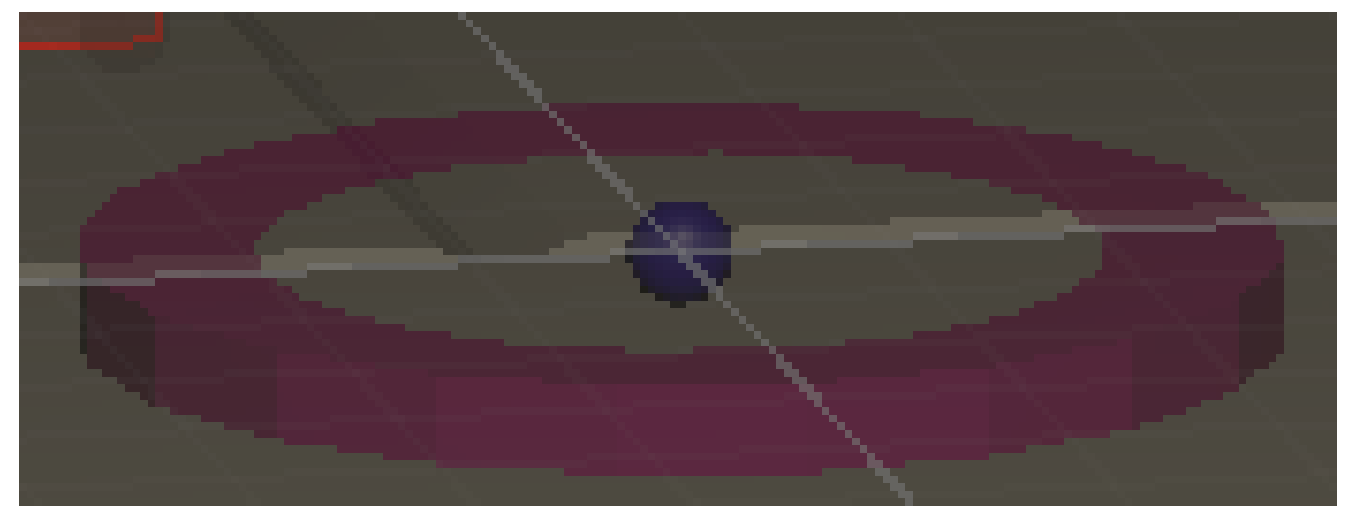

Fonte: Autoria própria

Os participantes realizaram algumas repetições do protocolo para se familiarizar com o uso do rastreamento das mãos e com as interfaces do protocolo. Ainda com a limitação motora, o rastreamento de mãos do Oculus pode ser utilizado para mover os objetos que representam as mãos no ambiente virtual. Desse modo, eles conseguiram realizar o protocolo de alcance proposto.

Por fim, uma limitação encontrada durante os testes foi a dificuldade de instruir os participantes enquanto eles utilizavam o Oculus, uma vez que a pessoa que explicava o funcionamento não podia ver em tempo real o que o participante via. A solução encontrada foi gravar um vídeo demonstrando como funciona o ambiente virtual e mostrá-lo para o participante antes do teste. Algumas sessões foram gravadas para verificar se o participante utilizou o sistema corretamente durante o protocolo. 



\section{Conclusões}

Este estudo apresentou um ambiente de RV adaptado para pessoas com LM para treinar AVDs. Uma análise cinemática foi feita para obter ângulos articulares de 4 pessoas com LM para entender o movimento que seria realizado no ambiente de RV e os resultados puderam caracterizar a ADL de alcance em um único plano.

O teste preliminar em pessoas com lesão medular reforça as escolhas de recursos para RV. O GIC pode ser usado apenas com movimentos da cabeça. O rastreamento de mão foi uma escolha melhor do que os controladores reais porque tem uma configuração mais fácil e pode rastrear a posição e velocidade das mãos em tempo real.

Embora este trabalho seja um estudo piloto, o uso de parâmetros cinemáticos para avaliar o ambiente de RV pode ser uma solução para a falta de dados quantitativos sobre os resultados das aplicações de RV em reabilitação. Em uma validação futura, dados cinemáticos poderiam ser usados para validar se o ambiente de RV melhorou ou não a amplitude de movimento de pessoas com lesão medular. 



\section{Referências}

American Spinal Injury Association. ASIA Impairment Scale. 2016. Disponível em: $<$ https://asia-spinalinjury.org/>. Citado na página 31.

Arthur C. Guyton, J. E. H. Tratado De Fisiologia Médica. [S.l.: s.n.], 2011. Citado 2 vezes nas páginas 24 e 29.

AUSTIN, P. D. et al. The short-term effects of head-mounted virtual-reality on neuropathic pain intensity in people with spinal cord injury pain: a randomised cross-over pilot study. Spinal Cord, Springer US, n. October, 2020. ISSN 14765624. Disponível em: <http://dx.doi.org/10.1038/s41393-020-00569-2>. Citado na página 44.

BRAUN, S. M. Motor learning in neurological rehabilitation: practising skills with movement imagery. 253 p. Tese (Doutorado) — Maastricht University, 2010. Disponível em: <http://arno.unimaas.nl/show.cgi?fid=19554>. Citado na página 43.

CHENEY, P. D. Role of Cerebral Cortex in Voluntary Movements. Physical Therapy, v. 65, n. 5, p. 624-635, 1985. ISSN 0031-9023. Citado na página 26.

$\mathrm{CHO}, \mathrm{K} . \mathrm{H}$. et al. Virtual reality training with cognitive load improves walking function in chronic stroke patients. Tohoku Journal of Experimental Medicine, v. 236, n. 4, p. 273-280, 2015. ISSN 13493329. Citado na página 43.

De Araújo, A. V. L. et al. Efficacy of Virtual Reality Rehabilitation after Spinal Cord Injury: A Systematic Review. BioMed Research International, v. 2019, 2019. ISSN 23146141. Citado na página 43.

DIMBWADYO-TERRER, I. et al. Effectiveness of the Virtual Reality System Toyra on Upper Limb Function in People with Tetraplegia: A Pilot Randomized Clinical Trial. BioMed Research International, Hindawi Limited, v. 2016, 2016. ISSN 23146141. Citado na página 44.

DUARTE, M.; WATANABE, R. Notes on Scientific Computing for Biomechanics and Motor Control. [S.l.]: GitHub, 2018. < https://github.com/BMClab/BMC>. Citado na página 52.

ENG, J. J.; TEASELL, R. W. SCIRE: Spinal Cord Injury Rehabilitation

Evidence - Foreword. 2007. 815 p. Disponível em: <http://icord.org/research/ scire-spinal-cord-injury-rehabilitation-evidence/>. Citado 2 vezes nas páginas 21 e 30.

FETZ, E. E.; CHENEY, P. D. Postspike facilitation of forelimb muscle activity by primate corticomotoneuronal cells. Journal of Neurophysiology, v. 44, n. 4, p. 751-772, 1980. ISSN 00223077. Citado na página 26.

FONSECA, E. P. da; SILVA, N. M. R. da; PINTO, E. B. Therapeutic Effect of Virtual Reality on Post-Stroke Patients: Randomized Clinical Trial. Journal of Stroke and Cerebrovascular Diseases, Elsevier Inc., v. 26, n. 1, p. 94-100, 2017. ISSN 15328511. Disponível em: <http://dx.doi.org/10.1016/j.jstrokecerebrovasdis.2016.08.035>. Citado na página 22. 
GATES, D. H. et al. Range of motion requirements for upper-limb activities of daily living. American Journal of Occupational Therapy, v. 70, n. 1, 2016. ISSN 02729490. Citado na página 21.

HAPTX. HaptX. 2019. Disponível em: <https://haptx.com/technology/>. Citado na página 40.

HARNETT, A. et al. Spinal Cord Injury Rehabilitation Practices. Spinal Cord Injury Rehabilitation Evidence. Version 7.0., p. 1-100, 2020. Disponível em: $<$ www.scireproject.com $>$. Citado na página 31.

HUTSON, T. H.; Di Giovanni, S. The translational landscape in spinal cord injury: focus on neuroplasticity and regeneration. Nature Reviews Neurology, Springer US, v. 15, n. 12, p. 732-745, 2019. ISSN 17594766. Disponível em: <http://dx.doi.org/10.1038/s41582-019-0280-3>. Citado na página 21.

JARAMILLO, J. P.; JOHANSON, M. E.; KIRATLI, B. J. Upper limb muscle activation during sports video gaming of persons with spinal cord injury. Journal of Spinal Cord Medicine, Taylor \& Francis, v. 42, n. 1, p. 77-85, 2019. ISSN 20457723. Disponível em: $<$ https://doi.org/10.1080/10790268.2018.1452391>. Citado na página 44.

Kandel, E. R., Shwartz, J. H. Principles of Neural Science. [S.l.: s.n.], 2013. ISBN 9780071810012. Citado 5 vezes nas páginas 23, 24, 25, 28 e 29.

KWON, J. S. et al. Effects of virtual reality on upper extremity function and activities of daily living performance in acute stroke: A double-blind randomized clinical trial. NeuroRehabilitation, v. 31, n. 4, p. 379-385, 2012. ISSN 10538135. Citado na página 43.

LEAP Motion. LEAP Motion. 2018. Disponível em: <https://developer.leapmotion.com/>. Citado na página 39.

LIM, D. Y. et al. A fully immersive virtual reality method for upper limb rehabilitation in spinal cord injury. Annals of Rehabilitation Medicine, v. 44, n. 4, p. 311-319, 2020. ISSN 22340653. Citado na página 44.

LINOWES, J. Unity virtual reality projects : explore the world of virtual reality by building immersive and fun VR projects using Unity 3D. [S.l.]: Packt Publishing, 2015. ISBN 9781783988556. Citado na página 41.

MAYNARD, F. M. et al. International standards for neurological and functional classification of spinal cord injury. Spinal Cord, v. 35, n. 5, p. 266-274, 1997. ISSN 13624393. Citado na página 30.

MIZUGUCHI, N. et al. Motor imagery and sport performance. The Journal of Physical Fitness and Sports Medicine, v. 1, n. 1, p. 103-111, 2012. ISSN 2186-8131. Citado na página 22.

MONTGOMERY, P.; CONNOLly, B. Clinical Applications for Motor Control. [S.l.: s.n.], 2003. 409 p. ISBN 1556425457. Citado 3 vezes nas páginas 27, 30 e 43.

MOORE, K.; DAlleY, A.; AGUR, A. Anatomia Orientada para a Clínica. [S.1.]: Guanabara Koogan, 2004. 1300 p. ISBN 9788527725842. Citado na página 36. 
OPSOMMER, E.; CHEVAllEY, O.; KOROGOD, N. Motor imagery for pain and motor function after spinal cord injury: a systematic review. Spinal Cord, Springer US, v. 58, n. 3, p. 262-274, 2019. ISSN 14765624. Disponível em: <http://dx.doi.org/10.1038/s41393-019-0390-1>. Citado na página 43.

PASCHE, D. F.; MENDES, V. L. F. Plano Nacional dos Direitos da Pessoa com Deficiência. [S.1.]: Ministério da Saúde, 2013. 68 p. ISBN 978-85-334-2083-0. Citado na página 21.

POZEG, P. et al. Virtual reality improves embodiment and neuropathic pain caused by spinal cord injury. Neurology, v. 89, n. 18, p. 1894-1903, 2017. ISSN 1526632X. Citado na página 45.

ROBERTSON, G. Research Methods in Biomechanics. Second edi. [S.1.]: Human Kinetics, 2013. ISBN 9780813806372. Citado 2 vezes nas páginas 32 e 33.

SCHUSTER-AMFT, C. et al. Effect of a four-week virtual reality-based training versus conventional therapy on upper limb motor function after stroke: A multicenter parallel group randomized trial. Plos one, v. 13, n. 10, p. 1-19, 2018. ISSN 19326203. Citado na página 43.

SOBOTTA. Atlas de Anatomia Humana - Sobotta - Vol1 e Vol2. [S.l.: s.n.], 2000. v. 1. 839 p. ISBN 3437419404. Citado na página 27.

TREVISAN, D. G. et al. Tendências e Técnicas em Realidade Virtual e Aumentada. XVI Symposium on Virtual and Augmented Reality, p. 215, 2014. Citado na página 21.

TRINCADO-ALONSO, F. et al. Kinematic metrics based on the virtual reality system Toyra as an assessment of the upper limb rehabilitation in people with spinal cord injury. BioMed Research International, v. 2014, 2014. ISSN 23146141. Citado na página 44.

UREY, H. et al. State of the art in stereoscopic and autostereoscopic displays. Proceedings of the IEEE, v. 99, n. 4, p. 540-555, 2011. ISSN 00189219. Citado na página 37.

VARGAS, V. Avaliação clínica e cinemática da função manual de pessoas com tetraplegia com a utilização de EENM e sistema híbrido. Tese (Doutorado) — UNICAMP, 2012. Citado 2 vezes nas páginas 35 e 47.

VAROTO, R.; CLIQUET, A. Experiencing Functional Electrical Stimulation Roots on Education, and Clinical Developments in Paraplegia and Tetraplegia With Technological Innovation. Artificial Organs, v. 39, n. 10, p. E187-E201, 2015. ISSN 15251594. Citado na página 21.

VILLIGER, M. et al. Virtual reality-augmented neurorehabilitation improves motor function and reduces neuropathic pain in patients with incomplete spinal cord injury. Neurorehabilitation and Neural Repair, v. 27, n. 8, p. 675-683, 2013. ISSN 15459683. Citado na página 22.

WINTER, D. A. Biomechanics and Motor Control of Human Movement: Fourth Edition. [S.l.: s.n.], 2009. 1-370 p. ISBN 9780470398180. Citado 2 vezes nas páginas 34 e 52.

WU, G.; CAVANAGH, P. R. ISB recommendations for standardization in the reporting of kinematic data. Journal of Biomechanics, v. 28, n. 10, p. 1257-1261, 1995. ISSN 00219290. Citado 2 vezes nas páginas 35 e 36. 
WU, G. et al. ISB recommendation on definitions of joint coordinate systems of various joints for the reporting of human joint motion - Part II: Shoulder, elbow, wrist and hand. Journal of Biomechanics, v. 38, n. 5, p. 981-992, 2005. ISSN 00219290. Citado 2 vezes nas páginas 35 e 36. 
Anexos 

ANEXO A - Documentos Comitê de Ética 


\section{PARECER CONSUBSTANCIADO DO CEP}

\section{DADOS DO PROJETO DE PESQUISA}

Título da Pesquisa: Uso de um ambiente de realidade virtual para treinar atividades funcionais de membros superiores em lesados medulares

Pesquisador: ALBERTO CLIQUET JUNIOR

Área Temática:

Versão: 4

CAAE: 20194619.1.0000.5404

Instituição Proponente: Hospital de Clínicas - UNICAMP

Patrocinador Principal: Financiamento Próprio

\section{DADOS DO PARECER}

Número do Parecer: 3.726.507

\section{Apresentação do Projeto:}

As informações contidas nos campos "Apresentação do Projeto", "Objetivo da Pesquisa" e "Avaliação dos Riscos e Benefícios" foram obtidas dos documentos apresentados para apreciação ética e das informações inseridas pelo Pesquisador Responsável do estudo na Plataforma Brasil.

\section{Introdução:}

No Brasil, há cerca de 6 a 8 mil novos tetraplégicos e paraplégicos por ano, sendo que a maioria das lesões na medula espinhal tem origem traumática (Ministério da Saúde, 2015). Além de limitar as capacidades motoras e sensoriais, lesão medular afeta diretamente a qualidade de vida dos pacientes e a realização de atividades de vida diária (AVDs). Os músculos abaixo do nível neurológico da lesão pouco ou nada respondem aos comandos cerebrais. Atividades cotidianas como andar ou comer se tornam desafios na vida dos portadores de lesão medular. No caso dos tetraplégicos, há ainda menos recursos para o tratamento pois a caracterização dos movimentos superiores é mais complexa do que a dos membros inferiores. Cada articulação adiciona mais 6 graus de liberdade ( 3 de translação e 3 de rotação) ao sistema. Além disso, há mais AVDs de igual importância para membros superiores, como comer, alcançar um objeto e mover a cadeira de rodas, do que para membros inferiores, em que a atividade funcional mais importante é o ciclo de marcha. Cada AVD requer uma análise cinemática diferente, o que dificulta ainda mais o estudo de

Endereço: Rua Tessália Vieira de Camargo, 126

Bairro: Barão Geraldo

CEP: $13.083-887$

UF: SP Município: CAMPINAS

Telefone: (19)3521-8936 Fax: (19)3521-7187 E-mail: cep@fcm.unicamp.br 


\section{UNICAMP - CAMPUS CAMPINAS}

movimento e o desenvolvimento de tecnologias para tetraplégicos.Existem alguns recursos reconhecidos pela comunidade científica que estimulam a neuroplasticidade cerebral. Neuroplasticidade é o processo no qual o cérebro se modifica de acordo com experiências vivenciadas (BRAINN, 2016). Nos lesados medulares, o aumento de neuroplasticidade cerebral pode resultar no aumento da massa cinzenta no nível neurológico da lesão, recuperação das raízes nervosas além do nível de lesão e reorganização de circuitos espinhais existentes (ENG et al., 2005). Neste âmbito, o Laboratório de Biocibernética e Engenharia de Reabilitação (LABCIBER), da USP, e o Laboratório de Biomecânica e Aparelho Locomotor (LABRAL), da UNICAMP, pesquisam e aplicam recursos e tecnologias inovadoras para a reabilitação de indivíduos com lesão medular. O destaque entre os recursos é a eletroestimulação neuromuscular (EENM) que, aliada à fisioterapia, visa recuperar e manter o tônus muscular (VAROTO; CLIQUET, 2015). A EENM utiliza pulsos elétricos para contrair músculos e, desta forma, pode ser aplicada em membros inferiores e superiores. $O$ uso contínuo da EENM associada à fisioterapia resulta no aumento da neuroplasticidade e, em alguns casos, recupera movimentos sem que haja necessidade da presença da EENM. Porém, as sequelas das lesões raquimedulares ainda desafiam a ciência reabilitativa. Pesquisadores buscam, constantemente, encontrar estímulos que promovam o aumento da capacidade neuroplástica nesses pacientes. Os ambientes de realidade virtual são exemplos disso.A Realidade Virtual (RV) é definida como uma interface avançada de usuário para visualização tridimensional e em tempo real de aplicações do computador (KIRNER, 2007). A interface exige alta capacidade de processamento, uma vez que as imagens devem ser renderizadas muito rapidamente. Há a RV imersiva, na qual o usuário utiliza um óculos para visualizar o ambiente de aplicação, e há a RV nãoimersiva, na qual o ambiente gráfico é projetado em uma tela ou monitor. Apesar da RV imersiva proporcionar uma experiência mais realista, a RV não-imersiva é mais utilizada por seu atrativo custo-benefício. A RV imersiva utiliza o HMD (Head-Mounted Display) junto com outros dispositivos de entrada para permitir a interação e melhor interação com o ambiente virtual. A RV já foi utilizada em tratamentos de doenças neurológicas como Acidente Vascular Cerebral (AVC) e resultaram em reabilitação de capacidades cognitivas e motoras (Pedreira da Fonseca; Ribeiro da Silva; PINTO, 2017). O AVC resulta em sequelas similares à lesão raquimedular como a perda das habilidades sensório-motoras. A reabilitação do AVC através da RV consiste no treino de atividades funcionais. Segundo Villiger et al, a repetição destes movimentos associado a um ambiente lúdico imersivo resultou recuperação motora e cognitiva de alguns pacientes, além de redução de dor crônica (VILLIGER et al., 2013). A base teórica deste tratamento é a imagética motora, que consiste na autorregulação cerebral por meio de um

Endereço: Rua Tessália Vieira de Camargo, 126

Bairro: Barão Geraldo

CEP: $\quad 13.083-887$

UF: SP Município: CAMPINAS

Telefone: (19)3521-8936

Fax: (19)3521-7187

E-mail: cep@fcm.unicamp.br 


\section{UNICAMP - CAMPUS CAMPINAS}

estímulo visual. Durante a prática mental, isto é, o paciente imagina o movimento que seria realizado, as áreas do cérebro ativadas são as mesmas das áreas que seriam ativadas durante a realização do movimento. A repetição do estímulo visual pode resultar na correção de disfunções motoras e cerebrais. Alguns atletas utilizam a imagética motora junto ao treinamento convencional para aperfeiçoar seus movimentos antes de uma competição (MIZUGUCHI et al., 2012). Diante disso, este projeto tem como objetivo criar um ambiente de RV para simular e exercitar as AVDs que solicitem os membros superiores em indivíduos com tetraplegia. Através do ambiente virtual, o paciente terá estímulos visuais e proprioceptivos em tempo real, uma vez que a propriocepção é a noção espacial do corpo.

Hipótese:

O uso de um ambiente de realidade virtual imersivo pode auxiliar no tratamento de tetraplégicos e possibilitar a recuperação de atividades funcionais de membros superiores

\section{Metodologia Proposta:}

4.2.1 Descrição das atividades com o GC e GIRVO GIRV participará duas análises biomecânicas e de uma intervenção com RV que será composta de 6 sessões semanais de 15 minutos cada. Em contrapartida, o GC não fará nenhuma intervenção, este grupo fará apenas duas avaliações biomecânicas: uma no início e outra ao término da pesquisa.4.2.2 Análise Biomecânica e Eletromiografia (EMG)A análise biomecânica será realizada no pré e pós intervenção da RV. Através do equipamento The Motion Monitor, a análise cinemática será feita com 12 câmeras VICON espaçadas igualmente em uma sala retangular. A coleta do sinal de eletromiografia é feita com sensores EMG posicionados nos músculos do bíceps braquial e tríceps dos lados direito e esquerdo. Além das câmeras, o sistema The Motion Monitor utilizará clusters (marcadores reflexivos) para detectar a posição de cada articulação e segmento do paciente. Durante esta coleta, serão utilizados 5 clusters correspondentes a braços e antebraços e tórax. Com o auxílio do programa do The Motion Monitor, um modelo tridimensional do paciente é construído e dele pode-se extrair informações de cinemática. Os gráficos correspondentes à momentos, velocidades e EMG podem ser gerados no mesmo programa que sincroniza todas as análises, gerando um único relatório com todas as informações coletadas. 4.2.2 Protocolo de membros superiores $O$ protocolo utilizado neste estudo é o deslocamento das mãos em 5 posições pré-definidas: 1-canto inferior esquerdo,2-canto superior esquerdo,3-centro,4-canto inferior direito,5-canto

Endereço: Rua Tessália Vieira de Camargo, 126

Bairro: Barão Geraldo

CEP: $\quad 13.083-887$

UF: SP Município: CAMPINAS

Telefone: (19)3521-8936

Fax: (19)3521-7187

E-mail: cep@fcm.unicamp.br 


\section{UNICAMP - CAMPUS CAMPINAS}

superior direito.Primeiramente, com a mão esquerda, o paciente deve estender o cotovelo para alcançar os pontos 1-2-1-3-1-4-1-5-1, nesta ordem. Depois, com mão direita, ele deve tocar nos pontos 5-4-5-3-5-2-5-15. Cada protocolo será repetido 3 vezes para evitar perda de dados. Ambiente de realidade virtual O HeadMounted Display (HMD) que será utilizado é o Oculus Rift, que possui dois controles sensíveis ao movimento. Os controles detectam a posição das mãos dos usuários no ambiente virtual, enquanto que os sensores de movimento do Rift detectam a direção da cabeça. O ambiente foi desenvolvido na Game Engine Unity 3D, que possui diversas ferramentas de modelagem e de programação que permitem o desenvolvimento de ambientes interativos. O Rift foi escolhido pela sua alta capacidade de processamento, dispositivos de entrada com sensores de movimento e portabilidade. As versões mais recentes do Rift podem operar independentemente do computador, o que facilita a aplicação dele em ambientes hospitalares. O processamento rápido possibilita a renderização em tempo real de imagens e, consequentemente, o retorno proprioceptivo também é fornecido em tempo real. Além do HMD, há dois controles com sensores para detectar movimentos e traduzí-los em ações no ambiente virtual. A figura abaixo mostra o Oculus Rift junto com os controles: Figura 2 - Oculus Rift e controles. Os controles serão atados aos braços dos pacientes e a posição dos braços no ambiente virtual fornecida pelos sensores de movimento dos controles serão o retorno proprioceptivo para o paciente. O ambiente virtual possuirá as mesma 5 posições mostradas na figura 1 e o paciente deverá memorizar e executar uma sequência de movimentos diferente gerada aleatoriamente em cada sessão. A exatidão do movimento em cada treino será armazenada no sistema e o usuário pode acompanhar seu desempenho e evolução durante o tratamento. As sequências são diversificadas para que os movimentos treinados se aproximem dos movimentos de flexão e extensão de cotovelo e de ombro que seriam realizados normalmente pelo paciente.As sessões com realidade virtual duram entre 10 e 15 minutos e serão realizadas 6 sessões. Metade dos pacientes farão parte do grupo controle, no qual não haverá intervenção com realidade virtual.4.3 Haverá gravação de fotos e vídeos durante a pesquisa e as imagens serão utilizadas apenas para esta pesquisa e serão descartados digitalmente ao final.

Critério de Inclusão:

Os participantes da pesquisa deverão apresentar nível de lesão raquimedular entre $\mathrm{C} 4$ e $\mathrm{C} 7$, com mais de 1 ano de lesão, entre 20 e 65 anos, ativos (não-sedentários).

Critério de Exclusão:

Endereço: Rua Tessália Vieira de Camargo, 126

Bairro: Barão Geraldo

CEP: $\quad 13.083-887$

UF: SP Município: CAMPINAS

Telefone: (19)3521-8936

Fax: (19)3521-7187

E-mail: cep@fcm.unicamp.br 


\section{UNICAMP - CAMPUS CAMPINAS}

Indivíduos com bloqueios articulares, portadores de comorbidades tais como disreflexia autonômica durante a coleta de dados, infecção urinária ativa, dor neuropática e fraturas dos membros superiores serão excluídos do estudo

\section{Objetivo da Pesquisa:}

Objetivo Primário:

Estudar a biomecânica de membros superiores em indivíduos com tetraplegia, bem como estudar seus protocolos de atividades funcionais. Aplicar a Realidade Virtual em pacientes com tetraplegia.

\section{Objetivo Secundário:}

Analisar os impactos da Realidade Virtual em pacientes com tetraplegia.Validar o uso da Realidade Virtual em pacientes com tetraplegia.

\section{Avaliação dos Riscos e Benefícios:}

Segundo informações do pesquisador: "Riscos: Em virtude de avaliar indivíduos jovens e ativos, os riscos de lesão nos membros é bastante reduzido. Entretanto, caso ocorra qualquer problema, como desequilíbrio ou dores musculares em decorrência dos testes musculares, os participantes da pesquisa serão avaliados e orientados pelo pesquisador fisioterapeuta quanto as medidas necessárias. Com relação a eletromiografia, os riscos envolvem desconforto do posicionamento dos eletrodos e, em alguns raros casos, alergia temporária ao adesivo do eletrodo. Benefícios: Não há nenhum benefício garantido. Entretanto, para o grupo intervenção, o uso da realidade virtual pode ajudar na recuperação dos movimentos, mas não há nenhuma garantia."

\section{Comentários e Considerações sobre a Pesquisa:}

Este protocolo se refere a um Projeto de Pesquisa intitulado "Uso de um ambiente de realidade virtual para treinar atividades funcionais de membros superiores em lesados medulares", cujo pesquisador responsável é o Prof. Dr. Alberto Cliquet Junior, e a pesquisa também contará com a participação do aluno de mestrado Gabriel Augusto Ginja, e da fisioterapeuta Letícia Vargas de Almeida. A Instituição Proponente é o Hospital de Clínicas (HC) da UNICAMP. Segundo as Informações Básicas do Projeto, a pesquisa tem orçamento estimado em $\mathrm{R} \$ 50,00$ (Cinquenta reais) e o cronograma apresentado contempla início da coleta de dados para outubro de 2019, com término em setembro de 2021. Serão recrutados, ao todo, 20 participantes que tenham lesão raquimedular entre $\mathrm{C} 4$ e $\mathrm{C} 7$, com mais de 1 ano de lesão. Os participantes terão que realizar o deslocamento dos membros superiores na direção de 5 posições previamente definidas. 10 participantes realizarão a atividade sem e 10 realizarão com os óculos de realidade virtual.

Endereço: Rua Tessália Vieira de Camargo, 126

Bairro: Barão Geraldo

CEP: $13.083-887$

UF: SP Município: CAMPINAS

Telefone: (19)3521-8936

Fax: (19)3521-7187

E-mail: cep@fcm.unicamp.br 


\section{UNICAMP - CAMPUS CAMPINAS}

\section{CEPUNICAMIP}

Continuação do Parecer: 3.726.507

Durante o procedimento, será coletado o sinal de eletromiografia, por meio de sensores posicionados nos músculos do bíceps braquial e tríceps dos lados direito e esquerdo. O objetivo será analisar os impactos da tecnologia de realidade virtual na biomecânica de membros superiores em indivíduos com tetraplegia.

\section{Considerações sobre os Termos de apresentação obrigatória:}

Foram analisados os seguintes documentos de apresentação obrigatória:

1 - Folha de Rosto Para Pesquisa Envolvendo Seres Humanos: Foi apresentado o documento "Folha_de_Rosto.pdf" devidamente preenchido, datado e assinado pelo coordenador de assistência do HC/UNICAMP.

2 - Projeto de Pesquisa: Foram analisados os documentos " Comite_de_Etica_V4.docx" e "PB_INFORMAÇÕES_BÁSICAS_DO_PROJETO_1422852.pdf" de 21/11/2019. Adequado.

3 - Orçamento financeiro e fontes de financiamento: Informações sobre orçamento financeiro incluídas no documento "PB_INFORMAÇÕES_BÁSICAS_DO_PROJETO_1422852.pdf" de 21/11/2019. De acordo com o pesquisador, a pesquisa será realizada com recursos próprios. Adequado.

4 - Cronograma: Informações sobre o cronograma incluídas no documento "PB_INFORMAÇÕES_BÁSICAS_DO_PROJETO_1422852.pdf" de 21/11/2019. Adequado.

5 - Termo de Consentimento Livre e Esclarecido: Foram apresentados os documentos "TCLE_Unicamp_GC_V3.docx"e "TCLE_Unicamp_GIRV_V3.docx". Adequado.

6 - Currículo do pesquisador principal e demais colaboradores: Contemplados no documento "PB_INFORMAÇÕES_BÁSICAS_DO_PROJETO_1422852.pdf" de 21/11/2019.

7 - Outros documentos que acompanham o Protocolo de Pesquisa:

- Carta_Resposta_Comite.docx

- termo_autorizacao_uso_imagem.docx

Conclusões ou Pendências e Lista de Inadequações:

As pendências foram devidamente respondidas pelos pesquisadores, portanto o projeto foi aprovado.

Endereço: Rua Tessália Vieira de Camargo, 126

Bairro: Barão Geraldo

CEP: $13.083-887$

UF: SP Município: CAMPINAS

Telefone: (19)3521-8936

Fax: (19)3521-7187

E-mail: cep@fcm.unicamp.br 


\section{UNICAMP - CAMPUS CAMPINAS}

\section{CEPUNICAMP}

Continuação do Parecer: 3.726.507

\section{Considerações Finais a critério do CEP:}

- O participante da pesquisa deve receber uma via do Termo de Consentimento Livre e Esclarecido, na íntegra, por ele assinado (quando aplicável).

- O participante da pesquisa tem a liberdade de recusar-se a participar ou de retirar seu consentimento em qualquer fase da pesquisa, sem penalização alguma e sem prejuízo ao seu cuidado (quando aplicável).

- O pesquisador deve desenvolver a pesquisa conforme delineada no protocolo aprovado. Se o pesquisador considerar a descontinuação do estudo, esta deve ser justificada e somente ser realizada após análise das razões da descontinuidade pelo CEP que o aprovou. O pesquisador deve aguardar o parecer do CEP quanto à descontinuação, exceto quando perceber risco ou dano não previsto ao participante ou quando constatar a superioridade de uma estratégia diagnóstica ou terapêutica oferecida a um dos grupos da pesquisa, isto é, somente em caso de necessidade de ação imediata com intuito de proteger os participantes.

- O CEP deve ser informado de todos os efeitos adversos ou fatos relevantes que alterem o curso normal do estudo. É papel do pesquisador assegurar medidas imediatas adequadas frente a evento adverso grave ocorrido (mesmo que tenha sido em outro centro) e enviar notificação ao CEP e à Agência Nacional de Vigilância Sanitária - ANVISA - junto com seu posicionamento.

- Eventuais modificações ou emendas ao protocolo devem ser apresentadas ao CEP de forma clara e sucinta, identificando a parte do protocolo a ser modificada e suas justificativas e aguardando a aprovação do CEP para continuidade da pesquisa. Em caso de projetos do Grupo I ou II apresentados anteriormente à ANVISA, o pesquisador ou patrocinador deve enviá-las também à mesma, junto com o parecer aprovatório do CEP, para serem juntadas ao protocolo inicial.

- Relatórios parciais e final devem ser apresentados ao CEP, inicialmente seis meses após a data deste parecer de aprovação e ao término do estudo.

-Lembramos que segundo a Resolução 466/2012, item XI.2 letra e, "cabe ao pesquisador apresentar dados solicitados pelo CEP ou pela CONEP a qualquer momento".

Endereço: Rua Tessália Vieira de Camargo, 126

Bairro: Barão Geraldo

CEP: $13.083-887$

UF: SP Município: CAMPINAS

Telefone: (19)3521-8936

Fax: (19)3521-7187

E-mail: cep@fcm.unicamp.br 


\section{UNICAMP - CAMPUS CAMPINAS

Continuação do Parecer: 3.726.507

pesquisador deve manter os dados da pesquisa em arquivo, físico ou digital, sob sua guarda e responsabilidade, por um período de 5 anos após o término da pesquisa.

Este parecer foi elaborado baseado nos documentos abaixo relacionados:

\begin{tabular}{|c|c|c|c|c|}
\hline Tipo Documento & Arquivo & Postagem & Autor & Situação \\
\hline $\begin{array}{l}\text { Informações Básicas } \\
\text { do Projeto }\end{array}$ & $\begin{array}{l}\text { PB_INFORMAÇÕES_BÁSICAS_DO_P } \\
\text { ROJETO 1422852.pdf }\end{array}$ & $\begin{array}{c}21 / 11 / 2019 \\
10: 25: 33 \\
\end{array}$ & & Aceito \\
\hline Outros & Carta_Resposta_Comite.docx & $\begin{array}{l}21 / 11 / 2019 \\
10: 24: 18\end{array}$ & $\begin{array}{l}\text { ALBERTO CLIQUET } \\
\text { JUNIOR }\end{array}$ & Aceito \\
\hline $\begin{array}{l}\text { TCLE / Termos de } \\
\text { Assentimento / } \\
\text { Justificativa de } \\
\text { Ausência } \\
\end{array}$ & TCLE_Unicamp_GIRV_V3.docx & $\begin{array}{l}21 / 11 / 2019 \\
10: 23: 19\end{array}$ & $\begin{array}{l}\text { ALBERTO CLIQUET } \\
\text { JUNIOR }\end{array}$ & Aceito \\
\hline $\begin{array}{l}\text { TCLE / Termos de } \\
\text { Assentimento / } \\
\text { Justificativa de } \\
\text { Ausência } \\
\end{array}$ & TCLE_Unicamp_GC_V3.docx & $\begin{array}{l}\text { 21/11/2019 } \\
10: 22: 07\end{array}$ & $\begin{array}{l}\text { ALBERTO CLIQUET } \\
\text { JUNIOR }\end{array}$ & Aceito \\
\hline $\begin{array}{l}\text { Projeto Detalhado / } \\
\text { Brochura } \\
\text { Investigador }\end{array}$ & Comite_de_Etica_V4.docx & $\begin{array}{l}\text { 21/11/2019 } \\
10: 21: 09\end{array}$ & $\begin{array}{l}\text { ALBERTO CLIQUET } \\
\text { JUNIOR }\end{array}$ & Aceito \\
\hline $\begin{array}{l}\text { TCLE / Termos de } \\
\text { Assentimento / } \\
\text { Justificativa de } \\
\text { Ausência } \\
\end{array}$ & termo_autorizacao_uso_imagem.docx & $\begin{array}{l}13 / 10 / 2019 \\
15: 41: 34\end{array}$ & $\begin{array}{l}\text { ALBERTO CLIQUET } \\
\text { JUNIOR }\end{array}$ & Aceito \\
\hline Folha de Rosto & Folha_de_Rosto.pdf & $\begin{array}{c}29 / 08 / 2019 \\
10: 01: 00 \\
\end{array}$ & $\begin{array}{l}\text { ALBERTO CLIQUET } \\
\text { JUNIOR }\end{array}$ & Aceito \\
\hline
\end{tabular}

\section{Situação do Parecer:}

Aprovado

Necessita Apreciação da CONEP:

Não

CAMPINAS, 26 de Novembro de 2019

\section{Assinado por:}

Renata Maria dos Santos Celeghini

(Coordenador(a))

Endereço: Rua Tessália Vieira de Camargo, 126

Bairro: Barão Geraldo

CEP: $13.083-887$

UF: SP Município: CAMPINAS

Telefone: (19)3521-8936 Fax: (19)3521-7187 E-mail: cep@fcm.unicamp.br 


\section{UNICAMP - CAMPUS}

CAMPINAS

\section{CEPUNICAMP}

Continuação do Parecer: 3.726.507

Endereço: Rua Tessália Vieira de Camargo, 126

Bairro: Barão Geraldo

CEP: $13.083-887$

UF: SP

Município: CAMPINAS

Telefone: (19)3521-8936

Fax: (19)3521-7187

E-mail: cep@fcm.unicamp.br 
ANEXO B - Gráficos do protocolo piloto de alcance 
Paciente A - Protocolo alcance braço Direito (coletas)
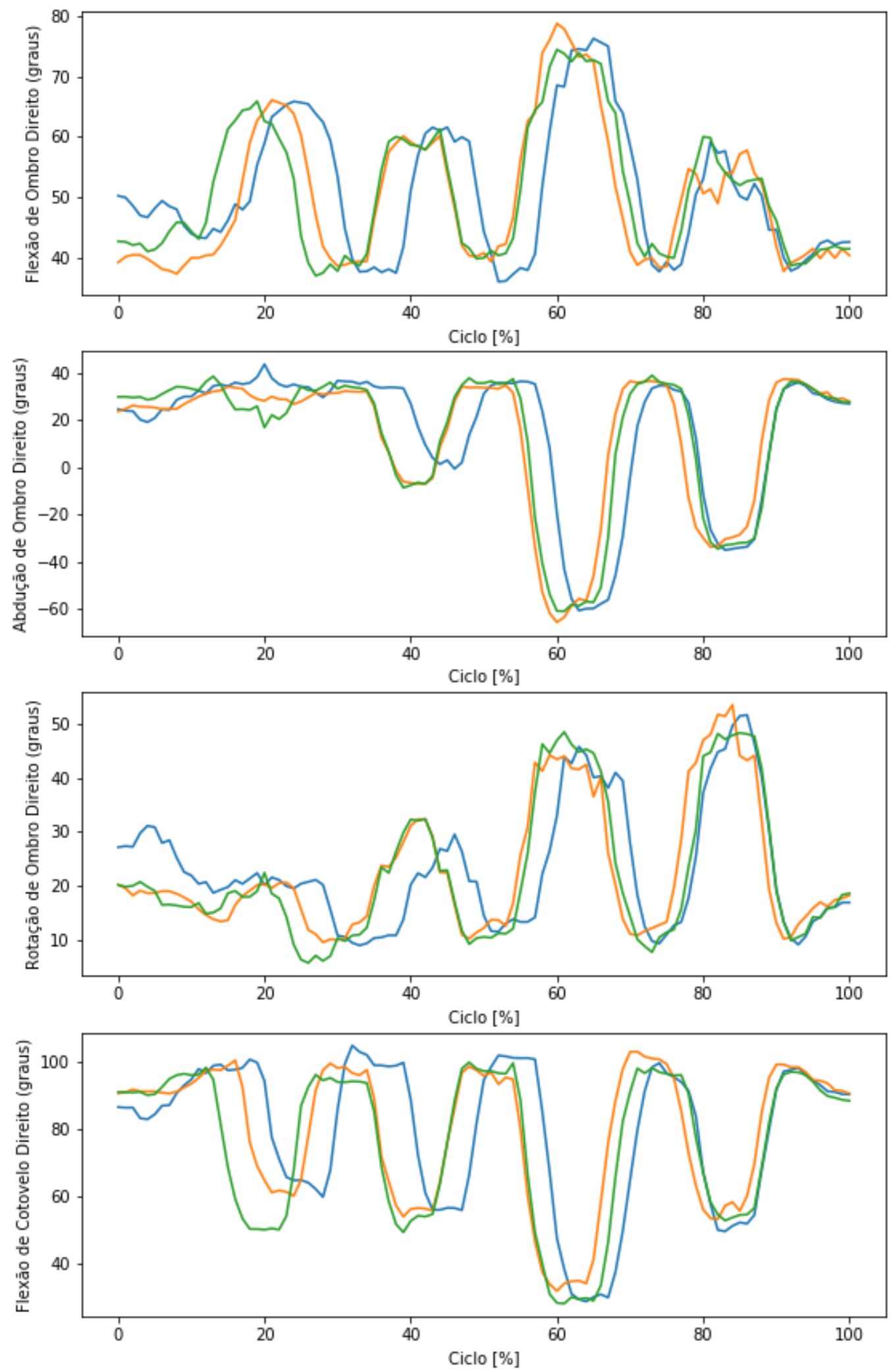
Paciente A - Protocolo alcance braço Esquerdo (coletas)
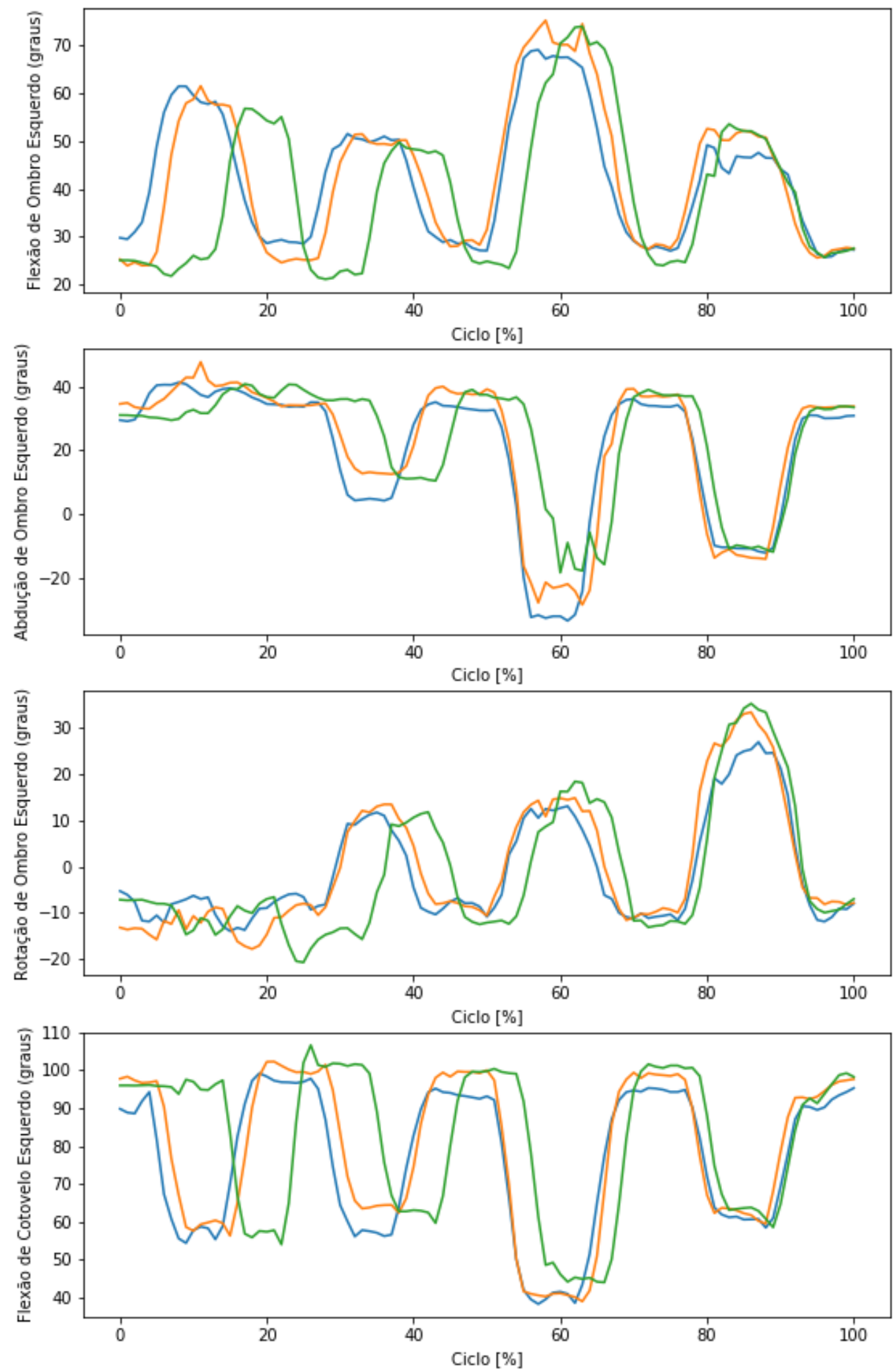
Paciente B - Protocolo alcance braço Direito (coletas)
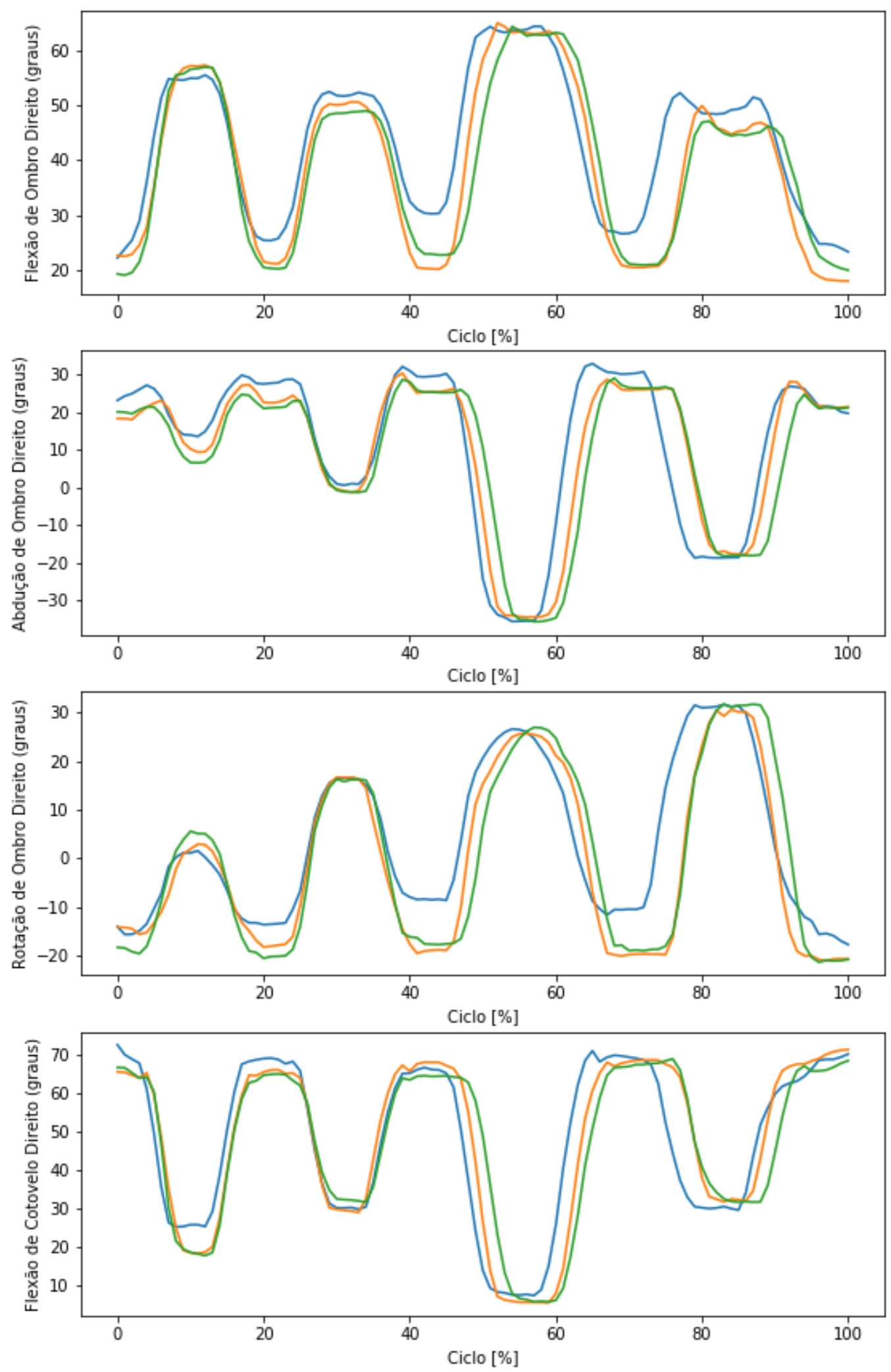
Paciente B - Protocolo alcance braço Esquerdo (coletas)
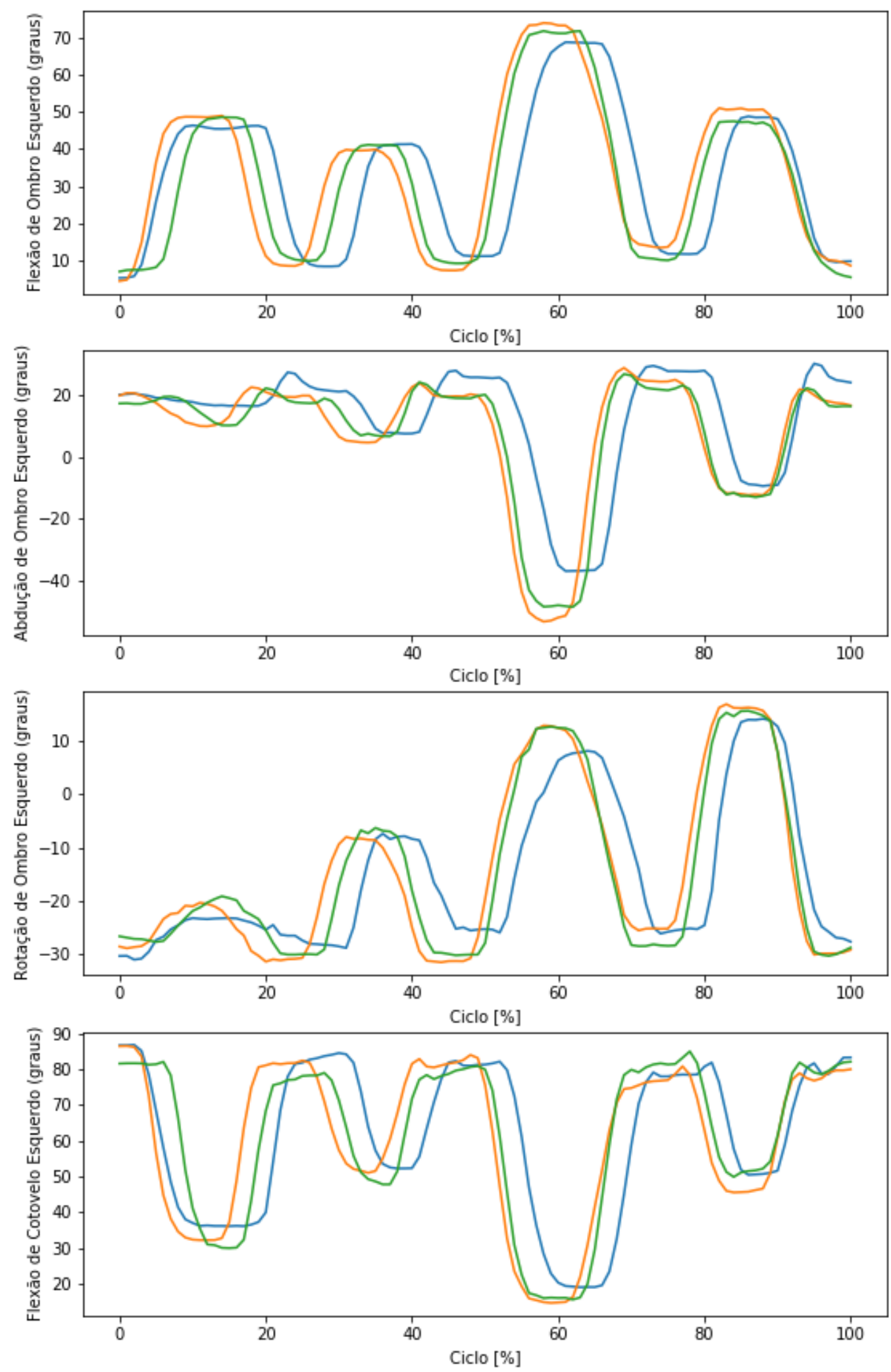
Paciente C - Protocolo alcance braço Direito (coletas)
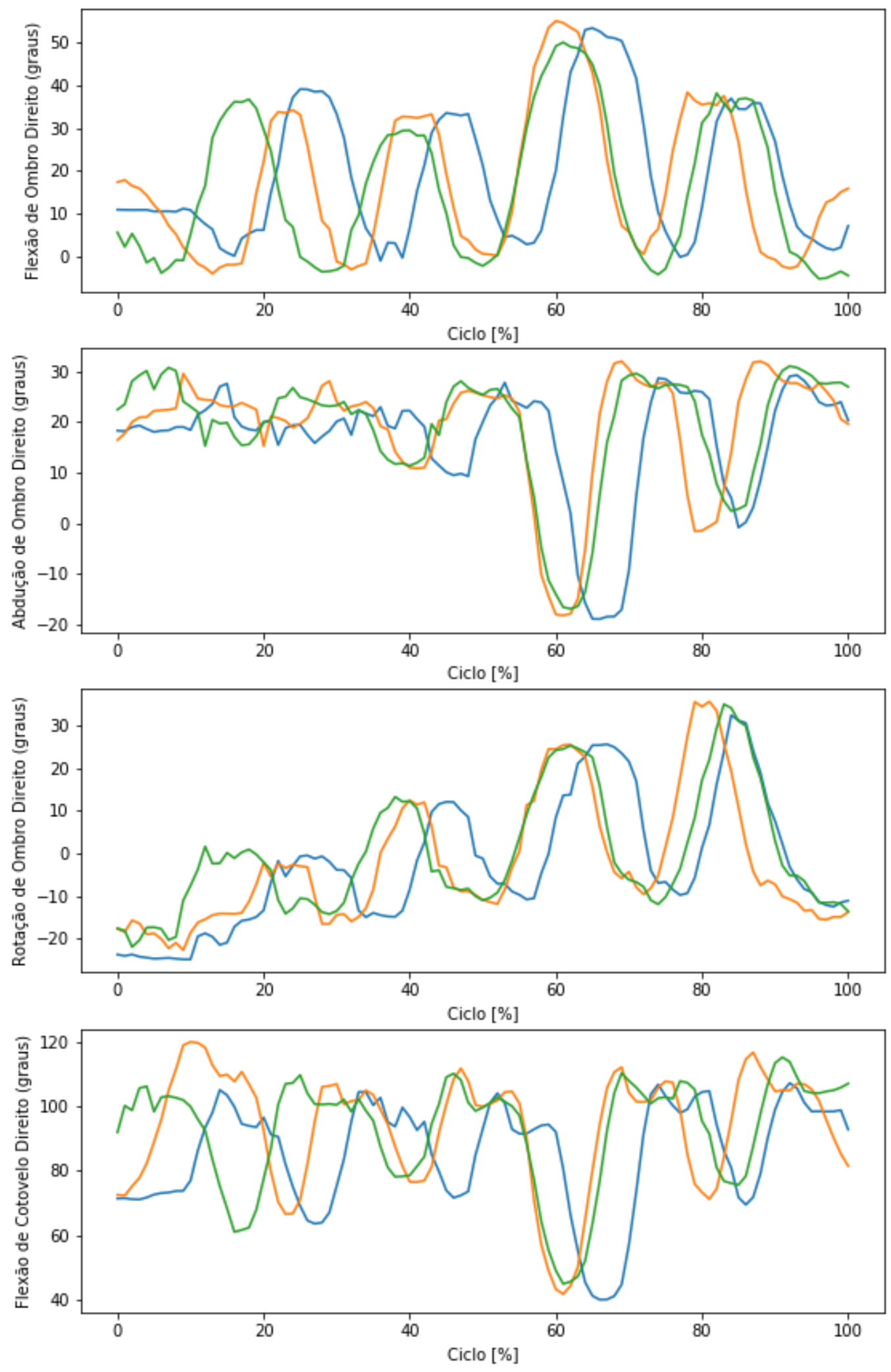
Paciente C - Protocolo alcance braço Esquerdo (coletas)
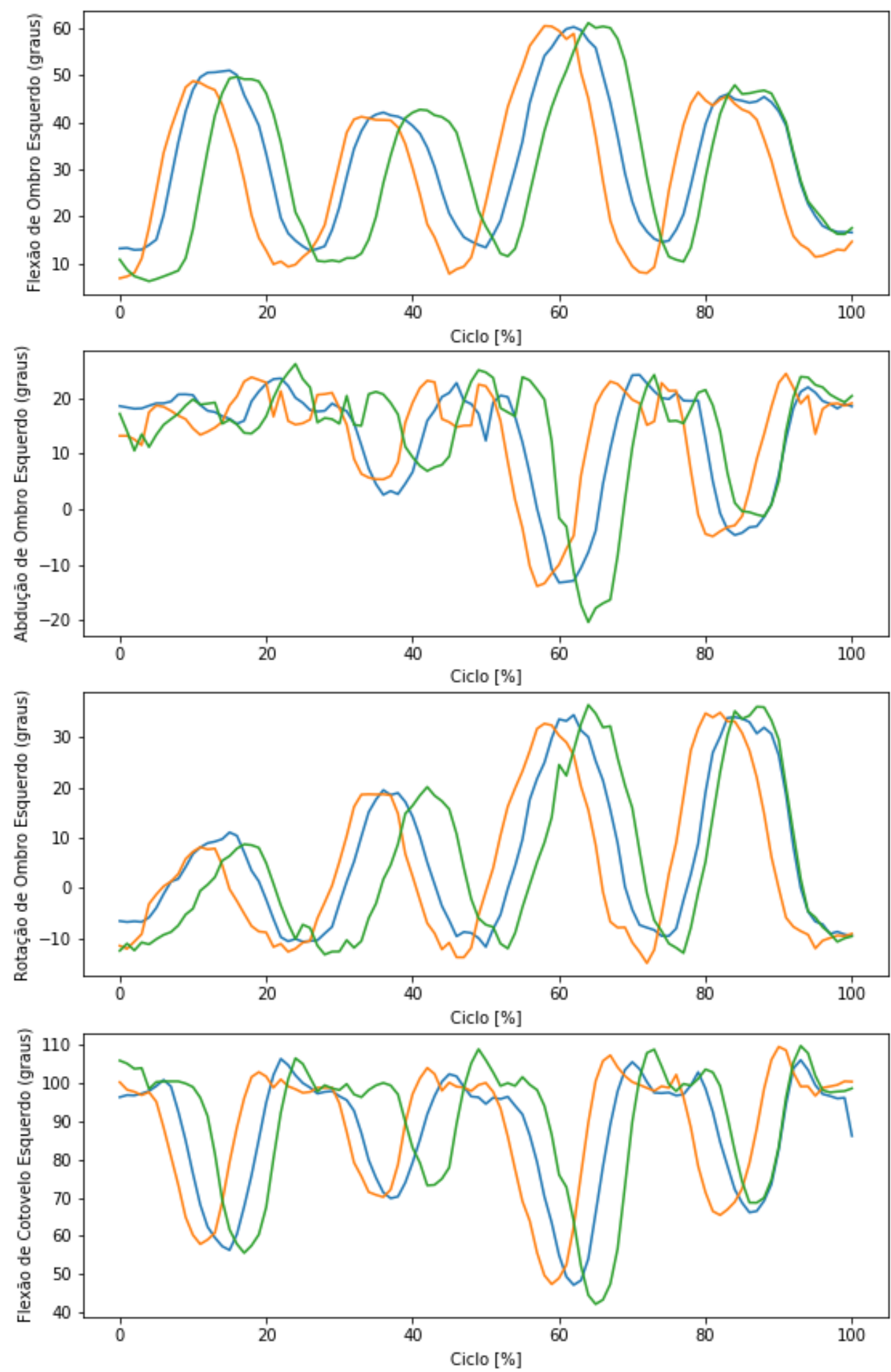
Paciente D - Protocolo alcance braço Direito (coletas)
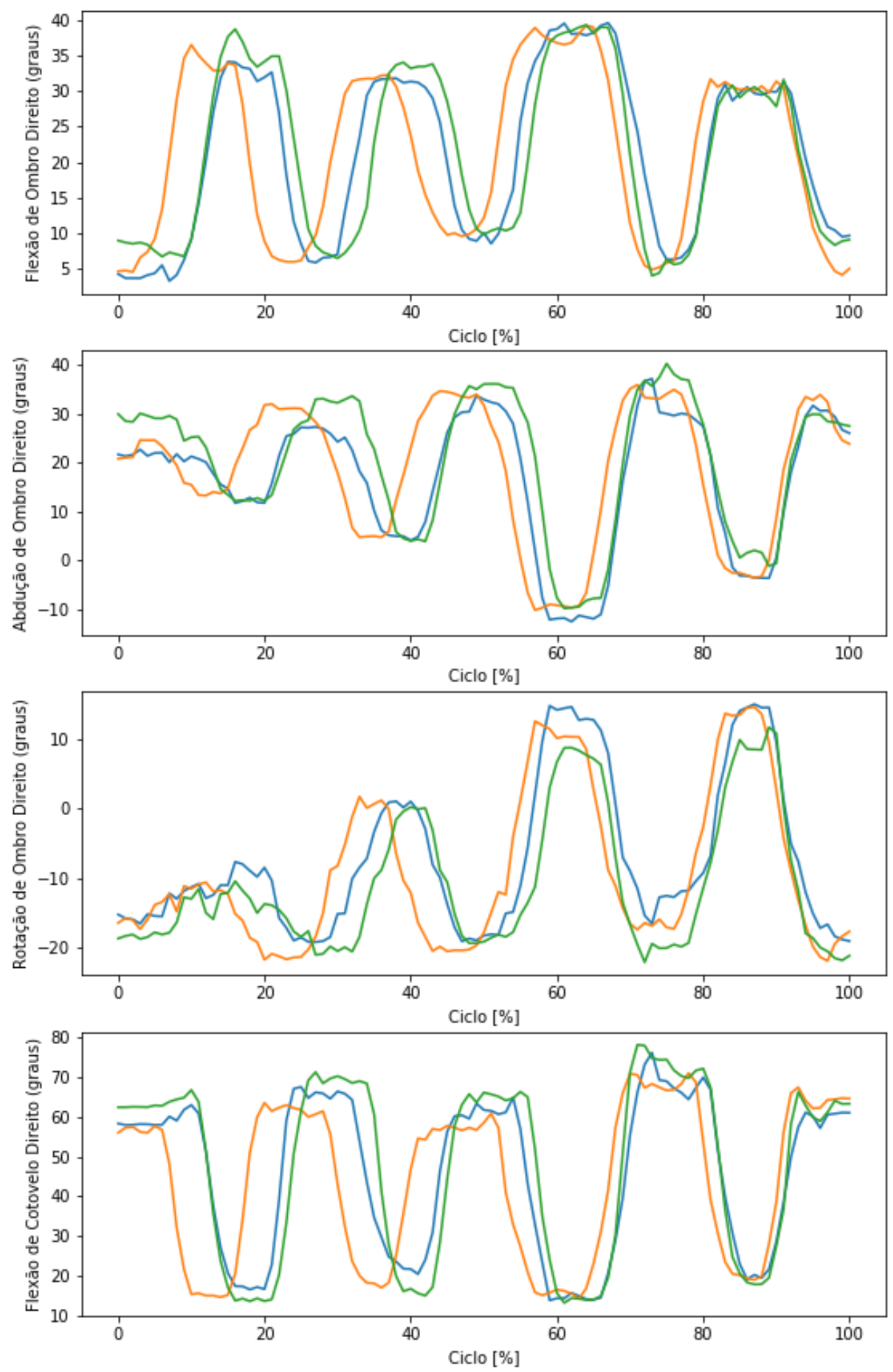
Paciente D - Protocolo alcance braço Esquerdo (coletas)
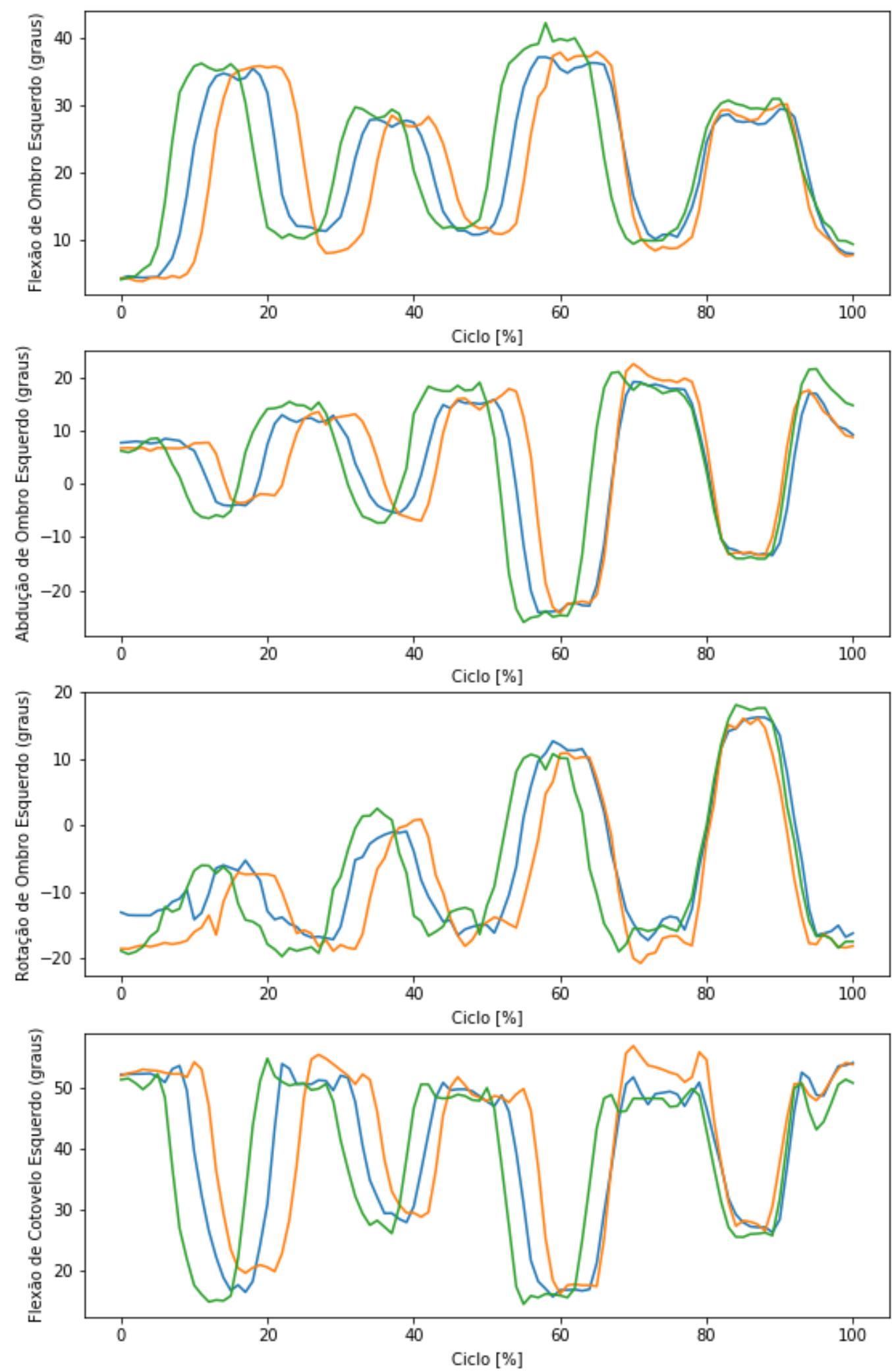
Paciente A - Protocolo alcance braço Direito (média e desvio padrão)
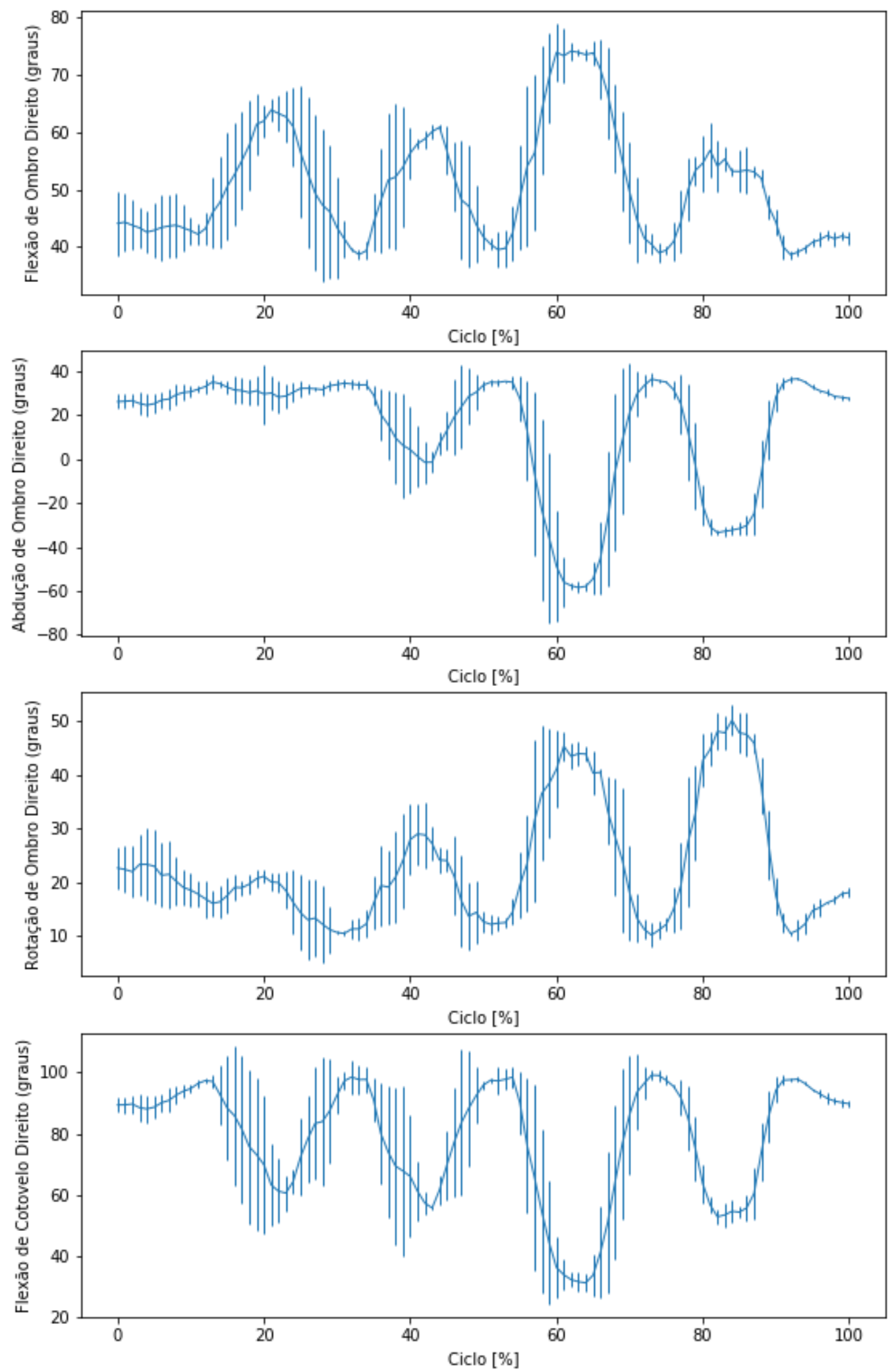
Paciente A - Protocolo alcance braço Esquerdo (média e desvio padrão)
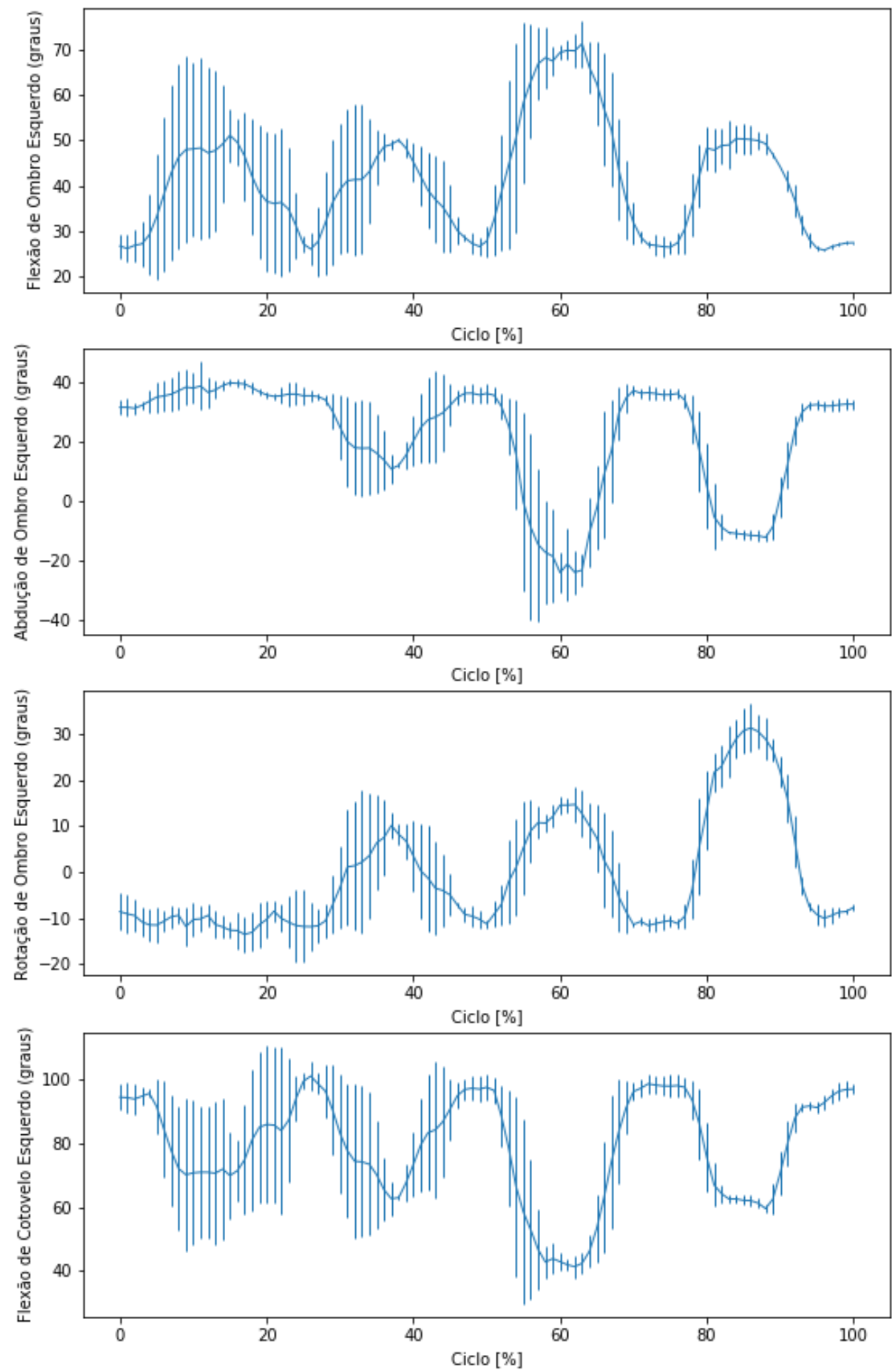
Paciente B - Protocolo alcance braço Direito (média e desvio padrão)
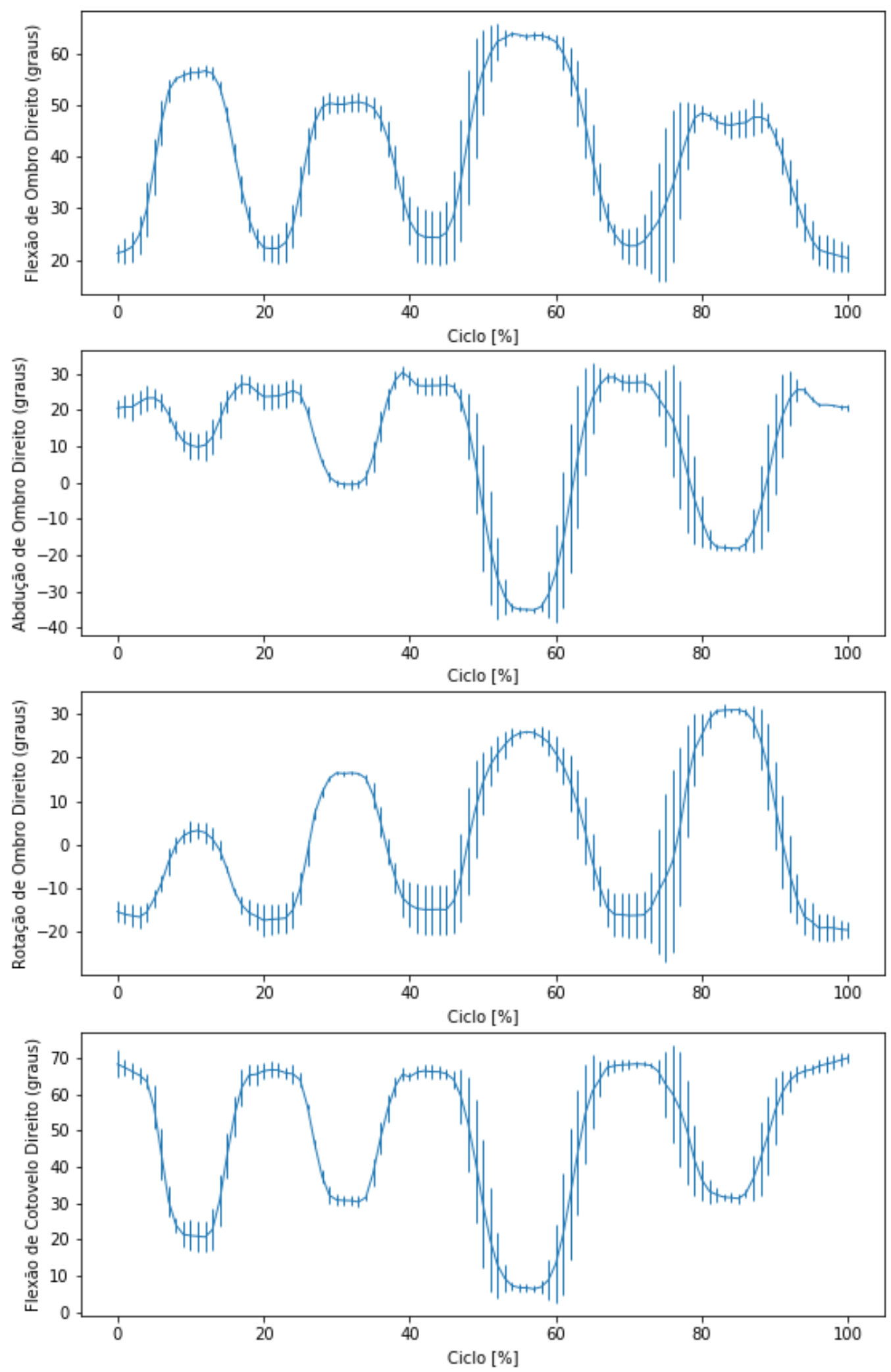
Paciente A - Protocolo alcance braço Esquerdo (média e desvio padrão)
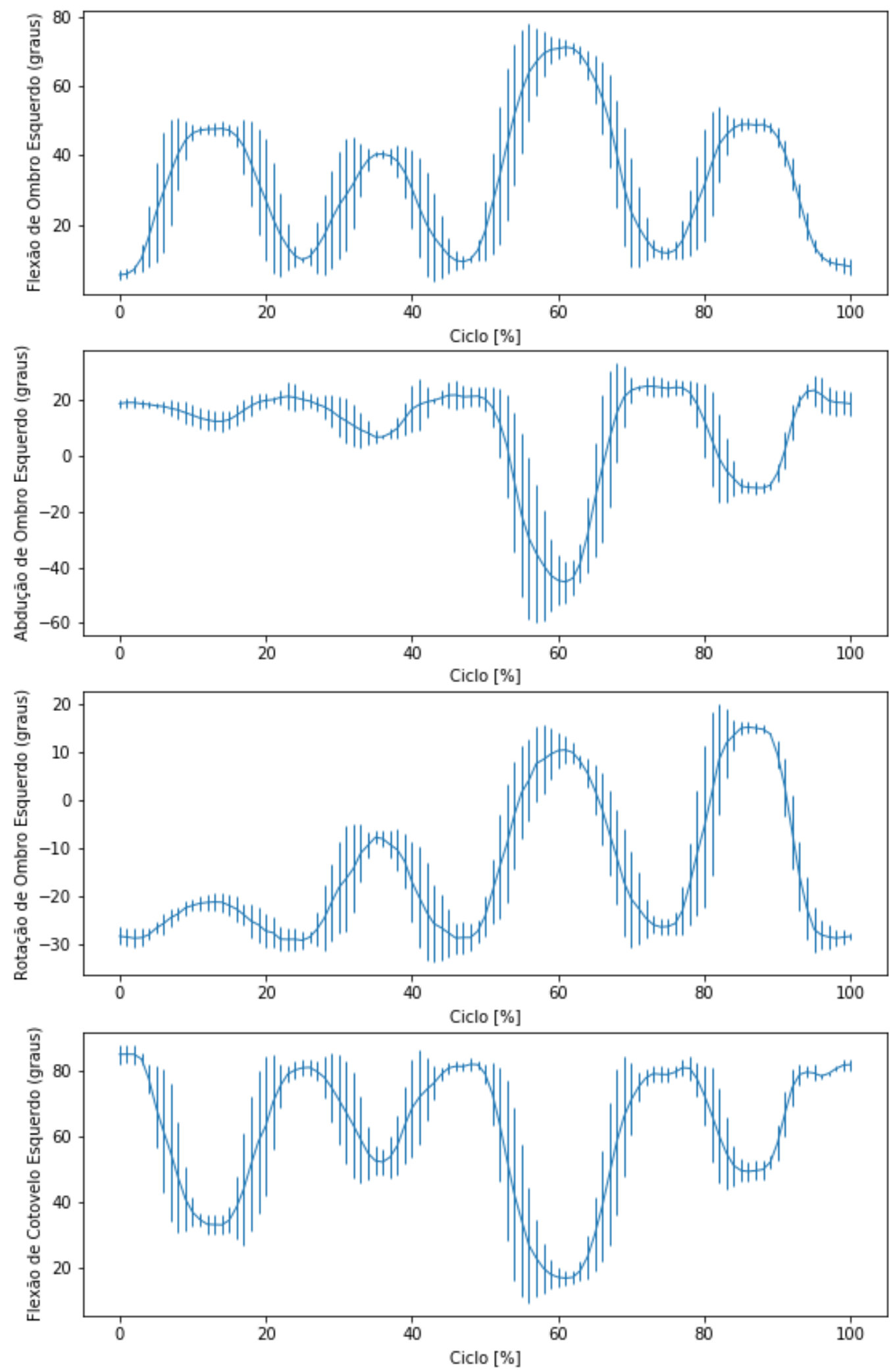
Paciente C - Protocolo alcance braço Direito (média e desvio padrão)
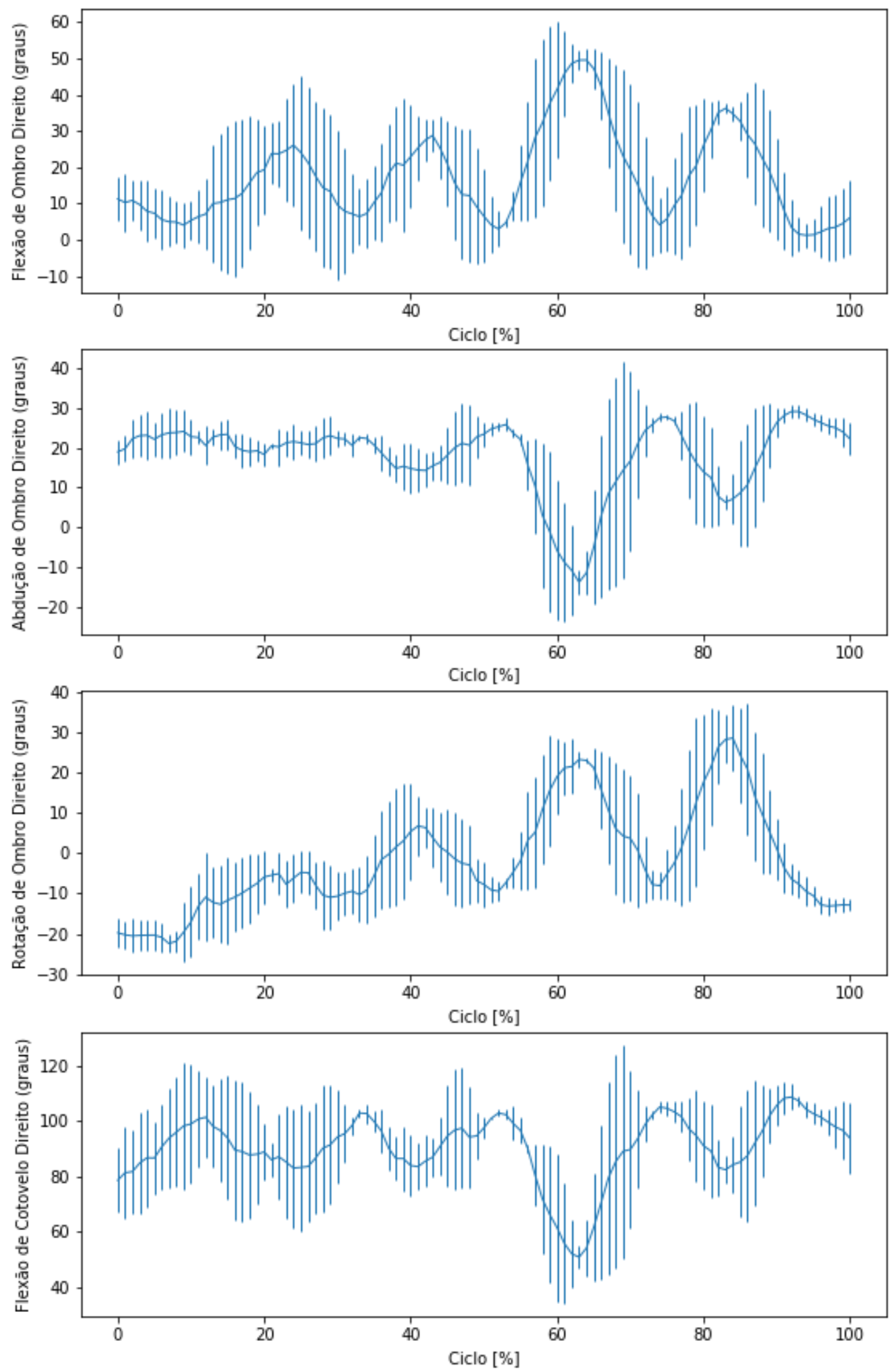
Paciente C - Protocolo alcance braço Esquerdo (média e desvio padrão)
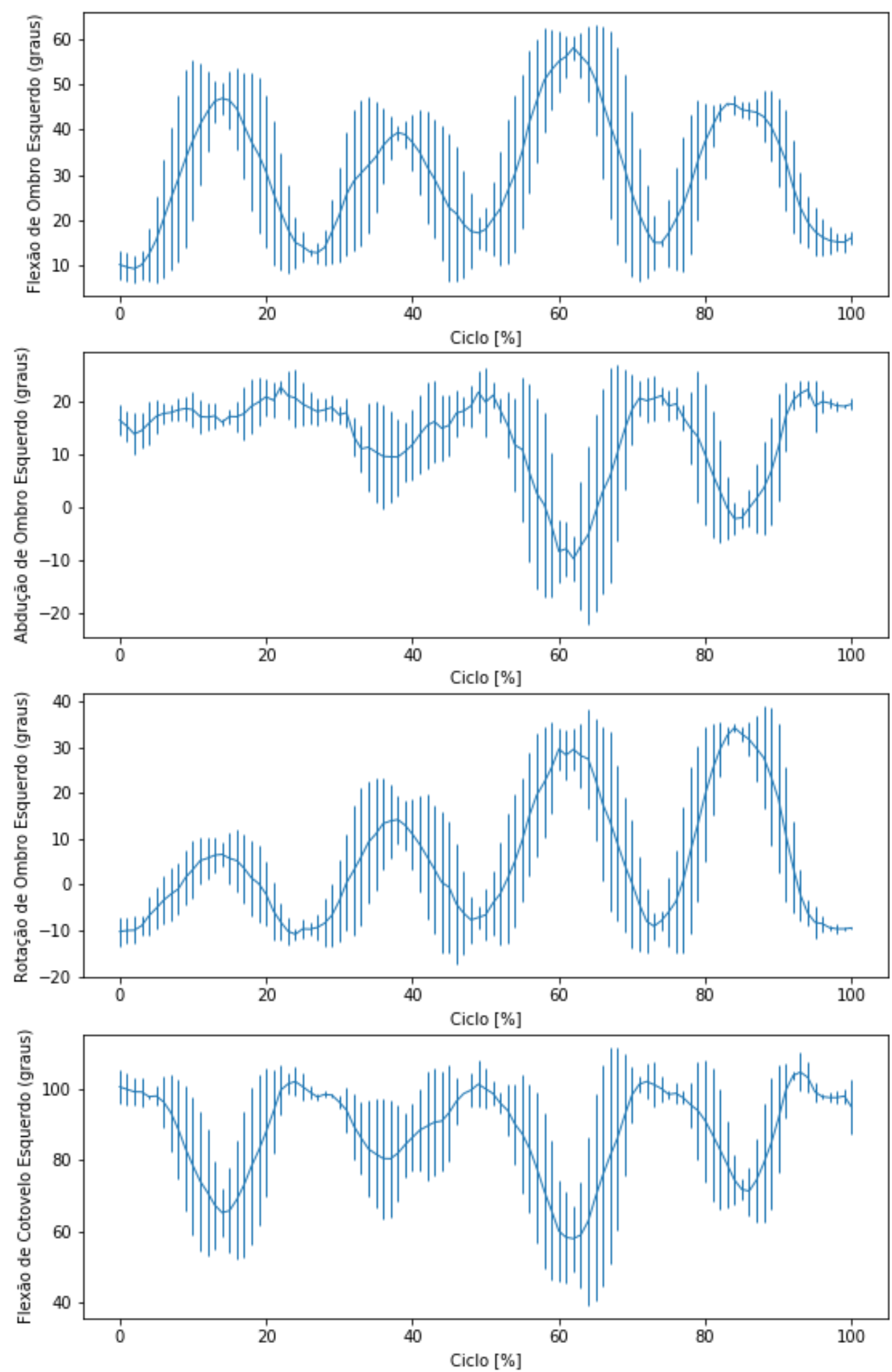
Paciente D - Protocolo alcance braço Direito (média e desvio padrão)
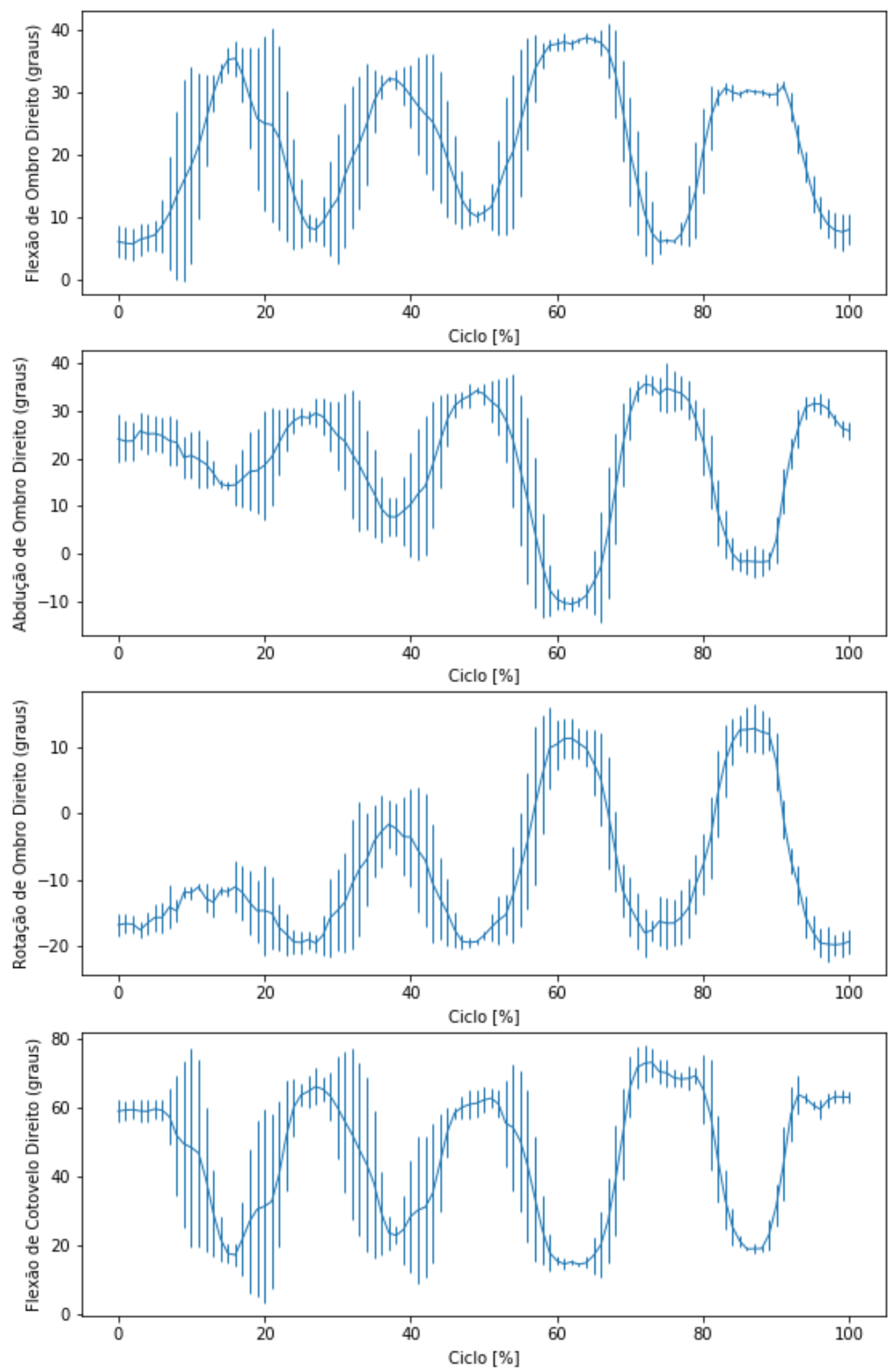
Paciente D - Protocolo alcance braço Esquerdo (média e desvio padrão)
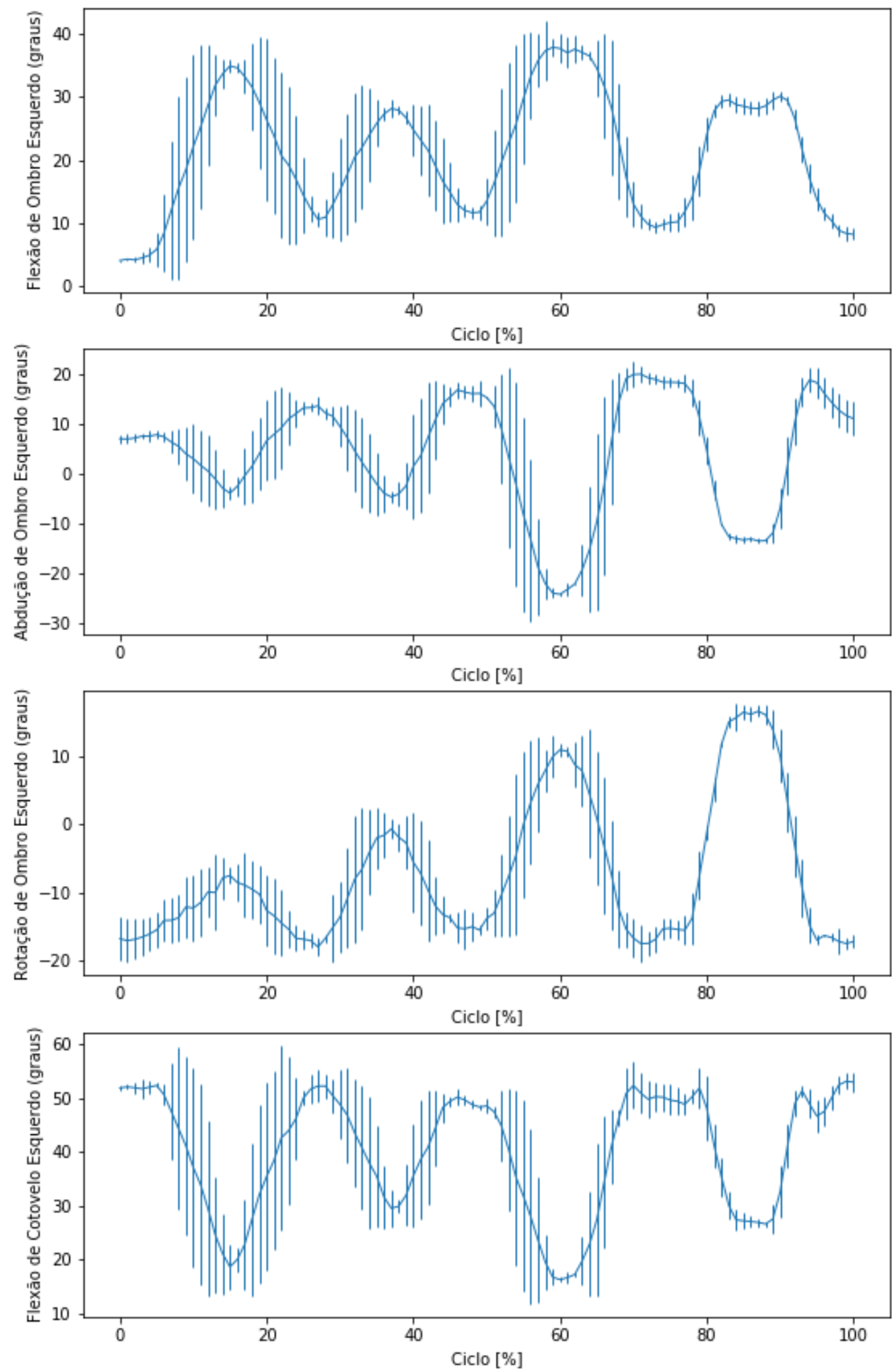